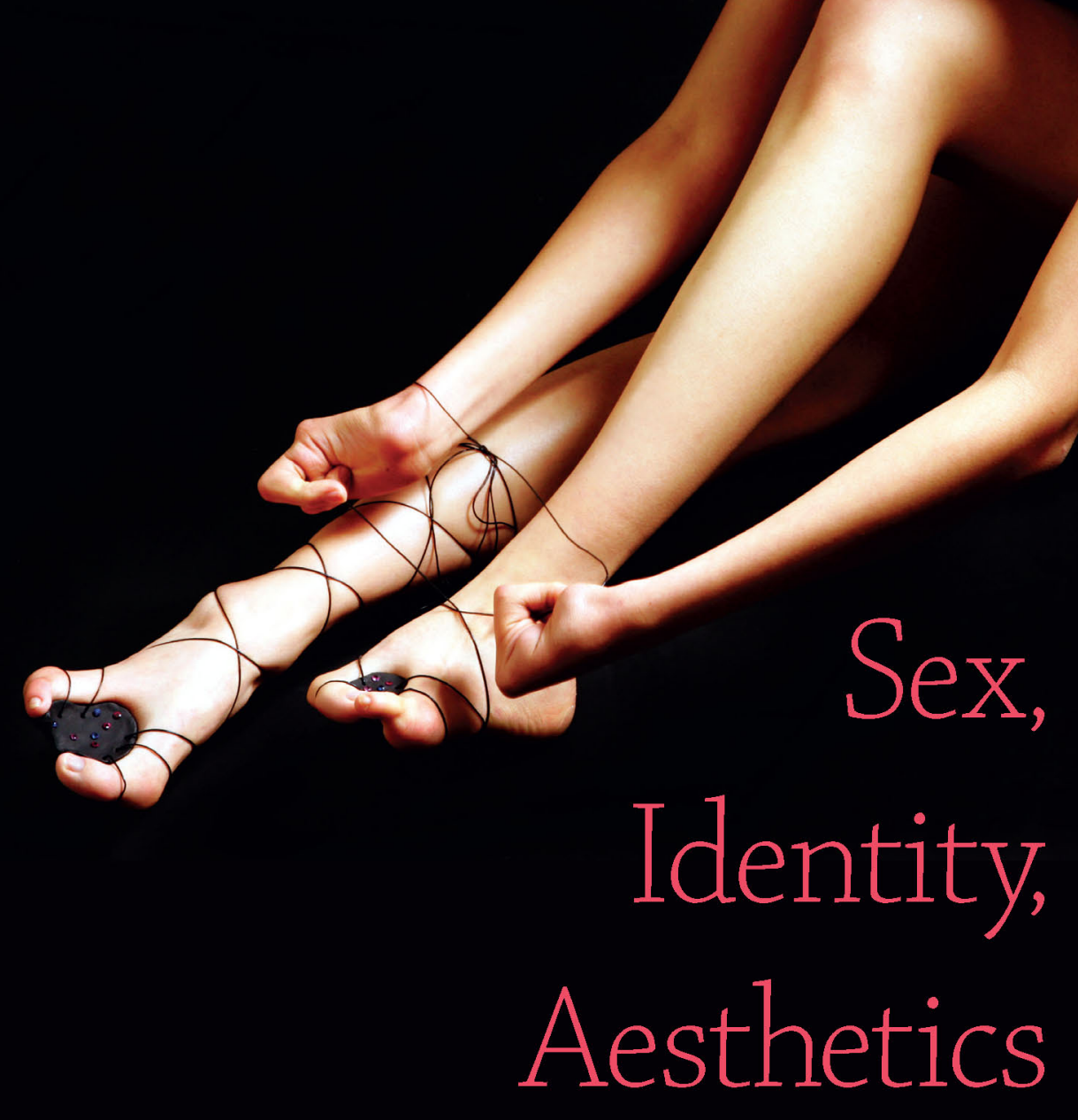

THE WORK OF TOBIN SIEBERS AND DISABILITY STUDIES

EDITED BY

Jina B. Kim

Joshua Kupetz

Crystal Yin Lie and Cynthia Wu 
Sex, Identity, Aesthetics 


\section{Sex, Identity, Aesthetics}

The Work of Tobin Siebers and Disability Studies

Jina B. Kim, Joshua Kupetz,

Crystal Yin Lie, and Cynthia Wu,

Editors

University of Michigan Press • Ann Arbor 
Copyright () 2021 by Jina B. Kim, Joshua Kupetz, Crystal Yin Lie, and Cynthia Wu Some rights reserved

\section{(cc) BY-ND}

This work is licensed under a Creative Commons Attribution-NoDerivatives 4.0 International License.Note to users: A Creative Commons license is only valid when it is applied by the person or entity that holds rights to the licensed work. Works may contain components (e.g., photographs, illustrations, or quotations) to which the rightsholder in the work cannot apply the license. It is ultimately your responsibility to independently evaluate the copyright status of any work or component part of a work you use, in light of your intended use. To view a copy of this license, visit http://creativecommons.org/licen ses/by-nd/4.0/

For questions or permissions, please contact um.press.perms@umich.edu

Published in the United States of America by the

University of Michigan Press

Manufactured in the United States of America

Printed on acid-free paper

First published October 2021

A CIP catalog record for this book is available from the British Library.

Library of Congress Cataloging-in-Publication data has been applied for.

ISBN 978-o-472-o3849-7 (paper : alk. paper)

ISBN 978-0-472-90247-7 (OA)

https://doi.org/10.3998/mpub.11769364

The image on the front cover is a photograph showing a pair of arms and legs. The model is seated, and the image is cropped so that the rest of the model's body is outside the frame. The model has variations in digits on their toes and fingers. They wear delicate custom-made couture sandals fitting only their specific anatomy. The model's hands are lacing up a sandal over their ankle and lower calf. Lettering spells out the title, Sex, Identity, Aesthetics: The Work of Tobin Siebers and Disability Studies, and the names of the editors: Jina B. Kim, Joshua Kupetz, Crystal Yin Lie, and Cynthia Wu.

"Can I be sexy for once?" by Chun-Shan (Sandie) Yi. Photographer: Cheng-Chang Kuo. Cover design by Paula Newcomb. 


\section{Contents}

Acknowledgments vii

Introduction: Reimagining Disability Studies $\quad 1$

JINA B. KIM, JOSHUA KUPETZ, CRYSTAL YIN LIE, AND CYNTHIA WU

\section{Part I: Sex}

1. Witnessing "Disability Experience on Trial”:

Toward Critique and Emancipation

ALLISON WEINER HEINEMANN

\section{Part II: Identity}

2. It Depends: Academic Labor and the

Materiality of the Body

CYNTHIA WU

3. Cracks Filled with Images:

Mental Disability, Trauma, and Crip Rhetoric in

Cereus Blooms at Night

JENNIFER MARCHISOTTO

4. Ghosts of Disability in Naomi Shihab Nye's Transfer

THERÍ A. PICKENS

5. Crawling Upstairs: Identity and Ideology in

Tobin Siebers's Disability Theory

96

THOMAS ABRAMS 
vi Contents

\section{Part III: Aesthetics}

6. Words and Images: Networks of Relationality in Deaf, Blind, and DeafBlind Aesthetics

REBECCA SANCHEZ

7. Musical Modernism and Its Disability Aesthetics JOSEPH N. STRAUS

8. Staging the Asylum: Javier Téllez's Disability Aesthetics LEON J. HILTON

9. Disability Aesthetics:

A Pedagogy for Teaching a Revisionist Art History AMANDA CACHIA

Contributors

Index

Digital materials related to this title can be found on the Fulcrum platform via the following citable URL https://doi.org/10.3998/mpub.117 69364 


\section{Acknowledgments}

This anthology was a labor of love. Many people contributed to its fruition. The entire process from start to finish took years. Tobin Siebers passed away on January 29, 2015. At the time, he held the position of V. L. Parrington Collegiate Professor of English at the University of Michigan. His colleagues sprung to action, planning a memorial service held on February 6, which drew relatives, neighbors, friends, students, colleagues, and other compatriots from near and far. Loved ones recounted touching and poignant stories, drawing laughter and tears alike from attendees.

Flash forward another year to February 12, 2016. Tobin's former students Jina B. Kim, Joshua Kupetz, Crystal Yin Lie, Shannon Walter, and Esther Witte had just finished hosting a two-day symposium in Ann Arbor addressing Tobin's contributions to disability studies. The event, "Crip Futurities: The Then and There of Disability Studies," brought dozens of speakers and attendees together to explore emergent directions in the field. Panels ranged in topics from bioethics and surveillance to disability poetics; crip pedagogy to intercultural and intermedial encounters; and theories of pain to the aesthetics of mental illness. Concerned with plural ways of being, engaging, and understanding, "Crip Futurities" was part of a collective and continual call for more diverse and accessible futures in scholarly, activist, and communal worlds. The organizers provided travel grants for participants lacking institutional means to offset their costs. It was funded by multiple University of Michigan sources: the Department of English Language and Literature; Rackham Graduate School; Institute for the Humanities; College of Literature, Science, and the Arts; and the University of Michigan Initiative on Disability Studieswhich Tobin founded and co-led for years. 
Cynthia thought the symposium might inspire someone to take up an anthology project on Tobin's work, not expecting at first for that person to be her. She returned home from Ann Arbor and waited to see who would jump at the opportunity. After a few months passed with no word in the disability studies world about something in the making, she rallied some of the symposium organizers to bring into being the volume we all thought should exist. Sex, Identity, Aesthetics was the end product.

We would like to thank LeAnn Fields, the editor at the University of Michigan Press with whom we initiated discussion about this anthology. LeAnn has a lengthy and impressive track record of acquiring books in disability studies, which dates back to the field's infancy. In preparation for retirement, LeAnn handed the project to Sara Jo Cohen, who valiantly shepherded it from beginning to end. We are grateful for her keen eye, attention to detail, generosity, and good humor. We thank two anonymous readers whose careful review made the manuscript much stronger.

Finally, we thank Indiana University, which provided the subvention in the form of a research startup for Cynthia, for this volume to be open access. We believe that removing economic and other barriers to accessing knowledge is a top priority and that universities should find ways, whenever possible, to ensure that it happens. 


\title{
Introduction
}

\author{
Reimagining Disability Studies \\ JINA B. KIM, JOSHUA KUPETZ, CRYSTAL YIN LIE, \\ AND CYNTHIA WU
}

Tobin Siebers was one of the most prominent authors in disability studies. His work in the field remains frequently cited. His scholarship on sexual and other affiliations, the links between structural location and coalitional politics, and aesthetic representation in the visual arts has shaped disability studies in indelible ways. The title of this volume, Sex, Identity, Aesthetics, reflects these contributions. As Siebers has argued, a consideration of ability status forces a rethinking of prevailing assumptions about the above cultural and social phenomena. This impels a revision of liberal humanism's major principles. How do we redefine personhood to account for the full range of physical, sensory, neurological, and intellectual ways of being? What does it mean to assert agency in the face of interdependence? What does a disability-friendly worldview and environment look like? How do we reimagine intimacy, kinship, relationality, and pleasure? How might the realm of representation inaugurate these conceptual shifts? Siebers examined these questions in ways that were crucial to disability studies and disability rights activism. His contributions to our thinking about uneven distributions of power persists after the passing of his natural life on January 29, 2015.

We write as Siebers's former students at the University of Michigan who were advised by him at various moments on disability studies' timeline. Cynthia Wu entered her doctoral program in the late 1990 s when disability studies started staking a claim for widespread relevance in the 
humanities. Rosemarie Garland-Thomson's Extraordinary Bodies: Figuring Physical Disability in American Culture and Literature (1997) made its splash. Shortly afterward, David T. Mitchell and Sharon L. Snyder's Narrative Prosthesis: Disability and the Dependencies of Discourse (2001) appeared. Readers of these books came to understand disabled characters in fiction as foils for shoring up nondisabled protagonists and advancers of plot without being afforded multidimensionality themselves. Jina B. Kim and Joshua Kupetz began their graduate career a decade later. At the time, Lennard J. Davis's Bending Over Backwards: Disability, Dismodernism, and Other Difficult Positions (2002) was already widely known for proposing to dissolve the disabled/nondisabled binary. Robert McRuer's Crip Theory: Cultural Signs of Queerness and Disability (2006) introduced disability studies to compulsory able-bodiedness. Following Adrienne Rich on compulsory heterosexuality, it argued that normative physical comportment and normative sexuality were intertwined. Crystal Yin Lie's more recent vintage places her in the midst of newer developments. Alison Kafer's engagement with time and futurity came to fruition in Feminist, Crip, Queer (2013). Julie Minich's Accessible Citizenships: Disability, Nation, and the Cultural Politics of Greater Mexico (2013) and Ellen Samuels's Fantasies of Identification: Disability, Gender, Race (2015) became key examples of critical ethnic studies' intersectional analysis of ability status. Sami Schalk's Bodyminds Reimagined: (Dis)ability, Race, and Gender in Black Women's Speculative Fiction (2018) and Therí Alyce Pickens's Black Madness :: Mad Blackness (2019) followed closely on their heels. Through this multigenerational timeline, we can map disability studies' turns and transformations.

This anthology was inaugurated to synthesize Tobin Siebers's disability studies scholarship and show its persistence in the wake of his passing. Despite our affiliation with him as our graduate mentor, this is not merely a laudatory festschrift. Tobin, himself, would not have wanted something providing only straightforward praise. Festschrifts are rarely of interest beyond those personally acquainted with the scholar. Even among friends, acquaintances, colleagues, and protégés who acquire a copy of the book, they tend to gather dust on a shelf, forgotten soon after publication. In contrast, we present a collection of chapters from disability studies scholars across disciplinary lines and career stages who engage critically with Siebers's work and demonstrate its ongoing relevance. Some authors in this volume had expressed concern after being invited to contribute because of their disagreement with some of Siebers's ideas and their inability to cite him in purely acclamatory 
ways. We had to reassure them this was not the purpose of the project. This volume is not only commemorative. We intend for it to spark additional dialogue. That being said, one of our goals in this introduction is to mine Siebers's contributions prior to the consolidation of disability studies in order to see the field's germination in places not ordinary associated with it.

\section{Looking Backward}

The last two books Siebers wrote, Disability Theory (2008) and Disability Aesthetics (2010), are most readily associated with this volume's focus. We can see some of the thinking for these books in nascent forms in Siebers's earlier works. From its inception, humanistic disability studies has interrogated perception. It makes transparent the power-laden dimensions of how we see bodies and minds in relation to their built and cultural environments. It reveals the normativities that inform ideas about the healthy and the pathological, the beautiful and the marred, the perfect and the flawed, and the functional and the disordered. In so doing, it challenges us to rethink what is acceptable, expected, upright, and good. It trains us to value the halting, the vulnerable, the incongruous, the asymmetric, and the uncontrolled. Not only does disability studies broaden perception in order to account more intentionally for the bodies and minds that exist, it also locates as its object of analysis perception itself. How do we create meaning out of what we take in from the world? How is the process of producing knowledge already bound up with power? Siebers's earlier work, which focuses on reading and interpretation, comes in handy here.

The Ethics of Criticism (1988) provided one of the earliest challenges to poststructuralism. The multiple approaches to reading literature that emerged in the decades leading up to the book's publication, Siebers observed, shared the common goal of facilitating a greater ethical good. These approaches tended to turn away from Enlightenment-descended concepts of the human in favor of examining language and its attendant forces. As the logic went, humans are constituted by language, not the other way around. By paying attention to language (and not the human from which it issues), poststructuralism proposed to account for the unexpected and unpredictable ways power operated. But rather than stop at making this claim about the common thread in the multiplicity of critical theory's voices, Siebers went on to explain how its tenets ultimately failed: 
The replacement of the human by the linguistic turns out to be a self-defeating gesture in every sense. For the human subject always returns in the act of writing, and to attempt its suppression in writing is ultimately an act of self-violence. Indeed, the violence directed against the concept of the self by modern theorists seems only one more version of the violence associated with human endeavors throughout history. (4-5)

Recentering the human may seem reactionary, potentially replicating the pitfalls of liberal humanism. However, Siebers revealed that poststructuralism came with unintended effects. It hides from itself its own capacity for harm, which is "never an infernal machine without a driver. It is never without a victim. If it may be called systemic, it is only so because it establishes languages and patterns of behavior that can be repeated by others" (7).

Far from dismissing poststructuralism because of its propensity for abdicating human responsibility, Siebers found an optimism cohering in it. He located this hope in the act of interpretation. By reading, literary critics bear the weight of an ethical seeing. Scholars "have a responsibility not only to supervise their own unjust practices as critics but to think about the ways in which language carries on the work of human prejudice, racism, sexism, classism, and nationalism" (7). In Siebers's formulation, the human agent dismissed in late twentieth-century literary theory returns in the form of the reading subject endowed with the capacity for ethical reflection. If we pull The Ethics of Criticism forward in time to bring it into conversation with the emerging work in disability studies a decade later, we see that among the "human prejudice[s]" this mode of criticism can address-in addition to those named by Siebers above-are those related to the unjust expectations leveled on the body and mind.

Cold War Criticism and the Politics of Skepticism (1993) extended the inquiry into interpretation that The Ethics of Criticism broached. It offered a cultural history of literary study in the era after World War II. As the United States and the Soviet Union escalated their conflicts, the threat of nuclear annihilation became ever-present in the global consciousness. Skepticism, Siebers argued, in literary interpretation existed in parallel formation with the prevailing tendency to question appearances and maintain vigilance in the face of danger. The collective anxiety during the Cold War remained surprisingly constant over the course of U.S. federal administrations of divergent political orientation. Regardless of whether the presidential office was held by a Democrat or a Republican, 
the policies enacted bespoke a preoccupation with managing the threat of destruction wrought by multinational war. Siebers regarded the works of literary theory from this era as historical artifacts reflecting the milieu of their time. Seemingly disparate schools of thought, ranging from the New Criticism to deconstruction to the New Historicism, showed several consistencies: a dogged adherence to reason over emotion, a preoccupation with the verbal and conceptual language of war, and an impetus toward scrutiny and examination, including reflexive self-examination.

Cold War Criticism and the Politics of Skepticism not only claimed that these differing political identifications and interpretive strategies possessed an overarching homogeneity — that being in their weaving of "the story of our skepticism about endings, interpretations, and calculations concerning numbers, troop movements, negotiations, and claims to truth and falsehood" (29). It also advanced that the myriad of critical ideologies, methodologies, practices, and positions originating from the Cold War's long historical reach collectively failed in their ethical intentions. Siebers located this failure in the presumption that skepticism's interpretive exertions allowed their agents to overcome the messy or limiting particulars of their material and cultural circumstances. Rather, "the cold war mentality in criticism, while well-meaning and ethically motivated, fails to escape the very context against which it designs its every purpose" (36). One of the solutions Siebers offered was that literary criticism might rethink the foundations on which it rested. Rather than confront textual objects with a skepticism that borders on suspicion, it could devise ways of reading that foregrounded "life-affirming principles in addition to the ascetic and skeptical ones that it has come to embrace"; this might entail making room for "pleasure, beauty, knowledge, and the world" $\left(1_{5}^{6-57)}\right.$. To be cautious, Siebers established from the onset that such a departure from skepticism might be seen as conservative. However, he also maintained that we need to differentiate between "thinkers who defend certain so-called traditional ideas against skepticism and those whose enmity to skepticism tends to situate them on the side of traditional ideas for the sole reason that our intellectual maps do not know where to place them" (6). The former dig their heels in on the side of power, while the latter are erroneously categorized with them because they seek a different way of seeing. Might the goal be, then, the fashioning of a different set of "intellectual maps"?

Siebers's provocation at the close of Cold War Criticism and the Politics of Skepticism feels familiar to those who have been paying attention to work on interpretive practices over the past generation. 
We are, of course, referring to a mode of reading that Eve Kosofsky Sedgwick identified in Touching Feeling as "reparative," which has been referenced countless times in queer theory and its adjacent fields. Sedgwick's schema resembles that of Siebers's. She made a corresponding observation about cultural theory's homogeneity in its reliance on-following Paul Ricoeur-a "hermeneutics of suspicion," a critical stance emerging from what she named as paranoia. Like Siebers, Sedgwick recognized that turning one's back on an interpretive strategy closely aligned with the foundations of critical thinking can seem "naïve, pious, or complaisant" (126). One risks the impression of siding with power and its refusal to make itself transparent. However, rather than jettison paranoid reading, Sedgwick preferred to regard it as one among many options for literary critics. The reparative alternative she proposed was an action "motivated by love" (149) that resonates with the survival strategies of queer-identified social outcasts. These reading practices view texts as something other than vessels for ideologies that need exposure. A reparative reading recognizes that "the culture surrounding [a queer object] is inadequate or inimical to its nurture; it wants to assemble and confer plentitude on an object that will then have resources to offer to an inchoate self" (149).

The fine details of Sedgwick's call for a revolutionary hermeneutics differ somewhat from those of Siebers's, which emerged ten years prior. However, the two overlapped so much that we were prompted to see if Sedgwick had cited Siebers, even if only in a footnote. She did not. Our first reaction, ingrained from the possessive claiming of ideas endemic to advancement in the academy, was to rail against this absence. How could she leave him out?! Upon further reflection, we realized that a more enabling way to regard the citational gap might be to let go of traditional concepts of property, intellectual or otherwise. Sedgwick's omission does not necessarily reveal an inadequacy or a nefariousness on her part. We are not invested in crying foul. Rather, the appearance of two very similar polemics most likely attests to literary criticism's collective weariness with interpretive methods that had worn too deep and predictable a groove by the turn of the twenty-first century to sustain themselves for much longer. In his own reading of Touching Feeling, Siebers made no mention of the resonances between it and Cold War Criticism and the Politics of Skepticism. His refusal to call attention to the fact that he proposed turning away from skepticism before Sedgwick did might be conceived of as reparative. He did, however, provide a paranoid reading of how Sedgwick invoked disability in several places, showing that the 
earlier forms of interpretation that make up the constitutive outside to his argument and the transformative one he advanced need not exist at odds with each other. ${ }^{1}$

We read The Ethics of Criticism and Cold War Criticism and the Politics of Skepticism as proto-disability studies tracts insofar as they encourage awareness of the power-laden ways that knowledge gets produced at the nexus of interpretation and perception. In the former, humans are reinstated their agency and, therefore, their duties as ethical subjects through the responsibility that reading endows. By refusing to transfer the burden of accountability for violence onto language, human readers can take initiative through hermeneutic practices that amend injustice. The self that is restored in this manner is not the one familiar to Enlightenment-descended modes of thought. Rather, this self emerges through the redress of wrongdoing as it reads. The latter volume extends these discussions with a different bent. Siebers showed that reading need not be motivated by the tried and true formula of treating texts with distrust. A sustaining or pleasure-seeking hermeneutics that reads with rather than against the grain has the potential to usher in ways of knowing that have heretofore remained obscured by late twentieth-century critical theory's oversights.

The interventions that originated from The Ethics of Criticism and Cold War Criticism and the Politics of Skepticism rethought poststructuralism or, at least, the ways it has been mobilized by some scholars. This intellectual commitment informed Tobin's leadership role in the collective known as the Future of Minority Studies. Throughout the first decade of the twenty-first century, a group of faculty members at Cornell University, Spelman College, Stanford University, Syracuse University, the University of Michigan, the University of Oregon, and the University of Wisconsin procured funding from a combination of internal and external sources to host conferences and summer workshops, support collaborative publishing ventures, and fund postdoctoral fellowships. Frustrated with what they saw as poststructuralism's detachment from power's real-world ramifications, these scholars proposed a different interpretive paradigm. Called "post-positivist realism," the approach sought to center material and structural critiques without falling back on untheorized notions of truth and objectivity. In time, scholars in their wake would come to understand the yoking of the discursive and the structural by another term, the "new materialisms." In addition to launching the above initiatives, the Future of Minority Studies mentored graduate students and junior faculty, many of them of color, through the processes of job hunt- 
ing and earning tenure. It established crucial networking opportunities for marginalized scholars outside of their home institutions.

The first anthology from the collective, Reclaiming Identity: Realist Theory and the Predicament of Postmodernism, coedited by Paula M. L. Moya and Michael R. Hames-García, set the stage for this work. The editors began by conceding that the problematizing of identity in the recent past has been useful in some ways: it called attention to how some of its mobilizations have overlooked intersectionality; it revealed the ways that identity taxonomies change over time; it established identity as a function of discourse, not essence. Yet, as Moya and Hames-García contended, identities remain crucial, for they "provide modes of articulating and examining significant correlations between lived experience and social location" (4). Identities may be socially constructed, but they still have real-life consequences. Although, at times, the editors may have overstated poststructuralist or postmodern thought's obliteration of materialist considerations, their concerns were well founded. This body of work is often invoked, even if sloppily, to invalidate the justice claims of women, people of color, and other social minorities. The second of the Future of Minority Studies' anthologies, Identity Politics Reconsidered, included a chapter by Siebers, one that eventually became part of his single-authored volume, Disability Theory, which we discuss in the next section. This follow-up to the first anthology extended its premises to include a consideration of ability status, which Siebers's contribution offered. The editors asked authors a set of open-ended questions about the relevance of identity, objectivity, and moral relativism in their respective fields. As the editors noted, there was a large range of responses received, even as all contributors recognized the dynamic and relational aspects of identity. Identities are "not mere descriptions of who we are but, rather, causal explanations of our social locations in a world that is shaped by such locations" (6). Hence, identities and the contexts that shape them are dialogic. Identities are the effects of structural forces. At the same time, these structural forces have relied on the differential leverage doled out to identities for their legitimacy and impact.

\section{Disability Studies, Emerged}

Disability studies analytics may have been only nascent in The Ethics of Criticism and Cold War Criticism and the Politics of Skepticism. But Siebers's later work, especially Disability Theory and Disability Aesthetics, arrived at a moment when the field had already gained traction. These volumes 
provided further ballast for the field and remain two of its most widely read and referenced texts. Disability Theory, not a traditional monograph but a collection of previously published and revised essays, challenges late twentieth-century foundational concepts in the humanities. It also bends the genre of the scholarly book, integrating personal anecdote and textual asides called "dossiers" throughout the volume. The dossiers are short excerpts from contemporaneous news items that show the extent to which popular misconceptions about disability weave themselves into the fabric of culture and society. We say that these anecdotes and news items are "integrated" into the text with full awareness of how frictive and incomplete any act of integration is. The insertion of these passages often does not follow a textually linear logic that yokes them with the material that precedes and follows them. Siebers allows the personal anecdotes and dossiers to provide a counterpoint to his cultural criticism without capitulating to the urge to explain their presence. The incorporation of the news stories is meant to "invoke feelings of horror and disgust at the blatant and persistent prejudices directed at disabled people" $(15)$. In turn, the jarring appearance of this material forces readers to challenge conventions of academic writing. These passages signal the imperfection of nonnormative bodies' and minds' integration into hegemonic structures. They may be integrated, but they stick out, and that is part of the point. The form of Disability Theory mirrors its content.

The bulk of disability studies scholarship today shows how disability troubles normative concepts of self, other, agency, labor, property, and relationality. Although poststructuralism has rightfully challenged the idea of a discrete self that is governed by free will, Disability Theory lays ground for an analysis that overcomes some of its gaps or conceptual temptations. To begin, it unpacks "identity," an idea that had fallen out of favor in recent generations. The reasons for identity's plunge include its tendency to render opaque the structural and material conditions that give rise to social taxonomies; its occasional failure to acknowledge that these categories change over time; its potential to blur recognition of its own instability, intersectionality, and complexity; and its stymying of coalitional work across lines of difference. More insidiously, it has been claimed that identity can be brandished in ways that thwart the very political transformations that constitute its goals. Siebers takes these charges head-on in a context that shows how disability, as a valence of political difference, might bring identity back in productive ways.

An example of work that dismisses identity is Wendy Brown's oftreferenced article, "Wounded Attachments." According to Brown, 
a politics of identity that foregrounds categories of race, sexuality, or gender is flawed because it demands not capitalism's dismantling but a multiculturalist incorporation of people formerly excluded from its fold. Moreover, following Friedrich Nietzsche, Brown avers that identity politics are couched in ressentiment, "the moralizing revenge of the powerless" (400). These justice claims rest on an attachment to historical wounds and injuries that bestow the claimant with an ethical capital that ultimately "becomes invested in its own subjection" (403). There are some gaps in Brown's argument. First, she sets up a strawperson in her critique of what a politics organized around one or more of the above identity categories does or does not advance. ${ }^{2}$ Second, she overlooks that vengeance can be part of ethical justice seeking, as Gregory Laski puts forward in his concept of "righteous revenge." Revenge is often demonized when expressed by people of color, especially African Americans, and overlooked or even lauded when wielded by whites. Third, and this is Siebers's critique of Brown, her antipathy to wounding and injury is ableist and leaves unquestioned the negative connotations surrounding disablement. She assumes "that individuals affected by pain and suffering are irrevocably impaired for political action" (79). Siebers proposes to recuperate identity from poststructuralist thought's evacuation by refusing the schema Brown and others like her set up. Identity-based models of organizing are not hopelessly self-interested and particular. In fact, as Siebers argues, charges of narcissism have historically been leveled against disabled people in order to invalidate their demands for redress. ${ }^{3}$ Identity does not impede the building of coalitions across social categories. Rather, "people who identify themselves as members of a community have entered into cooperation for socially valid reasons, and their identities represent direct responses to distinct and often verifiable conditions of society" (84). These decisions about affiliation are purposeful and must be respected as such.

Siebers's recuperation of human agency in ways that avoid a simplistic embrace of free will forms a throughline in his work. His concept of "complex embodiment" calls attention to the reciprocal dynamic between environments and the human subjects who inhabit and create them. This is a slight departure from how many disability studies scholars have conceived of the social model of disability, which locates disadvantage in a society created according to nondisabled standards (as opposed to the medical model of disability, which locates it in an individual's departure from those standards). Siebers concedes that the social model has been useful in certain ways. For instance, its interroga- 
tion of the disabling conditions of built and cultural environments has propelled social justice movements seeking to change them. However, he finds it averse to considering the body's materiality in ways that risk erasing some types of disabled lived experience. Additionally, he offers that it is unable to account for how people can and do transform their surroundings. Siebers's notion of complex embodiment "emphasizes ... that some factors affecting disability, such as chronic pain, secondary health effects, and aging, derive from the body" and that "the body and its representations [are] mutually transformative" (25). The built and cultural environment can disenfranchise the body. However, that body and its forms of embodiment also have the potential to alter the environment.

This dialectic between material bodies and their environments extends itself in another of Siebers's well-known claims, on disability as masquerade. This concept disrupts traditional understandings of passing or closeting. Using himself as an example, Siebers describes his experiences of traveling by plane. He feels compelled to exaggerate his limp when preboarding in order to head off objections by airline staff that he is not impaired enough to warrant this accommodation. Popular misconceptions of disability tend to obscure the types that are invisible or only subtly perceptible. ${ }^{5}$ Although Siebers feels conflicted about misrepresenting his natural gait, he also advances that disabled people's decisions to perform thusly cannot simply be dismissed as deception. Disabled people can masquerade in ways that make disability more legible (even if existing modes of legibility are flawed) for reasonable ends. First, it can placate gatekeepers in order to facilitate another kind of access-in his example, access to travel. ${ }^{6}$ The exaggerated visibility of impairment can also signal a disabled person's presence to other disabled people, thus establishing an affiliation with them. In these examples, disabled people show evidence of skill in reading and reproducing the markers of disability in hegemonic cultures. They "demonstrate[e] their knowledge about social organization and human perception" (117) in order to achieve their goals. The ways of conceptualizing disability outlined above, both as complex embodiment and as masquerade, do not undermine its status as an identity. In fact, they strengthen its claims as such because of how they lay bare the interlocking concerns of access, recognition, community, and visibility.

Siebers's discussion about how disability studies can nuance a broadreaching concept like identity bleeds into his thinking on how it might destabilize another broad-reaching concept, sex. We accept that prevail- 
ing standards of physical, mental, neurological, and sensory viability are untenable because they fail to value bodily and cognitive variation. We accept that built and cultural environments prevent full civic participation for bodies and minds that fall beyond the scope of normative functioning. Disability justice movements have sought full access for as many people as possible to places of employment, education, leisure, and commerce. They have demanded that they be redesigned to accommodate a wide range of abilities and ways of being. What often gets omitted from these justice claims is a consideration of access to sexual pleasure, agency, and dignity.

To explain why sex is a linchpin on which disability rights should turn, Siebers observes that, traditionally, sex has been inseparable from the ideology of ability. "Sex is the action by which most people believe that ability is reproduced, by which humanity supposedly asserts its future, and ability remains the category by which sexual reproduction as such is evaluated" (139-40). Siebers refers not only to eugenically informed notions of biological reproduction, whereby fitness for procreation rests on the perceived or real genetic status of parents and the desirability of passing identified traits to the next generation. He also invokes the very notion of entitlement to sexual activity itself-whether or not it is tied to conception, childbirth, or child-rearing. ${ }^{7}$ The farreaching hegemony of "health," as Siebers claims, permeates all aspects of culture and society, including notions about sex. "A sex life must be, first and foremost, a healthy sex life, and the more healthy a person is, the better the sex life is supposed to be." Conversely, "when disability is linked to sex, it becomes a clinical matter in which each disability betrays a particular limitation of sexual opportunity, growth, or feeling" (141-42). These perceptions have a real-life impact on disabled people, for whom engaging in sexual activity is often met with ableist barriers. The caution stemming from good intentions or outright disregard from medical professionals, caregivers, family members, and group home staff may deny disabled people access to sex, which ultimately deprives them of the full range of human rights.

Siebers proposes that making sexual access a priority for the disabled would increase access for sexual minorities in general, given that the sexual practices of disabled people often run counter to the dictates of heteronormativity and ability. This seeking of access involves retooling common concepts about sex. Some disabled people may need personal care attendants to prepare for sex, challenging the notion that its proper iterations should take place only in the presence of partners directly 
participating. Many disabled people may privilege nonpenetrative sex, which broadens definitions of what it entails and where it can occur because it need not take place in private. Taken together, a disability positive worldview would acknowledge that sex has "an ebb and flow that spreads it out among other activities" and that "its physiognomy does not necessarily mimic conventional responses of arousal, penetration, or orgasm" (151). Concluding, Siebers writes that "if we are to liberate disabled sexuality and give to disabled people a sexual culture of their own, their status as sexual minority requires the protection of citizenship rights similar to those being claimed by other sexual minorities" (154). Here, Siebers's argument for identity reenters the conversation. As an identity category, disability matters because of how rights taken for granted by the nondisabled have historically been denied. What Siebers calls "sexual citizenship" is as crucial to political transformation as other forms of access and inclusion.

Disability Theory and Disability Aesthetics were meant to be a single volume, but late in their composition, the author realized the chapters encompassing them would be better served by parceling them into two separate books. The latter work, which centers disability in art, connects with Siebers's earlier publications addressing reading and perception. It also builds on material from an anthology Siebers edited, The Body Aesthetic: From Fine Art to Body Modification, which establishes that the notion of aesthetics is always bound up with ideas about the human body. The connection between artistic beauty and the physical body is intensely political. This is true, according to Siebers, whether that linkage is invoked by those on the right or on the left (113). Moreover, artists themselves have harnessed this power-laden correlation between aesthetics and the body by producing their own work that intervenes in normative standards. Disability Aesthetics takes stock of methodological shifts that have occurred in the years preceding it. The most notable of these focuses on valences of social difference within an established canon of art. The so-called culture wars of the 1990 may have framed the struggle for representational change as an opening of a heretofore entrenched canon to include authors, artists, and textual representations from the social margins. Some scholars, taking a different tactic, have unearthed evidence of politicized difference within existing canons. Variances from an imagined norm have always been there for readers willing or able to see them.

In Disability Aesthetics, Siebers downplays the schema of inserting marginalized difference into an established canon in favor of revealing 
difference's widespread presence in the artistic record. Disability has appeared front and center in many artistic works, even those not overtly associated with disability. Claiming "that disability has a rich but hidden role in the history of art is not to say that disability has been excluded." On the contrary, "disability is rarely recognized as such, even though it serves as the very factor that establishes works as superior examples of aesthetic beauty" (4). This assertion diverges somewhat from those of earlier disability studies scholars who made a case for the widespread prevalence of disability in literature. This previous line of inquiry mostly (but not completely) invested itself in decrying depictions of disability that served as foils to construct nondisabled normativity. What Siebers advances is different. The anatomical flaws on many representations of the human physical form, such as the Venus of Milo, bestow an arresting magnificence. Disability makes this sculpture beautiful. The example from classical Greek sculpture becomes the foundation for Siebers's argument about the centrality of disability in established canons of modern and contemporary art.

In addition to reading difference into an existing canon, Disability Aesthetics provides examples of the reading practice retroactively recognized as reparative that Siebers proposed in Cold War Criticism and the Politics of Skepticism. Disability Aesthetics foregrounds artists such as Paul McCarthy, Judith Scott, Marc Quinn, Mary Duffy, Aristide Maillol, and Susan Dupor, whose work values the aesthetics of imperfection. Rather than exercising the more familiar strategy of approaching these art pieces skeptically or with paranoia, Siebers fashions an interpretive logic through which representations of disability are viewed in more politically enabling ways. A female figure's incomplete reflection, which connotes amputation, conveys more beauty than the referent reclining before it. Disembodied hands in a river allude to their capacity for communication and expression. Not only does Siebers recover defective bodies from the realm of the disfavored, he also shows that extremely normative bodies, such as those exhibited by Nazi sculpture, generate discomfort for being "deeply unreal" and verging into "pure kitsch" (32).

Some of the works discussed in Disability Aesthetics are not uncomplicatedly regarded as art, such as the art vandalism perpetrated by people cast as mentally ill. Yet the reparative gesture Siebers makes urges us to think otherwise. This list of incidents includes László Toth's hammer attack on Michelangelo's Pietà, Hans-Joachim Bohlmann's pouring of acid on Peter Paul Rubens's Portrait of Archduke Albrecht, and Dennis Heiner's smearing of Chris Ofili's The Holy Virgin Mary with white paint. 
Siebers takes these seemingly violent and senseless textual amendments seriously while coyly claiming that he does not endorse vandalism. He calls attention to how discourses of mental disability factor into concepts of artistic beauty. "Given the sometimes startling resemblance between vandalism approved as aesthetic and outlawed as psychopathological, it is nevertheless hard to avoid asking whether prejudices against mental disability are essentially tautological. Is mental disability thought unaesthetic simply because we cannot view it as creative?" (97). Siebers's rhetorical question asks readers to suspend their assumptions about who can and cannot be an artistic agent.

\section{Looking Ahead}

This volume contains three parts, "Sex," "Identity," and "Aesthetics," each exploring a concept Siebers addressed through his thinking about disability, power, and perception. We assembled a wide scope of contributions across theoretical frameworks, approaches, and overall aims to display how far-ranging Siebers's ideas have been and continue to be. Some authors here are firmly grounded in literary criticism. Others use similar methods to examine visual, performance-based, or aural texts. One looks at material from the news media. A few incorporate autoethnography or lived experience. Some chapters contain a steady engagement with Siebers's writings, while others touch on his work briefly but still in ways that express its salient influence. Although it is true that our desire to commemorate Siebers's life work was what inaugurated this project, we hope this collection will transcend a narrow focus on his oeuvre and show what disability studies contributes to our understandings of culture and normativity.

"Part I: Sex" contains a single chapter. It takes Siebers's claims about full equal rights and sexual access for disabled people in a different direction, that being of redress for sexual injury. Allison Weiner Heinemann's "Witnessing 'Disability Experience on Trial': Toward Critique and Emancipation" focuses on the realm of the law. Heinemann invokes Siebers's theory of complex embodiment in order to incorporate disability experience into contemporary feminist movements against sexual violence. Disabled people are disproportionately subject to sexual assault and abuse, but disability remains noticeably absent from highprofile conversations about these issues. Heinemann stresses the need to witness disabled experiences of sexual assault and honor disability testimony. Her chapter positions disability experience as a means of trans- 
forming legal approaches to and understandings of sexual subjectivity and agency.

"Part II: Identity" comprises chapters on Siebers's call to revisit identity as a useful mechanism through which to seek justice. Cynthia Wu's "It Depends: Academic Labor and the Materiality of the Body" draws upon Siebers's memoir Among Men (1998) and her lived experience to address the links among pleasure, writing, pain, disability, and identity in the academy. Although the absence of identity claims in both Wu's and Siebers's life writing is conspicuous, it is a strategic omission. It is also accompanied by action to even the balance of power in the academy. In "Cracks Filled with Images: Mental Disability, Trauma, and Crip Rhetoric in Cereus Blooms at Night," Jennifer Marchisotto's analysis of Shani Mootoo's novel explores the porous boundary between identity and representation, being and becoming that typically trades under the name of the aesthetic. Crip rhetoric appears as a modality of utterance that begins in the absolute subjectivity of one's embodied experiences, many of which confound normative conventions of articulate expression. For Therí A. Pickens, Siebers's concept of complex embodiment problematically subordinates forms of disability beyond instances of nonnormative embodiment. "Ghosts of Disability in Naomi Shihab Nye's Transfer" brings theories of disability and race to bear on complex embodiment so that disability "ghosts," which are disabled pasts that refuse to be silenced, can become visible. In "Crawling Upstairs: Identity and Ideology in Tobin Siebers's Disability Theory," Thomas Abrams revisits Siebers's recuperation of identity politics and his critique of poststructuralist theory in order to terraform a new disability studies landscape that replaces ideology with a materialist politics. Asserting that scholars too often presume that ideology derives from a single, totalizing worldview, Abrams demonstrates how more practical benefits arise from the careful study and description of material practices of disablement.

"Part III: Aesthetics" features authors who discuss art from multiple perspectives, be it from the vantage point of visual and performance studies, music criticism, or pedagogy. Rebecca Sanchez's "Words and Images: Networks of Relationality in Deaf, Blind, and DeafBlind Aesthetics" complicates Siebers's depiction of the relationship between written language and visual images as separate, competing categories. Sanchez examines the nuanced collapse of words and images in signed language, tactile communication, and audio/visual description, arguing that these modes of representation create new relational possibilities in their experimentation and self-reflexivity. Joseph N. Straus suggests 
that the claims Siebers makes about disability aesthetics in modern art can also be made about modernist music. "Musical Modernism and Its Disability Aesthetics" reads the features of modern music as representations of disabled bodies. It argues that modern music has a fundamental interest and investment in disability as its locus of artistic innovation and auditory pleasure. Leon Hilton pushes Siebers's work into new artistic and geographic terrains in "Staging the Asylum: Javier Téllez's Disability Aesthetics." Examining two of Téllez's works, Hilton considers forms of disablement that are less legible, such as psychiatric injury and mental illness, as effects of the transnational reach of biopolitics and capitalism. Amanda Cachia's "Disability Aesthetics: A Pedagogy for Teaching a Revisionist Art History" closes out this section and, thus, this volume. Cachia offers a model for how Siebers's thinking can interrogate nondisabled assumptions in the theory and praxis of performance studies, art history, and art discourse. She describes hands-on, collaborative, multimodal exercises she designed for the classroom that encourage students to investigate institutional and structural inequality. The pedagogy of disability aesthetics offers a revisionist art history that centers the practical and theoretical value of disability and access.

$$
* * *
$$

The process of creating an anthology is a long one. We end by reflecting on the events that have transpired in the United States over the course of this volume's germination. In the early stages of our planning, the leadup to the 2016 election dominated the public consciousness. During campaign season, Donald Trump was soundly vilified for his mocking of disabled journalist Serge Kovaleski from the New York Times. Numerous media sources denounced his contemptuous imitation of Kovaleski's impairment, providing video documentation of it, yet Trump still denied behaving in this manner. Around the same time, Trump published a book under his name entitled Crippled America: How to Make America Great Again, which used scare tactics to warn about the United States' flagging economy. By invoking metaphorical language that connoted physical disability, the title appealed to a conservative readership panicked about the country's viability. The subtitle's promise to "make America great again" suggested a rehabilitative endeavor to restore the nation to a purported state of wholeness during an imagined past, one where a European-descended citizenry enjoyed the fruits of a white supremacist society unencumbered by resistance.

Trump's presidency has only shown that his threats to follow through 
on policies endangering vulnerable populations were not empty. His first action after being sworn in was to impose restrictions on refugees from targeted countries (known colloquially as his "Muslim ban"). He followed up with crackdowns on undocumented immigrants and asylum seekers at the U.S.-Mexico border and ramped up deportations of longtime residents in the nation's interior. He gutted the Affordable Care Act, dialed back environmental protections, denied climate change, mounted an inadequate response to hurricanes that struck the Gulf Coast and Puerto Rico in 2017, and widened the wealth gap with tax reforms. More recently, Trump allowed the COVID-19 pandemic to spread rampantly throughout the country by suppressing the warnings of public health officials. He prioritized the economy by lifting stay-at-home restrictions before the infections and deaths had diminished. African American, Latinx, and Native American populations saw the highest rates of mortality. Elderly residents of nursing homes found themselves at grave risk of infection and likely death. East Asian Americans were routinely harassed and subjected to physical violence in light of COVID-19's characterization as a "Chinese virus." Many survivors of COVID-19 illness are projected to live with long-term disabilities. In the early months of the pandemic, the killing of Minneapolis resident George Floyd by four police officers accelerated a protest movement against policing and the prison industrial complex. By and large, victims of police brutality are disproportionately physically or psychosocially disabled, or both, as well as Black, which speaks to the ongoing importance of considering intersectionality in social movements such as these. Disabled people, regardless of racial demographic, have always shouldered the brunt of state violence and neglect. However, many disabled activists have also been at the forefront in contesting policies that will produce hardship for almost all and outright deathliness for the most disenfranchised.

Disabled people may be regarded as hopelessly narcissistic by an ableist society, as Siebers has pointed out. Erroneous assumptions about their capacity for empathy and communion with the nondisabled world relegate them to positions of marginality and cultural invisibility. However, the actions of a dedicated critical mass of disabled activists, along with allies across a range of social identities, have shown them to be at the vanguard of civilly disobedient actions that will benefit everyone, no matter their impairment status or their self-identification. Call it universal design in the realm of political resistance and transformation. The chapters in Sex, Identity, Aesthetics extend Siebers's proposal to incorporate disability into all aspects of social structures, humanistic inquiry, and lived experience. 
Notes

1. For these critiques, see Siebers, Disability Theory, 157-6o. It must be mentioned that as Sedgwick experienced the intellectual decline that accompanied the progression of cancer, she came to offer her own embrace of the nonnormative bodymind's radical potential. One of her friends reported on how Sedgwick recounted the logic of being hampered by her previous mental lucidity because of what that ability allowed her to ignore about mental incapacity. See Davidson.

2. Brown published this article in 1993. Thus, she was writing before the bulk of contemporary scholarship on coalitions among communities of color appeared. This body of work shows how various social justice movements compelled ways of thinking that do not pit identity claims against bridge-building across disparately defined groups. Additionally, these scholars do show how identity claims have aligned with anticapitalist critique in multiple contexts. See Espiritu, Maeda, Okamoto, and Lee for just a few examples. Were Brown to revisit her argument today in light of the work that has emerged since, she may very well believe differently.

3. Siebers, Disability Theory, 34-52.

4. Rosemarie Garland-Thomson makes a similar argument about the role of identity politics in disability rights activism. Contesting Wendy Brown, GarlandThomson claims that it is not necessary to relinquish "identity as a set of variable fits and misfits, a potentially productive fusion of coincidence between one's particularity and the material status quo" in order to come to a coalitional consciousness of what one wants to achieve politically. See "Misfits: A Feminist Materialist Disability Concept," 604.

5. The thinking that Siebers lays out in this chapter would eventually pave the way for further work. One example is Ellen Samuels's research on the harassment that disabled parking pass users experience when they do not align with nondisabled culture's ideas about disability. See Fantasies of Identification, 12 1-40.

6. Akemi Nishida notes a similar strategy employed by disabled students seeking accommodations from universities. They might perform legible forms of compliance for disability services offices staff to gain access to education. However, the fact that they appear to align with expected comportments of disability in the face of authority does not necessarily mean they are disciplined into docility. See "Respondent Remarks."

7. For an insightful study on the abridgements of sexual and procreative freedoms for the intellectually disabled, see Gill.

\section{Works Cited}

Alcoff, Linda Martín, Michael Hames-García, Satya P. Mohanty, and Paula M. L. Moya, eds. Identity Politics Reconsidered. New York: Palgrave Macmillan, 2006. Brown, Wendy. "Wounded Attachments." Political Theory 21, no. 3 (August 1993): $390-410$.

Davidson, Cathy. "Handicapped by Being Underimpaired: Teaching with Equality at the Core." HASTAC, 7 July 2015, hastac.org/blogs/cathy-davidson 
/2015/07/07/handicapped-being-underimpaired-teaching-equality-core. Accessed 29 June 2020.

Davis, Lennard J. Bending Over Backwards: Disability, Dismodernism, and Other Difficult Positions. New York: New York University Press, 2002.

Espiritu, Yen Le. Asian American Panethnicity: Bridging Institutions and Identities. Philadelphia: Temple University Press, 1992.

Garland-Thomson, Rosemarie. Extraordinary Bodies: Figuring Physical Disability in American Culture and Literature. New York: Columbia University Press, 1997.

Garland-Thomson, Rosemarie. "Misfits: A Feminist Materialist Disability Concept.” Hypatia 26, no. 3 (Summer 2011): 591-6o9.

Gill, Michael. Already Doing It: Intellectual Disability and Sexual Agency. Minneapolis: University of Minnesota Press, 2015.

Kafer, Alison. Feminist, Queer, Crip. Bloomington: Indiana University Press, 2013.

Laski, Gregory. "Reconstructing Revenge: Race and Justice after the Civil War." American Literature 91, no. 4 (December 2019): $75^{1-81 .}$

Lee, Sonia Song-Ha. Building a Latino Civil Rights Movement: Puerto Ricans, African Americans, and the Pursuit of Racial Justice in New York City. Chapel Hill: University of North Carolina Press, 2014.

Maeda, Daryl J. Chains of Babylon: The Rise of Asian America. Minneapolis: University of Minnesota Press, 2009.

McRuer, Robert. Crip Theory: Cultural Signs of Queerness and Disability. New York: New York University Press, 2006.

Minich, Julie. Accessible Citizenships: Disability, Citizenship, and the Cultural Politics of Greater Mexico. Philadelphia: Temple University Press, 2013.

Mitchell, David T., and Sharon L. Snyder. Narrative Prosthesis: Disability and the Dependencies of Discourse. Ann Arbor: University of Michigan Press, 2001.

Moya, Paula M. L., and Michael R. Hames-Garcia, eds. Reclaiming Identity: Realist Theory and the Predicament of Postmodernism. Berkeley: University of California Press, 2000.

Nishida, Akemi. Respondent remarks. Queerness and Disability, 20 February 2015. Conference presentation, Graduate Center of the City University of New York, New York.

Okamoto, Dina G. Redefining Race: Asian American Panethnicity and Shifting Ethnic Boundaries. New York: Russell Sage, 2014.

Samuels, Ellen. Fantasies of Identification: Disability, Gender, Race. New York: New York University Press, 2014.

Schalk, Sami. Bodyminds Reimagined: (Dis)ability, Race, and Gender in Black Women's Speculative Fiction. Durham, NC: Duke University Press, 2018.

Sedgwick, Eve Kosofsky. Touching Feeling: Affect, Pedagogy, Performativity. Durham, NC: Duke University Press, 2003.

Siebers, Tobin, ed. The Body Aesthetic: From Fine Art to Body Modification. Ann Arbor: University of Michigan Press, 2000.

Siebers, Tobin. Cold War Criticism and the Politics of Skepticism. Oxford: Oxford University Press, 1993.

Siebers, Tobin. Disability Theory. Ann Arbor: University of Michigan Press, 2008. Siebers, Tobin. The Ethics of Criticism. Ithaca, NY: Cornell University Press, 1988. 
PART I

Sex 


\title{
ONE | Witnessing "Disability Experience on Trial": Toward Critique and Emancipation
}

\author{
ALLISON WEINER HEINEMANN
}

Content warnings: sexual violence, rape culture

I.

When the \#MeToo movement spread virally in October 2017, it offered new possibilities of communicating and sharing lived accounts of sexual harassment, abuse, and assault. Individually voiced testimonies, whether given in detail or simply marked by the hashtag and two words, became amplified in a voluminous collective outcry that exposed the pervasively systemic rot of rape culture and sexual violence. When the \#TimesUp movement subsequently commenced at the beginning of 2018, it combined legal action with grassroots activism, revealing how experiences of sexual harassment and assault carry evidentiary weight-beyond just being part of the massively collective cultural record-in potentially litigating perpetrators. But while both movements have allowed for certain voices to be heard, and for certain measures of justice to be brought, they have excluded many others from the narrative.

Among the many experiences invisibilized are those of disabled people. In February 2018, Disability Visibility Project ${ }^{1}$ and Rooted in Rights ${ }^{2}$ joined "to lift up the voices of disabled survivors so that their stories could be heard" (Rooted in Rights). Their collaborative work includes a Twitter chat; ${ }^{3}$ the creation of the hashtag \#DisabilityToo; a web-based compendium of resources, research reports, and accounts from writers with disabilities; and an invitation for disabled people to share stories 
that will "amplify the voices of [the] community and to spread understanding about what people with disabilities are facing when it comes to sexual abuse and assault" (Rooted in Rights). Part of what needs to be understood is the omission of disability experience itself from the movements. Emily Ladau, disability activist and editor-in-chief of the Rooted in Rights blog, vocalizes the necessary call for representation in one of her Tweets from the February 2018 Twitter chat: "Meaningfully include disabled people in the \#MeToo and \#TimesUp movements. Hear us. See us. Listen to us. Do not speak over us. Do not speak for us. Believe us" (@emily_ladau).

That disabled people not only face higher rates of sexual assault but also have their experiences left out of what purport to be inclusive movements, attests to what Tobin Siebers, in Disability Theory, has called the "ideology of ability," which "is at its simplest the preference for ablebodiedness. At its most radical, it defines the baseline by which humanness is determined, setting the measure of body and mind that gives or denies human status to individual persons" (8). We encounter such an ideology at work, among many other instances, through assumptions that people with disabilities do not need to be included in conversations about sexuality or surviving sexual assault because they are considered to be asexual-at the same time that they are often hypersexualized; through power imbalances created by a culture of medicalization that result in disproportionate coercion and abuse by doctors, personal assistants, and family members; and through a legal system that has historically regulated the sexual rights of people with disabilities via restrictive laws limiting marriage as well as mandating involuntary sterilization. As Siebers illuminates, the ideology of ability "affects nearly all of our judgments, definitions, and values about human beings, but because it is discriminatory and exclusionary, it creates social locations outside of and critical of its purview, most notably in this case, the perspective of disability" (8).

Given this "outsider" position, then, disability identity has the potential to "disturb and critique" the ideology of ability (Siebers, 9). As the major projects of his groundbreaking 2008 book, Disability Theory, Siebers thus identifies the necessity of "mak[ing] [the ideology's] workings legible and familiar," and significantly, of revealing how "disability creates theories of embodiment more complex than the ideology of ability allows" (9). Advancing a disability identity politics becomes vital to realizing both projects, and it is especially through the redefinition of disability as "social location complexly embodied" that such a politics 
is made possible (14). "Identities, narratives, and experiences based on disability," Siebers argues, "have the status of theory because they represent locations and forms of embodiment from which the dominant ideologies of society become visible and open to criticism" (14). Through disability experience in particular, situated knowledge claims can ariseclaims that lay bare the "blueprints" (32) of the ideology of ability at work in our social constructions, including in what Siebers calls the "sex of architecture" (127).

In this chapter, I pay tribute to Siebers's "Disability Experience on Trial," in which he crucially advances not only a theory of disability as complexly embodied but also makes a critical intervention in reclaiming the value of experience itself, which has been discounted by poststructural scholars like Joan Scott. In doing so, Siebers situates experience as neither reductively positivistic nor as merely a product of discourse, but instead makes clear that experience is central to raising verifiable knowledge claims about bodies that "display the workings of ideology and expose [that ideology] to critique and the demand for political change" (33). "Disability Experience on Trial" further helps us to understand how disability experience can give weight to legal claims to access, not just with respect to physical access, but to sexual access as well. Ultimately, I want to extend Siebers's work in a call for an embodied approach to the law, especially in how it deals with disabled survivors' experiences with sexual assault. It is Siebers's attention to embodied experience that offers the possibility of "both critique and emancipation" (123), and it is such an approach that we need not only to envision meaningful frameworks for justice in the legal system but also to take up vital responses beyond the law, such as the one made by the Disability Visibility Project and Rooted in Rights collaboration.

II.

In the sixth chapter of Disability Theory, Siebers considers two instances of "disability experience on trial." The first entails the 2004 Supreme Court case, Tennessee $v$. Lane, in which the Court departed from a trend of restrictive interpretations of disability law to hold that Title II of the Americans with Disabilities Act (ADA) allows plaintiffs to sue states for denying them access to public services, in this case to Tennessee courtrooms. Siebers reveals how the Court not only gave weight to the individual accounts of respondents George Lane and Beverly Jones but also recognized a larger catalog of both historical and contemporaneous 
experiences of disability discrimination and exclusion, in many cases perpetuated by the judiciary itself; as Siebers argues, "the fact that Lane's experience is representative of discriminatory behavior writ large" is what ultimately compelled the Court (123). Collectively, experiences "of pervasive unequal treatment in the administration of state services and programs, including systematic deprivations of fundamental rights" have constituted, as Justice John Paul Stevens concludes in writing for the majority, the "sheer volume of evidence demonstrating the nature and extent of unconstitutional discrimination against persons with disabilities in the provision of public services" (Tennessee $v$. Lane).

But the idea of experience as evidentiary concerns the second instance, for Siebers, of "disability experience on trial." Siebers here turns to the implications of Joan W. Scott's 1991 essay "The Evidence of Experience," in which Scott takes issue with historians "of difference"namely those working to reveal marginalized women's, queer, and working class histories-who seek to "challenge . . normative history" by "documenting the lives of those omitted or overlooked in the past" (Scott, 776). Scott does acknowledge that historical work that relies on "the authority of experience" has successfully "occasioned a crisis for orthodox history by multiplying not only stories but subjects," allowing for the emergence of "new evidence" that "call[s] old narratives into question" (776). At the same time, however, Scott contends that such work "depends on a referential notion of evidence which denies it is anything but a reflection of the real" (777). To take a positivistic approach that unquestionably accepts such accounts as "authoritative," and thus to fail to consider how these experiences are discursively constituted and represented, Scott argues, "precludes critical examination of the workings of the ideological system itself" (778). Scott consequently insists that "this kind of appeal to experience as incontestable evidence and as an originary point of explanation-as a foundation on which analysis is based- . . seriously weakens the critical thrust of histories of difference" (777). Ultimately, Scott maintains that histories of difference that attempt to dismantle foundational narratives and ideologies by legitimating experience as evidentiary only reproduce "the epistemological frame of orthodox history." And when that happens, she argues, such histories dangerously "naturalize" difference by "tak[ing] as self-evident the identities of those whose experiences are being documented" (777). While Scott admits that "experience is not a word we can do without," she calls for alternative approaches that "insist . . on the discursive nature of 'experience' and on the politics of its construction" (797). 
Scott thus cautions us against an uncritical conception of experience that merely re-creates orthodoxy, but as Siebers contends, "it is not clear that her critique of experience is ultimately compatible with [emancipatory] goals" (Siebers, 122). Poststructuralist critiques such as Scott's turn on "the desire for absolute critique," where "the more radical and absolute the critique, the greater its potential for emancipation"; what such critiques result in, however, is a "process of subtraction" that leaves us with uncertain ground on which to form knowledge claims (122). While Siebers acknowledges that "the ability to turn critique against itself" may serve its own value, "the question arises whether the desire for absolute critique always serves politically progressive goals. Is the banishment of experience, for example, radical or reactionary?" (122).

Siebers is not at all alone in asking such a question. In the wake of Scott's publication, feminist scholars in particular have responded that "Scott's devaluation of experience leaves us without a way to engage . . . meaningfully" with texts that voice accounts of lived experience, especially to contest the entwined conditions of white supremacy, patriarchy, heteronormativity, settler colonialism, and capitalism (Stone-Mediatore, 116). ${ }^{4}$ While resisting the reproduction of an orthodox frame is key, a discursive approach in fact reduces experience to language, to merely-in Scott's own words- "the substitution of one interpretation for another" (794). "Ironically," philosopher Shari Stone-Mediatore contends, "such a [discursive] theory reverses the empiricist privileging of subjective experience over language only to retain its one-dimensional, visionoriented structure" (121).

In turn rejecting what Stone-Mediatore calls the "flattening [of] experience into discursively constituted perception" (122), Siebers argues that experiences such as George Lane's expose the "blueprints" of society's architectural inaccessibility and exclusion. In this way, disability clearly evidences its social construction, but experiences of disability, and the identities that are embodied in lived experiences, cannot be reduced to mere "socially constructed fictions" (Siebers, 126). Experiences reveal the socially constructed inner workings of ideologies, including the ideology of ableism that claims that people with disabilities should be subject to, rather than agents of, legal regulation. There is, moreover, "the political promise arising from the knowledge that experience is constructed" (Siebers, 127).

Siebers's key claim that "disability experience has the potential both to augment social critique and to advance emancipatory political goals" rests, then, on a realist approach to identity (122). "By 'realism," Siebers 
clarifies, "I understand neither a positivistic claim about reality unmediated by social representations, nor a linguistic claim about reality unmediated by objects of representation, but a theory that describes reality as a mediation, no less real for being such, between representation and its social objects" (30). Identities are created by socially constructed experiences, but "they are nevertheless meaningful and real precisely because they are complexly embodied" (30). We encounter both the social construction and complex embodiment of identity "whenever forbidden bodies and minds enter spaces"-for example, as Siebers notes, when Rosa Parks sat at the front, rather than the back, of the bus, and when George Lane attempted to use a wheelchair to enter the Polk County Courthouse (125). The fact that spaces are constructed and regulated to privilege certain bodies and minds is not just about ideology alone, but about a literal "lack of fit [that] reveals the ideology of ability controlling the space" (Siebers, 124). ${ }^{5}$ Identities complexly embodied in lived experience of discrimination and exclusion thus have what Siebers calls "verifiable knowledge claims" to make about such spaces: they can deconstruct "the lines of force, the blueprint" of architecture and processes that exclude and otherize; they can reveal the material structures of oppression (124). Invoking Linda Alcoff, Siebers makes clear that "identities are indexical entities," and thus "real within a given location" (quoted in Siebers, 125). That doesn't mean, contra Scott, that identities, and the experiences in which they are located, are "natural entities," but rather that they are "social facts that exist in human society as part of a causal network" (Siebers, 126), serving as "points of departure" for verifying knowledge claims about social constructions in reference to one another (127).

Ultimately, Siebers argues that "the experiences of people with disabilities help to clarify the fact that identities may contain legitimate claims to knowledge, and this knowledge, once verified, is a valuable weapon against the oppression of minority people" (127). The weight given to disability experience in Tennessee $v$. Lane, then, allows us to understand why the evidence of experience-quite literally-matters, and thus as a firm counter to Scott and other poststructuralist theorists, Siebers advises that "from now on, it might be better to keep in mind the political implications of our arguments and to put them in service of both critique and emancipation" (122-23).

The work of critique and emancipation through disability experience cannot, however, be limited to securing physical access alone. Sexual access is also necessary. Siebers reminds us that, of the evidence of dis- 
ability experience examined in Tennessee $v$. Lane, the Court gave considerable attention to "a variety of public and legal practices discriminating against the sexual practices and reproductive rights of disabled people" (128). Invoking the impact of (the still-unoverturned) Buck v. Bell (1927), which deemed state statutes legalizing forced sterilization to be constitutional, as well as state laws (many still-unrepealed) that have criminalized the marriage of people with disabilities, "the Court does not set aside sex in its consideration of disability discrimination but asserts the relevance of sexual experience of unequal treatment under the law" (128). ${ }^{6}$ But while Tennessee $v$. Lane ultimately makes "a crucial and unexpected intervention in the legislation of accessibility for public buildings," and "looks like a major success" when considering the dearth of regulation concerning single-family dwellings, disability law has historically been, and continues to be, limited in ensuring physical access, and even more so when it comes to sexual access (Siebers, 127). "And yet," Siebers illuminates, "there is such a thing as the sex of architecture, and it affects the sexual practices allowed by various spaces and the artifacts in them. Sex may seem like a private activity, but it is wholly public insofar as it is subject to social prejudices and ideologies and takes place in a built environment designed according to public and ideal conceptions of the human body" (128). Thus disability activism on this front maintains a "focus that extends from public venues concerned with sexual and reproductive health, such as hospitals and doctors' offices, to private spaces where sex manuals, products, devices, and assistance are used to create new sexual environments better suited to people with disabilities" (130).

In calling for not only sexual access but also a sexual culture for disabled people, Siebers allows us to recognize how the distinction between private and public collapses, to both oppressive and liberatory endsoppressive because the constant presence and forces of medicalization intrusively interfere with the right to privacy; liberatory because "the rights of sexual citizenship change the conditions of enablement for sexual expression, defying medicalization and redefining privacy according to the sexual needs and desires of dependent and interdependent people" (Siebers, 149). At the same time that disability studies, namely through its critique of medicalization, can offer a meaningful lens to reconceptualize this distinction, and as much as we can envision new possibilities for politicizing sexuality in a way that "redefines people with disabilities as sexual citizens" (148) - which goes far beyond just expressing sexuality in public-we have to remember that marginalized disability experiences happen "not [in] heteroclite and mobile spaces 
of transgression, fancy, or revolution but places with real-world qualities where human beings want to experience pleasure, creativity, knowledge, and recognition-basic needs often ignored and unsupported when it comes to the disability experience" (133-34).

And as much as Siebers points to the promise of the law through Tennessee $v$. Lane, I want in the remaining portion of this chapter to briefly explore how the law, particularly in its capacity to redress sexual violence against people with disabilities, so often frustrates both the meeting of these basic needs and the possibility of sexual citizenship. As I will reveal, it is in fact Siebers's attention to the complex embodiment of lived experience that offers a necessary, critical intervention in the law. "The belief seems to be that oppression will end as soon as minority identities vanish," Siebers contends, "but without a theory that can verify how social identities are embodied complexly in lived experience, how they become real, it is not clear that we can understand what oppression is and how it works" (126).

III.

In 2012, Jane, ${ }^{7}$ a woman living with Down syndrome, testified before the Superior Court of Fayette County, Georgia that she was raped three times, over the course of twelve hours, in October 2010 by William Jeffrey Dumas. A jury convicted Dumas-who did not testify in his own defense ${ }^{8}$ - on two counts of rape and one count of aggravated sodomy of Jane, who was twenty-four at the time of the assault, for which Judge Christopher McFadden, a state appellate judge sitting in on the lower court, gave only the minimum sentence of twenty-five years (Munford).

But in January 2014, Judge McFadden reversed the jury's verdict and granted Dumas's motion for a new trial, under the claim that the convictions ran counter to "the principles of justice and equity" (State of Georgia v. William Jeffrey Dumas). Despite an acknowledgment that "the evidence was sufficient to sustain [the] convictions"-DNA evidence proved that it was Dumas's semen on the bed in which Jane slept on the night of the assaults, and a medical examination revealed evidence consistent with forcible penetration-McFadden found Jane's testimony to be "conclusory and skeletal," giving rise to what he called "certain improbabilities and discrepancies" (State of Georgia v. William Jeffrey Dumas). Above all, McFadden held that Jane quite simply did not "behave like a victim" between the time at which she alleged she was first assaulted and when she reported it-just less than twenty-four hours later-to the family 
friend with whom she was staying (and at whose house the events had happened). Moreover, McFadden argued that Dumas “didn't behave like someone who had recently perpetrated a series of violent crimes against [Jane]." In the end, McFadden couldn't sanction the convictions with the "approval of [the] court's mind and conscience" (State of Georgia $v$. William Jeffrey Dumas). McFadden's decision quickly drew attention from the media and ire from the public, to the extent that he ultimatelyafter initial refusal-recused himself from the retrial. ${ }^{9}$ While some commentators called out the motion for its obvious reification of rape culture, given McFadden's implication that there was a "right" way to be both a victim and a perpetrator, others were drawn to the fact that Jane "suffers from," as many media accounts put it, Down syndrome (Perry).

While gratuitous attention to Jane's disability should be dismissed for the sensationalistic mawkishness that it is, Jane's experience as a woman living with Down syndrome does raise several significant considerations. People with disabilities, especially intellectual and developmental disabilities, are sexually assaulted at higher rates than people without disabilities, and individuals who are multiply marginalized experience even higher rates. ${ }^{10}$ As legal scholar Jaime Lindsey makes clear, however, "this heightened vulnerability is not an inevitable consequence of disability but is caused by situational factors which make [people with disabilities] more vulnerable" (296). Legal researchers Janine Benedet and Isabel Grant have written extensively on such situational factors for people with mental disabilities, ${ }^{11}$ noting that

the belief that mental disability is a scientific, objectively determined diagnosis leads to certain characteristics being applied to persons with a mental disability without any consideration of the degree to which social construction determines those characteristics. For example, the common assertion that people with mental disabilities are compliant may overlook the fact that this compliance is reinforced and rewarded by support systems that provide few opportunities for dissent ... Legally, it may cause us to miss the multifaceted ways in which people with mental disabilities resist or object to sexual assault and also to assume that compliance represents consent rather than acquiescence in the face of coercion or exploitative inducements (135).

Benedet and Grant have further traced the systemic resistance that individuals with disabilities face in seeking to report and adjudicate sexual violence: "their allegations of sexual assault are disbelieved, their 
expressions of consent judged inadequate and their credibility challenged at every step of the legal process" (198). Much of the issue is the law's failure-whether substantively or procedurally - to account for experiences that don't cohere with its rigidly normative conceptions of agency and autonomy. But much also has to do with pervasively problematic perceptions of people with disabilities-in particular, women with intellectual and developmental disabilities — as both nonsexual and "oversexed" beings. As Benedet and Grant show, "This group of women is simultaneously labelled as asexual and childlike, on the one hand, and hypersexual and sexually indiscriminate on the other, stereotypes which permeate our treatment of legal issues like consent and sexual history" (139). Judge McFadden's rhetoric certainly aligns with other courts' decisions that have discounted women without disabilities for not "behaving" enough like "victims" in the wake of sexual assault, but we must be especially attentive to the way in which "Jane's troubling case reveals the intersections between rape culture and the way we strip agency from people with disabilities" (Perry).

In highlighting the Fayette County Superior Court's failure to take into account the situational factors that complicate the ways in which sexual assault survivors with disabilities report and testify to their experiences, I want to draw attention to how this omission is indicative of the legal system's larger "failure to understand 'embodied subjects,' that is, subjects that are constituted in and through the body, where mind and body are indivisible" (Karpin, 283). Isabel Karpin argues that such a failure "is at the heart of the legal system's failure to deal justly and appropriately with those who are not [deemed] normative beings. The hegemony of normativity is problematic not just because it excludes those who do not fit its ideal but because normativity itself is an illusion" (283). As feminist legal scholars like Karpin illuminate, the law's emphasis on "normative" values of objectivity, autonomy, and rationality privilege a transcendent mind over body, meaning that "to continue to structure the laws around the possibility of transcendence is to insist on the universality of a narrow version of embodiment. In the current political and historical moment privileged embodiment is white, heterosexual, economically secure, able-bodied and male" (Karpin, 283). Even in cases dealing with sexual assault, "where the body is part of the contested terrain that gives structure to the legal proceedings," the legal system conceives of subjects as transcendent "minds, not as sexed bodies" (Ngaire Naffine, quoted in Karpin, 284). Karpin's careful attention to case law from both the United States and Australia reveals that when matters of the body are 
considered, disability is either gratuitously invoked or reduced to mere flesh; direct testimony of lived experience with a disability, in one's own terms and framing, is always suppressed. As Karpin concludes:

When assault intersects with disability, it is evident that despite the proliferation of body and body parts in the legal discourse, there is still no space for the development of a narrative of what it is to live in bodies. . . . Typically in cases of sexual assault those moments when the subject is perceived to be most in control of their selfhood, are the points when they are least embodied, and therefore, not in need of (or indeed constituted by) their embodied identity. (284)

What, then, would it take to incorporate both theory and praxis that allow for a recognition of complex embodiment-whose "ultimate purpose," as Siebers argues, "is to give disabled people greater control and knowledge over their bodies in situations where increased knowledge and control are possible" - into the legal system (27)? It would have to mean more than just bringing the body "back in," as feminist legal scholars Ruth Fletcher, Marie Fox, and Julie McCandless make clear, lest the body/mind dichotomy simply gets reversed, and to avoid what Karpin identifies as legal trends in which disabled bodies are reduced to "flesh." It would mean shifting the way in which the law "consider[s] the body [from] an object of analysis [to] a category of analysis. . . . A thicker conception of embodiment . . . would seek to account for the ways in which we value the living physical body as it enables our being in the world and our interactions with others" (Fletcher, Fox, and McCandless, 321).

A further "shift in analytical focus from sexual difference to embodied difference," Fletcher, Fox, and McCandless suggest, would "help . . . avoid assumptions that sexual difference will be the primary signifier of embodiment, and allows for an intersectional approach to bodily differences" (334). In working toward this "more complete picture of how embodiment is legally constructed, from feminist and other perspectives" (Fletcher, Fox, and McCandless, 334), we are reminded of Siebers's "hope that the knowledge given by disability experience might renew the incentive to reclaim and to retheorize other experiences of minority identity, despite the argument by Scott and others that they have no critical value" (Siebers, 122). Fletcher, Fox, and McCandless propose four framings for a more nuanced understanding of embodiment in the law: the subjective, the intersubjective, the material, and the symbol, highlighting that their "aim is not to posit an alternative 
legal framework for regulating embodied choices, but to articulate a conceptual framework for analyzing how embodiment is and should be valued in law" (336). In its call for an embrace of intersubjective and interdependent relationality over objective, independent rationality, an embodied approach to the law would "disrupt notions of a singular universal body as an appropriate object of regulation” (Fletcher, Fox, and McCandless, 344-45).

Critically, an embodied approach to the law, especially to sexual assault cases, would bring necessary focus to disability experience as evidence. To consider such experience as evidentiary is not, as Siebers clarifies, to confer on it "absolute status as knowledge," but instead to conceive of it as what "remains intimately connected to political and social existence," and thus as what is capable of raising knowledge claims that reveal and critique the ideology of ability, especially as that ideology dictates normative expectations about both sexual experience and survival in the aftermath of assault (82). As Karpin insists:

The development of the embodied subject of law . . . will require an attention to particularity and situated knowledges. It will require legal reasoning to forgo its reliance on universal standards that claim fairness precisely because they are applied across the board without regard to actual effects. It will require judges, lawyers, and other legal actors to radically reimagine the subject before the law as materially heterogeneous and structured through the particularity of embodiment, history, culture and politics. (284)

One practical but potentially revolutionary way to prompt such a reimagining of the legal subject would be to allow testimony to be given as "experiential narrative," rather than as set responses to standard questions that preclude the possibility of "testimony which speaks to what it means to live in and through a particular body" (Karpin, 293). Karpin argues that "the presentation of evidence in experiential narrative form would, arguably, offer up a more embodied testimony since it would enable the witness to identify the harm done in a way that was meaningful for her embodied subjectivity" (288). Lest such testimony privilege some accounts as "authentic" over others-Karpin in fact here invokes Scott - the act of what Karpin calls "a second kind of witnessing (the witness of the witness)" plays a critical role in attesting to an intersubjective understanding of the situated and embodied knowledge that has been articulated (288). In this way, embodied testimony offers the possibility 
both of critique, in its own terms, and, as witnessed by and shared with others, of political emancipation.

IV.

We are reminded that Siebers refers in Disability Theory to his dossier entries-the narratives, often from news articles, that importantly intervene in the text—as "testimony." As Siebers explains, "The dossier tends to contain testimony about the oppression of disabled people, sometimes framed in their own language, sometimes framed in the language of their oppressors" $(14-15)$. The dossier is an unapologetic, "deliberate act of identity politics," not only as theory but also as praxis. It represents not just epistemological claims, but ultimately a "shar[ing] of experiences" that allows "this theoretical component [to] be directed toward political ends" (Siebers, 20-21).

In closing, then, I would like to echo Ladau's call, on behalf of many, to include disability experiences in movements against sexual assault. The work of Disability Visibility Project and Rooted in Rights attests to the ongoing need for the sharing of such dossiers of disability testimony, which demand to be witnessed, and believed.

Notes

1. The Disability Visibility Project was founded by disability activist Alice Wong, and "is an online community dedicated to recording, amplifying, and sharing disability stories and culture." See disabilityvisibilityproject.com

2. Rooted in Rights "produces videos and social media campaigns exclusively on disability rights issues. .. . [Its] social media sites and website are platforms for people with disabilities, disability rights advocates and their allies to learn, connect and organize for change." See rootedinrights.org

3. See wakelet.com/wake/8f00ba67-4f98-4676-8662-343fd4300e9c

4. Stone-Mediatore, while recognizing the need to "avoid naturalizing experience," maintains that many experiential-oriented narratives-including, for example, the work of Gloria Anzaldúa, bell hooks, and Michelle Cliff-“do intervene in the ideological processes that constitute experience" (117). StoneMediatore ultimately proposes a way of reading that draws upon the work of Chandra Mohanty, in which the "narration of . . . experience is no mere reporting of spontaneous consciousness," but instead entails an "arduous and creative process of remembering, reprocessing, and reinterpreting lived experience in a collective context." Such "rethinking and rearticulating obscured, often painful memories" works to "transform experience, enabling one to claim subjecthood and to identify with oppositional struggles" (125). 
5. On the matter of a "lack of fit," see Garland-Thomson. As GarlandThomson illuminates, and in acknowledgment of how the concept expands upon Siebers's work: "The idea of a misfit and the situation of misfitting that I offer here elaborate a materialist feminist understanding of disability by extending a consideration of how the particularities of embodiment interact with their environment in its broadest sense, to include both its spatial and temporal aspects. This article, in other words, offers an account of a dynamic encounter between flesh and world" (592). See also Price, who extends the concept of "misfitting" "beyond 'the physical realities of our lives' (Garland-Thomson, 602) and into our mental landscapes as well" (272).

6. Of course, what the Court leaves unnamed, and thus without institutional recognition (especially of its own complicity in not overturning Buck), are the egregious acts of coercive sterilization that continued well into the late twentieth century, as well as the structure of disability policies like Supplemental Security Income (SSI) that disincentivize marriage for couples with disabilities by allocating lower benefits than the couple would receive if living together, but not married. On the persistence of eugenic logics in the late twentieth century, especially as value attributions of "fitness" intersect across disability, gender, and race, see Kluchin.

7. The claimant's name was redacted in the published court order on the motion for a new trial. As a way to counter the media's depersonalization of the claimant, disability blogger Sarah Levis gave the claimant the name of "Jane," which journalist David M. Perry also adopted in his commentary on CNN.com. See both Levis and Perry.

8. In interviews with the police, however, Dumas did denounce Jane for having similarly accused someone else in a previous instance; the sheriff's office found Dumas's accusation to be unfounded, and the prosecutor argued that such a lie was further evidence of Dumas's guilt. See Munford.

9. The Fayette County Superior Court—under a different judge-heard the retrial in August 2015. Jane retestified, and this time, Dumas was forced to testify. Of the three counts, the jury ultimately convicted Dumas on only one count, resulting in a sentence of twenty-five years in prison and probation for life. See Nelms.

10. It's important to note that statistics tend to vary, especially when accounting for particular lived experiences, which can affect who has access to, and the privilege of some security in, reporting in the first place. Generally, people with disabilities are cited as being twice as likely to experience rape and sexual assault, with women with disabilities being four times as likely. An NPR series from 2018, using unpublished figures from Bureau of Justice statistics, indicates that people with intellectual disabilities may be a staggeringly seven times as likely to experience sexual assault than people without disabilities. See Shapiro. See also Martin et al. and the extensive body of work by Janine Benedet and Isabel Grant, especially the article cited in this chapter. In highlighting the disproportionate impact on women with disabilities, I want to make clear that such a focus does not ignore the fact that men with disabilities are also targeted at higher rates than men without disabilities. Further, in drawing attention to the gendered disproportionality at stake, it is important to acknowledge nonbinary concep- 
tions of gender, and thus the especially disproportionate rates at which trans and nonbinary individuals experience assault, as well as the disproportionate rates at which people of color experience assault, especially compounded when considering the intersections of multiply marginalized identities. For a key article on how privilege determines whose experiences are accounted for in statistical reporting, especially in reports on campus assault, see Brubaker et al.

11. I invoke here the broad umbrella term that Benedet and Grant deliberately employ; as they write, they sought a "term that could describe, in a shorthand way, women whose disabilities affect cognition, perception, intellectual ability or decision-making, but who are otherwise a heterogeneous group. The terms 'developmental disability' and 'intellectual disability' are more commonly used, but describe only a subset of the women whose experiences of sexual violence are at issue in our work" (133).

\section{Works Cited}

Benedet, Janine, and Isabel Grant. "Sexual Assault and the Meaning of Power and Authority for Women with Mental Disabilities." Feminist Legal Studies 22, no. 2 (2014): 131-54.

Brubaker, Sarah Jane, Brittany Keegan, Xavier L. Guadalupe-Diaz, and Bre'Auna Beasley. "Measuring and Reporting Campus Sexual Assault: Privilege and Exclusion in What We Know and in What We Do." Sociology Compass 11, no. 12 (2017): 1-19.

Disability Visibility Project, disabilityvisibilityproject.com. Accessed 3 June 2018.

@emily_ladau (Emily Ladau). "Meaningfully include disabled people in the \#MeToo and \#TimesUp movements. Hear us. See us. Listen to us. Do not speak over us. Do not speak for us. Believe us." Twitter, 21 February 2018, 4:54 p.m., twitter.com/emily_ladau/status/966476270451286021

Fletcher, Ruth, Marie Fox, and Julie McCandless. "Legal Embodiment: Analysing the Body of Healthcare Law." Medical Law Review 16, no. 3 (2008): 321-45.

Garland-Thomson, Rosemarie. "Misfits: A Feminist Materialist Disability Concept." Hypatia 26, no. 3 (2011): 591-6o9.

Karpin, Isabel. "Peeking through the Eyes of the Body: Regulating the Bodies of Women with Disabilities." In Disability, Diversability and Legal Change, edited by Melinda Jones and Lee Ann Basser Marks, 283-3oo. Amsterdam: Martinus Nijhoff, 1999.

Kluchin, Rebecca M. Fit to Be Tied: Sterilization and Reproductive Rights in America, 1950-1980. New Brunswick, NJ: Rutgers University Press, 2009.

Levis, Sarah. "Christopher McFadden: What Do We Do When a Judge Is Wrong?" Girl with the Cane, 2 March 2014, www.girlwiththecane.com/christopher-mcfa dden. Accessed 3 June 2018.

Lindsey, Jaime. "Developing Vulnerability: A Situational Response to the Abuse of Women with Mental Disabilities." Feminist Legal Studies 24, no. 3 (2016): 295-31.

Martin, Sandra L., Neepa Ray, Daniela Sotres-Alvarez, Lawrence L. Kupper, Kathryn E. Moracco, Pamela A. Dickens, Donna Scandlin, and Ziya Gizlice. "Phys- 
ical and Sexual Assault of Women with Disabilities." Violence Against Women 12, no. 9 (2006): 823-37.

Munford, John. "Hampton Man Gets 25 Years for Raping Down Syndrome Victim." The Citizen, thecitizen.com/2012/10/31/hampton-man-gets-25-years-ra ping-down-syndrome-victim. Accessed 3 June 2018.

Nelms, Ben. "Dumas Gets 25 Years in Rape of Down's [sic] Syndrome Woman, 24." The Citizen, thecitizen.com/2015/09/02/dumas-gets-25-years-rape-dow ns-syndrome-woman-24. Accessed 3 June 2018.

Perry, David M. "Rape Cases: When Judges Just Don't Get It." CNN, 11 March 2014. www.cnn.com/2014/03/11/opinion/perry-rape-disabled-georgia/ind ex.html. Accessed 3 June 2018.

Price, Margaret. "The Bodymind Problem and the Possibilities of Pain." Hypatia 3o, no. 1 (2015): 268-84.

Rooted in Rights, rootedinrights.org. Accessed 3 June 2018.

Scott, Joan W. "The Evidence of Experience." Critical Inquiry 17, no. 4 (1991): $773-97$.

Shapiro, Joseph. “Abused and Betrayed.” NPR, www.npr.org/series/575502633 /abused-and-betrayed. Accessed 3 June 2018.

Siebers, Tobin. Disability Theory. Ann Arbor: University of Michigan Press, 2008. State of Georgia v. William Jeffrey Dumas, 2012R 0018 (Fayette Cty. 2014).

Stone-Mediatore, Shari. "Chandra Mohanty and the Revaluing of 'Experience." Hypatia 13 , no. 2 (1998): 116-33.

Tennessee v. Lane, 541 U.S. $5^{09}$ (2004). 
PART II Identity 


\title{
Two | It Depends: Academic Labor and the Materiality of the Body
}

\author{
CYNTHIA WU
}

On February 6, 2015, at the memorial the University of Michigan held for Tobin Siebers, a colleague who knew him well mentioned that toward the end of his life, Tobin often forewent the pain medication he was prescribed after his cancer diagnosis in order to remain mentally lucid enough to write. In the moment, the statement gave me pause. Isn't the desire to work at all costs an extension of the ableism that accompanies capitalism? Isn't the belief that one must always be working (even in the face of terminal illness) a flaw in the culture of the professoriate? Are we now learning about these tendencies even among revered disability studies scholars, who should be most critical of them? When I considered that statement a bit more, though, I realized that for Tobin the delicate balancing of mind and body may have been rooted not in self-policing but in something else-a sense of purpose or even pleasure. Moreover, the cognitive satisfaction that comes with writing may be corporeal on some level. It affects the body and not always in ways we can readily express. Whether accompanied by pain, pleasure, or both, writing is an act borne on the body. This also goes for authors who make the opposing choice to take pleasure in writing while cognitively impaired. ${ }^{1}$ We might say that the products of our academic labor-be they conceived in joy, aching, clarity, fuzziness, or any combination of these-bear the traces of our embodiment.

This chapter is an experiment in cripping the genre of the academic essay. It, first, plays with form by bending traditional notions of linearity; 
second, it uses autoethnographic ingredients in its analysis of academic cultures; and, third, it makes transparent the body's work that brings writing to fruition. I take the title of this chapter "It Depends" from Eva Feder Kittay's concept of dependence and its ability to lay bare the interconnectedness of all human life. Although many disabled people are denigrated for their visible reliance on others for survival-in their use of caregiving services, for instance-Kittay urges a radical imagining of dependence that ascribes it to everyone, disabled or not. The rights-seeking discourses of many social minorities, including those of the disabled, often link dignity with autonomy. However, Kittay argues that the dignity that comes from full human rights would be better served by valuing not autonomy but care and interconnectedness. Furthermore, "our societies should be structured to accommodate inevitable dependency within a dignified, flourishing life-both for the cared for, and the carer" (54). This ethic attends to the needs of all parties in caregiving relationships. Correspondingly, the granular specifics of connections between disabled people and their care providers should inaugurate a larger "public ethic of care based on the idea that we are all involved in nested dependencies" $\left(5^{6}\right)$. Everyone depends on others. Independence is an illusion.

Kittay's respecting of interpersonal dependence can be used to think through the discursive dependences of disability identity. Disability is an identity that depends on its context. This statement is not controversial or original. Disability rights activists and disability studies scholars have long argued that a person's ontology does not make them disabled. Rather, disability gets defined by how a person's rights are diminished when their built and cultural environments pose barriers to the physical, psychosocial, sensory, or intellectual impairments they possess. The reasoning goes: if you eliminate the barriers, you eliminate the disability. Like the fiction of the autonomous individual that Kittay's argument dismantles, disability is not an abstracted state of being removed from its historical and material contexts. I want to add that if we think of disability as an identity that always depends on its environment, those of us with impairments that only occasionally interface with hostile environments or whose environments present only small barriers might not feel secure in our entitlements to its claim. We may think of ourselves as "not disabled enough." Yet the bulk of humanities-based scholarship on identity, broadly speaking, has put forth that it is contingent. This, we have long been comfortable with. This line of thinking has also advanced that identity's contingency does not render it moot. In fact, the opposite 
is true: identities matter because they are produced by and respond to historical and structural forces that have consequences. Hence, it would follow that the shifting sense of entitlements to disability's claim that many of us feel is a key example of identity's instability and, therefore, its validity. The question of whether or not one is disabled can be summed up thusly—it depends.

At the same time, I allow space for thinking about the body's materiality that legitimizes our perceptions of its impairments that persist apart from any environment not amenable to them. This is where bodily pain enters the conversation. We do not often talk about the body that hurts and what happens when it is complicated by the valences of race, class, gender, or any other identity categories that make academia's barriers and hierarchies obvious. The relationship between pain and disability is not clear-cut. Many disabled people do not experience pain, and simply being in pain does not make one disabled. Seeing pain through the lens of the social model is also inadequate, because given only one choice, I would much rather be pain-free than have society organized to make it more equal for those in pain. However, in the absence of the former, I am motivated to work for the latter. The connection between pain and disability begs more exploration.

I had not until recently begun to disclose the specifics of my body's pain. I exist in a liminal category. I cannot fully operate according to what academia demands, but my day-to-day life is also distant from other kinds of chronic pain-the types that Alyson Patsavas's research examines, which have the tendency to be co-opted by mainstream accounts that "depict pain as an inhuman experience that ruins the lives of those it affects" (207). I can function according to normative expectations well enough to forget about my difference. My bodily discomfort is at a level that does not arouse abjection. The people who know about it do not pity me. I am not on prescription medication nor do I use a mobility device, although that could change in the future. I do need to be proactive in how I manage my body. I need more sleep than most people. I am vigilant about how I expend my energy, but my daily routine probably differs only slightly from that of the average nondisabled person. I do not want to glamorize the state of being in pain, which Elaine Scarry contends is inarticulable to others and, therefore, isolating. Sometimes (but only sometimes), it is. But neither do I want to relegate it to that of mere deficit or obscure the possibility of finding pleasure in the midst of a life where it exists. 


\section{Pleasure Writing}

Elsewhere, I have argued that within higher education's capitalist structures, which alienate us from our labor, we might reclaim some agency by committing to and loving the act of writing. Doing so alone does not eliminate the problems of the neoliberal university, but it does mitigate its psychic harms. This love is an act of resistance although it may be small. ${ }^{2}$ I can understand the angst surrounding the oft-repeated claim that academia is a publish-or-perish world. However, I entered this profession in order to harness the time and resources to write, not because I grudgingly accepted the requirement to do so as its trade-off. I speculate that Tobin regarded his own craft of writing similarly. In fact, he most likely modeled this way of being in academia for me and many other students.

In his creative nonfiction, Siebers has admitted that "the most profound insight of my life, the one I am most ashamed of, is that I am a better man when I am writing than when I am not" (Among Men, 111). ${ }^{3}$ This may explain why he so highly protected his ability to compose that he chose to withstand the pain from illness and its treatment rather than alleviate it with mind-altering substances. He goes on to state that writing presents an opportunity to establish and then chase an idealized version of himself, one that can never be caught. Hence, writing generates a self plagued by anxieties about, first, its wish to metamorphize in ways not true to itself and, second, its ultimate failure in actualizing that standard. Siebers muses that these dissatisfactions might parallel "the conditions of trying to be a man"-invoking, if only obliquely, the poststructuralist destabilization of gender (111). However, his thoughts about discourse mark a departure from the Foucauldian, which stipulates that the self does not preexist language but comes into being through it. There is a self in Siebers's vision of how writing occurs. This is a self that claims responsibility for the language that originates from it. ${ }^{4}$ Then, Siebers suspects that he does not really have a "true affinity" (113) for writing, so pleasure may not be the best word to describe what he gains. He experiences something else, "virtue" in its practice, insofar as writing for him is "a form of repair" where the writer must "imagine the true form of things on the basis of their ruins and then find a way to restore them to working order" (113). This describes, of course, the lengthy process of writing, editing, revising, rewriting, and polishing. As anyone who has written anything knows, the effort that goes into molding an unwieldy rough draft into a finished piece that aligns 
with normative standards of textual proficiency is hard work. Writing is an act of correction or, even, cure.

The above claims predate Siebers's work in disability studies, but-as the editors of this volume mention in the introduction-we can read the material that came before his embrace of the field as evidence of proto-disability studies thinking. Does Siebers's admission that he feels "ashamed" about his relationship to writing suggest he is troubled by his craving for perfection in the face of a disability politics that prompts us to want otherwise? This may be a possibility. That he uses the word "virtue" to identify what he feels during the process of making linguistic order out of disorder, remedy from malady, refinement out of scruffiness, resonates with Eunjung Kim's claim that cure often invokes the discourse of morality in its coerciveness. Disabled people receive an enormous amount of pressure to comply with the mandates of rehabilitation. According to Kim, the resistance or the inability to be cured is often condemned as a moral failing. Moreover, "the violence associated with cure exists at two levels: first the violence of denying a place for disability and illness as different ways of living and, second, the physical and material violence against people with disabilities that are justified in the name of cure" (14). Yet what often gets omitted in these contestations of cure is an acknowledgment that we may sometimes desire it and feel wistful when it escapes our reach. We may want cure at the same time we are aware of its problems. In certain cases, it may be the ethical objective. However, we regret our political lapses for indulging in this wish.

I am distressed by my love for writing because it reproduces normative values in the academy. For me, writing is the best part of this job. I enjoy some of the work associated with teaching. However, being in the classroom extracts an enormous amount of energy because I am introverted. I learn a lot from my students (and a significant amount of what I learn improves my writing), but I also wind up drained by the intensity of the interactions. Most tasks that fall under the realm of service require figuring out and then cooperating with institutional bureaucracy, which bewilders me. Service's payoff is that, occasionally, something worthwhile happens, but my anxiety about it often stifles the motivation. Writing, on the other hand, presents no such drawbacks. It happens in solitude. It permits the exercise of creativity in ways that provide immediate satisfaction. Academics complain, rightfully, about the glacial pace of scholarly publishing. Yet seeing one's work in print comprises only a small portion of the delight that comes from an activity where the journey feels just as worthwhile as the destination. It is due to serendipity, not design, that 
the aspect of the job I most willingly do is the one that garners the most professional capital. For someone who refuses to stop challenging the hierarchies of value in this occupation, this is hard to digest.

That writing comes more readily for me than other parts of the job does not, I sincerely hope, generate smugness. It produces relief. It mitigates the increased workloads this profession creates for people with embodiments similar to mine, which I have described in a piece of creative nonfiction as "Asian-raced and genderqueer" (Wu, 40). The brandishing of multiculturalism in higher education without structural change, as scholars like Sara Ahmed, Roderick A. Ferguson, and Stephanie Kerschbaum have argued, only mobilizes difference in order to shore up neoliberal practices. Moreover, minoritized faculty are disproportionately conscripted for this labor. Whether diversity work is the mentoring of students, which feels meaningful, or the type that legitimizes capitalist structures, which is soul killing, it is still work. It still takes time away from research and writing, which is what this profession tangibly rewards the most. I am not someone who cranks out a new book once every few years. However, the fact that I find writing pleasurable has palliated some of the damaging effects of university life for faculty with minoritized identities. The dreaded associate-professor stall—an occupational hazard for those who shoulder heavy diversity workloads and a condition often wrongly blamed on the individual experiencing the stalling-never felled me. That is a relief.

In The Slow Professor, Maggie Berg and Barbara K. Seeber attempt to reclaim pleasure in academia. The corporate university, they argue, imposes a hastened pace at which academics must work. This has led to the deterioration of intellectual community, which is the very raison d'être for institutions of higher learning. The university's constant pressuring of faculty to produce research (and to produce it ever more quickly) causes faculty to devote themselves to this endeavor at the cost of quiet contemplation and relationship building. When research is prized in this manner, much of what made the academy a place for intellectual growth and community disintegrates. Berg and Seeber propose that academics resist these demands by slowing down and recalibrating how they think and speak of research. Instead of relentlessly pursuing publications, they might center the aspects of research and writing that are unquantifiable - the ideas and how these ideas might facilitate the academy's liveliness (57). A shift like this would mount a resistance against the corporate university's instrumentalizing of knowledge and its quantification. 
I have noticed a similar trend in my two decades of college teaching regarding the increased credentialing students believe they need to amass. Rarely do undergraduate students today graduate with a single major, which is sometimes accompanied by a single minor. Double majoring and double minoring have become common, with some students even taking on three majors or minors. Institutions' enthusiasm over the creation of "micro-credentials," such as badges and certificates, compound the problem. Many students tell me they regularly enroll in course overloads for these reasons. Hence, like faculty chasing their next publication in return for the professional reward another line on their curriculum vitae would confer, students have become conditioned to rack up as many majors, minors, and other designations as possible in order to arm themselves against an uncertain economy. It is not hard to imagine why they, too, are reluctant to slow down, reflect deeply, and pay more than perfunctory attention to the knowledge their courses are meant to offer.

Berg and Seeber borrow their book's title from the slow food movement, which they reference several times throughout The Slow Professor. Slow food cultivates a deliberate appreciation of cuisine and a respectful awareness of the labor required at all steps to bring it to table. It eschews capitalism, abuses of human and nonhuman animal life, artificial or processed ingredients, and unsustainable agricultural practices. This ethos promises a "combination of 'Politics and Pleasure" that contests many aspects of commercial food production, which prioritizes speed and efficiency (11). I need to offer, however, that this valuing of the slow in cuisine assumes an agential consumer whose income allows the patronage of more expensive food industries. It also assumes a daily routine that provides adequate breaks from work and other life responsibilities for the savoring of one's food in a leisurely manner. Similarly, the imperative to slow down in one's research in order to partake in the life of the mind is most feasible for faculty in positions of privilege. Full professors at institutions with low teaching loads will find the prioritizing of academia's anticapitalist pleasures simpler than will faculty working under more restrictive conditions. As an aside, Berg and Seeber mention contingent faculty- the demographic most likely to eat fast food in their car between teaching assignments at multiple schoolsonly once and very briefly.

This prizing of the slow takes on another meaning when disabled faculty are considered. Ellen Samuels, in a meditation on a term she coined, "crip time," sheds light on the contradiction that university 
employment offers for disabled people. Sustaining a nine-to-five job can be prohibitive for some because of the regimentation of the workday. Samuels, herself, returned to school for a $\mathrm{PhD}$ to gamble on a faculty career precisely because she believed academia's greater flexibility would be more amenable to her health conditions. She has found this to be the case, to a certain extent. Although crip time exposes the alternate temporalities many disabled people contend with, Samuels declares that she "loved the rhythm of reading and writing and thinking [in academia] and I realized that this time was also my time, even though it was hard" (n.p.). These sentiments dovetail nicely with Berg and Seeber's proposition to center ideas, not productivity, in university work. However, the long hours, despite their flexibility, impact disabled academics in especially grueling ways. Samuels, who looks younger than her age because of how her impairment affects her connective tissues, expresses discontent about "not being taken seriously, of working my sick self into the ground to climb the tenure ladder while being perceived as a perpetual graduate student." It is exhausting to compensate for academia's presumptions about disabled faculty. Samuels's declaration calls attention to the unevenness of who can and cannot afford to slow down in their pursuit of normative markers of success. Faculty members with embodiments and social identity categories that target them with skepticism about their competence will have less latitude.

\section{Pain, Labor, Identity}

As I write this, my body hurts. Writing is a source of pleasure, but it is also a source of pain. Then again, everything is. I have a good desk chair, an entry-level Herman Miller, which I make more forgiving by lining the hard seat with a thick terrycloth towel. I acquired this necessary luxury, which had cost almost as much as a month's rent for me, early in my career. It helps the situation. Sometimes, though, I happily trade comfort for a change of scenery at a cafe or to babysit a pot on the stove as I work on the kitchen island. I do not notice the pain at times, because it is like water to a fish. I have difficulty remembering what my life was like before it, having developed symptoms when I was fourteen. My diagnosis came much later, at the age of forty-two-an autoimmune disorder. ${ }^{5}$ I was not devastated when I received it. I was vindicated. I finally had proof of its existence, complete with a name to call it. However, like many people in this situation, I am not and have never been sure whether I should call myself disabled. This uncertainty comes not from a compulsion to 
distance myself from disability's historically negative connotations but from the ambiguity and instability in disability identity.

In a keywords essay, Julia Miele Rodas provides a comprehensive overview of how the term "identity" has been used in the field of disability studies. Much of the scholarship on identity argues that it is always relational, a designation that requires a constitutive outside in order to become legible. For disabled people, the disability rights movements of the 196os generated a collective demand for redress of institutionalized inequality. It also became a source of bonding and relationship building in the face of an ableist society. These "activists not only impacted public policy but also shifted and helped to shape a disability community, galvanizing a diverse and diffuse population of disabled people and helping to forge what many have come to understand as disability identity" (Rodas, 103). The notion that disability is not a defect, begging medical correction, but a socially and politically constructed category came from this activist history. However, even within prevailing concepts of identity that cast it as fluid, opinions differ about how best to move forward from this position. As Rodas continues, some scholars in disability studies, such as Lennard J. Davis, regard the assertion of disability identity as retrograde. Others, like Rosemarie Garland-Thomson and Tobin Siebers, caution that claims about the drawbacks of identity politics often mischaracterize its iterations, which are far from homogenous and $d o$ recognize its intersectionality and contingency (Rodas, 103).

The variations in scholarly concepts of identity broaden even more when we consider the nonacademic uses of the term. The late author Ellis Avery was a childhood friend of mine. During a research trip to New York City in 2013, one I kept quiet from friends and family there because of the need to focus on work, I had the premonition I would still run into someone I knew. That person turned out to be Ellis, who I saw exiting the elevator at the Port Authority Bus Terminal while I was waiting to board my return ride to Buffalo. She had just acquired a mobility scooter, and she excitedly offered to let me try it. I, being ambulatory, explained why it was inappropriate for able-bodied people to do so. We argued, and this conversation eventually found its way into her memoir several years later. In a polemical chapter about the politics of visibility and mobility device use, Avery describes an evening at the theater with her spouse before referencing our interaction. "An usher hailed me as 'Wheelchair,' and asked Sharon, 'Are you with Wheelchair?' When I offered a friend a turn on my scooter, she turned me down, joking that she didn't want to appropriate my identity. My name is not Wheelchair. My scooter is 
not my identity" (Avery, 159-6o). The description of the usher's clumsy address of Avery, calling her by her mobility device, segues into a passage that reveals my ineffective attempt to explain why people like me need to refrain from playing with the accoutrements of disabled people as if they were toys. This misunderstanding between Avery and me turned on our differing definitions of "identity." In this context, Avery had been interpreting the term to mean her personhood. I, on the other hand, regarded it as a social location.

Avery and I have diagnoses that are closely related, which points to the futility of allowing scientific medicine's interpellative power to dictate identity. The detached and empirical voice of medical authority may hail us by similar names, which are determined by a blood test, but our lived experiences could not differ more from each other's. If that elevator she needed to take at Port Authority had been broken, we most certainly would have missed our chance meeting. People with mobility impairments remind me that, when taking public transportation, they always confirm ahead of time the elevator's functioning at their departure and arrival stations if they are not at street level. Otherwise, an alternate route must be charted. Conversely, it does not cross my mind to notice if an elevator at a given transit stop is out of service, because I always take the stairs or escalator. This vigilance about how and where to move in normative ableist space is not a regular part of my kinesthetic grammar.

I did temporarily occupy the location of disability a few years ago after complications from foot surgery. Ahead of time, my podiatrist informed me that the routine procedure had a two-week recovery period. Those two weeks stretched into several months, and the research trip and two conferences I lined up beforehand, wrongly assuming that my healing would have been completed by then, turned into opportunities to experience the barriers associated with air travel. Skycaps may take longer than expected to show up with wheelchairs or may not show up at all. Gate changes, which are mere annoyances for the fully ambulatory, risk resulting in missed flights, especially if they are last minute and the new departure area is far away. Having already familiarized myself with Siebers's concept of disability as masquerade-whereby a disabled person must exaggerate their impairment in order to align with nondisabled ideas of what disability looks like-I was prepared for the potential problems of not seeming disabled enough to preboard (Siebers, Disability Theory, 96119). I later realized that this temporary bout with a partial impairment could pave a way for me to think about the chronic illness that, unlike 
recovering from foot surgery, has been lasting. If I do not feel disabled enough to claim that word as my own, it may be because I had been thinking about nomenclatures for identity incorrectly.

A corollary to how I regard my pain in relation to identity may be found in Siebers's depiction of his origins from a working-class family. Siebers never uses the term "working class" in his memoir, Among Men. In several instances, he identifies his family's economic position by appealing to description. Multiple passages mention his father's bluecollar job and a work ethic associated with it. This father "had a thirdgrade education" $\left(5^{2}\right)$ and his own father-Siebers's grandfather-was "a mason and a carpenter" (101). A vignette musing on the state of marriage begins with mention of the author's parents' wedding. Too "poor" for much of a honeymoon, his mother and father drove from their small Wisconsin town to visit Milwaukee and returned the next day where his father returned to "work in the sour air of the mill, fixing the machines that make paper" (59). However, the declaration of being working class never appears. The memoir's narrative present situates the author, an adult taking a backward glance at his childhood, in a very different social location. Here, the omission of the term "working class" is a strategic one. As many people who advocate for racial equality have long experienced, the voicing of working-class identity among white men is frequently mobilized to discredit those justice claims. This happens in the academy as well as in other spaces. (Additionally, the identity claim of being working class in these contexts overlooks intersectionality, because a disproportionate number of people of color are economically disenfranchised. Class has long been tied to race in the United States because of historical circumstances related to race and property ownership.) Siebers's refusal to articulate his early life history through recourse to this identity claim is ethical. He refrains from the utterance of workingclass identity because of how it has often functioned in dismissing critiques of racism.

The pride that Siebers takes in his socioeconomic origins is obvious, but the slipperiness and contingency of working-class identity become salient when we consider that some people move across class strata, as he did. Yet Tobin was still known for his mentoring of students from working-class backgrounds. At his memorial, I spoke with several of his former graduate students across multiple racial categories who told me versions of the same story: they felt out of place at the elite university; their own parents never went to college; they wanted to drop out of the program. (One had actually scheduled a meeting with Tobin not to seek 
counsel but to inform him of her impending departure.) After confiding in Tobin about these concerns and learning he had similar life experiences, they came away with a renewed sense of their entitlement to an advanced degree. They all finished their PhD. Generally, I am not a fan of identity-based mentoring in the way it often gets rallied to justify faculty hiring. First, it lets majoritized faculty off the hook in learning how to teach and advise all students. Second, it ties the value of minoritized faculty to an institution's demographics rather than to the faculty members' intellectual contributions, which may have nothing to do with their identity. However, that Tobin was able to reach students who otherwise did not find the university hospitable indicates that, in the class-privileged realm of the academy, he had knowledge forged from the material conditions of his personal history that these students found credible. Having done this, he inspires me to commit more decisively to something similar, a cultivation of credibility on the basis of shared lived experience in my own mentoring work.

For me right now, the identity "disabled" hinges on whether or not I need workplace accommodations. This is a definition that-I acknowledge-is flawed for multiple reasons. First, it is specific to one context and reifies employment as the linchpin on which this label turns. Second, many employers discourage employees from seeking modifications to their workplace. What does "needing" access mean in a context where, as María Elena Cepeda has pointedly stated, people are coerced into "making due" without? Third, the experience of requesting accommodations is not uniform for all employees. Yoonmee Chang, for instance, argues that because of the model minority myth, which casts Asian American people as hypercapable, disabled Asian Americans can find themselves fighting an uphill battle when attempting to convince institutions they truly require changes to their space, schedules, or other workplace features. (This is not to say that accommodations requests are smoothly handled as a matter of course. Many disabled people, regardless of racial category, will tell you they are not.) However, even as I remain unsure about the legitimacy of my disability identity in the context of work, I am very certain about another aspect of my identity therein-that of a tenured faculty member. From this social location, I have the freedom and obligation to draw attention to disability-related issues that impact others.

"I have a chronic illness," I announce to two colleagues, one the chair of a department my program is collaborating with on a joint hire and the other the chair of the search committee. I make that statement as a way 
of framing what I say next, that we need to be mindful of the candidates' comfort when we draw up the itinerary for campus interviews. These events, which last a minimum of two days and may even take three, are a morning-to-night test of endurance that often only the most able-bodied can perform. Ask any academic job candidate who has ever survived one. For reasons related to disability and many other factors, campus interviews are often not the best determinant of who can reliably carry out the job. ${ }^{6}$ During the meeting with my colleagues, I offer easy fixes for the interviews' protracted nature, so long as academia continues to depart from other professions' more streamlined hiring practices. I stress scheduling enough downtime for the candidate. I suggest holding small-group meetings, where multiple stakeholders can speak with the candidate simultaneously, rather than a series of one-on-ones that, strung together, stretch the day out longer. In order to account for why this is important to me, I use an intentional set of words, per Siebers's portrayal of his economic background. "I have a chronic illness" explains a material state of being rather than declaring an identity, which "I am disabled" (or "I am working class") would do.

Regarding identity categories, Lennard J. Davis's neologism dismodernism was met with criticism for being utopian when it emerged in 2002. It may warrant revisiting in light of the scholarship that has since emerged. Dismodernism, according to Davis, is a recalibration of how we think about disability identity in relation to the granting of accommodations. It does not rely on filtering the not-really-disabled or not-disabledenough from the "legitimately" disabled. Instead, Davis proposes that we accommodate everyone's access needs-in effect, making everyone disabled and worthy of the adjustments they seek. Referencing how the Americans with Disabilities Act has played out, whereby the overwhelming majority of legal cases have been decided in favor of employers and not disabled plaintiffs, Davis offers that this result has stemmed from "a fear of creating a protected class that is too large" (24). Yet that is precisely the point: "the very criticism of the category of disability as being too large, as containing too big a protected class, is actually a fait accompli with the notion of identity in general" (26). Davis's line of thinking advances that a truly revolutionary system would abandon the concept of disability identity because virtually everyone would be disabled. That category would become meaningless because its constitutive outside, the nondisabled, would no longer exist.

Davis's argument, as we return to it almost two decades later, seems much less a provocation or thought experiment and more of a plau- 
sible situation when engaging with disability. Since then, scholars such as Margaret Price have advocated for pedagogy that is radically inclusive, applying the principles of universal design to teaching. Rather than field accommodations as they come and adjust accordingly with each student's institutionally issued mandates, Price argues that educators should think about disability in a systemic way. They should consider the varied and changing terrain where bodies and minds come together with the cultures and environments of learning. They should then make transformations as opportunities arise. Price conceptualizes this processoriented method as finding "ways to move," as opposed to the scripting and steadfast following of guidelines (Mad at School, 88). One of the hallmarks of disability, she argues, is that "it manifests human unpredictability" ("Un/shared Space," 159). There is no knowing definitively in advance what to do. There is only learning as we go and building on that knowledge for future experiences. Similarly, Jay Timothy Dolmage critiques the institutional means through which accommodations are currently established:

Walk into any faculty mailroom in the beginning of a semester, and look for the envelopes from "disability services." It is like a lottery of sorts—not having a letter in the mailbox signals that disability will not be a concern that semester. . . not having an envelope in your mailbox encourages you to not import or carry-forward past strategies you may have developed for accommodating students, and not to develop new ones. (92)

In the scenario Dolmage lays out, the presence or absence of disability among one's enrolled students operates as a binary code. Either disability is there, or it isn't. Either one "deals with" it in a particular classroom and during a particular semester, or one doesn't. This mode of thinking about accommodations fails to impel a holistic rethinking of being and doing that Davis and Price advocate. When identity is determined by a student's registration with a university office that gatekeeps in line with clinical medicine, Dolmage suggests, educators miss the opportunity to broaden access for everyone.

\section{It Depends}

If the ideal Davis laid out years ago, formerly denigrated as utopian, can become conceivable through large-scale, habituated processes of listening to and heeding demands for access, can we, as Davis predicted, ren- 
der disability moot? I remain uncertain about Davis's projection about a future that eliminates disability identity thusly. Despite how much more reasonable dismodernism sounds in light of the scholarship that has come in its wake, it might be more productive to interrogate what exactly is so unfavorable about identity that makes us desire its eradication. As Julie Avril Minich argues: "Identity politics are just as easily mobilized to contest the neoliberal state as to reinforce it. Furthermore, while it is true that identity claims can flatten out the heterogenous experiences and attributes of the members of an identity group, it does not logically follow that this flattening is necessary or inherent to political projects predicated on identity" (161). For Minich, identity is a politically neutral entity. Its ability to resist normative values or its tendency to become coopted by power is contingent on how it is mobilized. In and of itself, it does not naturally incline toward one or the other. It can be deployed in simplistic ways, or it can be more nuanced. It depends.

Returning to my nod to Eva Kittay, "it depends" might be the best response to the questions this chapter raises about the multiple uncertainties it broaches. Like the above reluctance to set rules about access in stone and opting for a perpetual openness to accommodation, the answers to these questions change according to circumstance. Would one trade physical comfort for mental lucidity? Or for a venue that serves coffee? Or for the sake of convenience? Does academic writing solidify power-separating the haves from the have-nots in a disparately resourced profession? Or can writing contest it? Is the writing we do imprinted on the body? Or imprinted by the body? What does it mean to take pleasure in that work? Or just to find it worthwhile? Is cure always opposed to the politics we want to advance? Does pain make me disabled? When does it matter? Do we still need to talk about identity? What do we gain by doing so? What do we lose if we stop? It depends. Following Kittay's debunking of the fantasy of personal independence, I claim that none of the possible answers to these questions can stand autonomously. The interrelated contingencies of meaning on matters of disability require us to consider the context always.

Notes

1. For instance, see Davidson.

2. See Wu, "A Small Act of Resistance."

3. In order to indicate when I am referring to Tobin Siebers, the person, or Tobin Siebers, the author, I switch between first name and last name, respectively.

4. This recognition of the self in writing, which is made in the context of 
memoir, aligns with Siebers's earlier claim in his scholarship that recognizing the human agent behind the act of writing is ethically sound. See The Ethics of Criticism.

5. For a discussion of how autoimmunity might provide disability studies with an analytic to complicate self versus other binaries, see Ferri.

6. For more on disability and the academic job search, see Price, Mad at School.

\section{Works Cited}

Ahmed, Sara. On Being Included: Racism and Diversity in Institutional Life. Durham, NC: Duke University Press, 2012.

Avery, Ellis. The Family Tooth: On Meeting and Cheating Death. New York: McNally Jackson, 2015.

Berg, Maggie, and Barbara K. Seeber. The Slow Professor: Challenging the Culture of Speed in the Academy. Toronto: University of Toronto Press, 2016.

Cepeda, María Elena. "Twice Unseen: Navigating Invisible Disability within the Neoliberal Academy." Conference presentation, American Studies Association, 10 November 2018, Atlanta, GA.

Chang, Yoonmee. "Asian Americans, Disability, and the Model Minority Myth." In Flashpoints for Asian American Studies, edited by Cathy Schlund-Vials, 24153. New York: Fordham University Press, 2017.

Davidson, Cathy. "Handicapped by Being Underimpaired: Teaching with Equality at the Core." HASTAC, 7 July 2015, hastac.org/blogs/cathy-davidson/2015 /07/07/handicapped-being-underimpaired-teaching-equality-core

Davis, Lennard J. Bending Over Backwards: Disability, Dismodernism, and Other Difficult Positions. New York: New York University Press, 2002.

Dolmage, Jay Timothy. Academic Ableism: Disability and Higher Education. Ann Arbor: University of Michigan Press, 2017.

Ferguson, Roderick A. The Reorder of Things: The University and Its Pedagogies of Minority Difference. Minneapolis: University of Minnesota Press, 2012.

Ferri, Beth. "Metaphors of Contagion and the Autoimmune Body." Feminist Formations 30, no. 1 (Spring 2018): 1-20.

Kerschbaum, Stephanie. Toward a New Rhetoric of Difference. Champaign, IL: National Council of Teachers of English, 2014.

Kim, Eunjung. Curative Violence: Rehabilitating Disability, Gender, and Sexuality in Modern Korea. Durham, NC: Duke University Press, 2017.

Kittay, Eva Feder. "The Ethics of Care, Dependency, and Disability." Ratio Juris 24, no. 1 (March 2011): 49-58.

Minich, Julie Avril. Accessible Citizenships: Disability, Nation, and the Cultural Politics of Greater Mexico. Philadelphia: Temple University Press, 2013.

Patsavas, Alyson. "Recovering a Cripistemology of Pain: Leaky Bodies, Connective Tissue, and Feeling Discourse." Journal of Literary and Cultural Disability Studies 8, no. 2 (2014): 203-18.

Price, Margaret. Mad at School: Rhetorics of Mental Disability and Academic Life. Ann Arbor: University of Michigan Press, 2011. 
Price, Margaret. "Un/shared Space: The Dilemma of Inclusive Architecture" In Disability, Space, Architecture: A Reader, edited by Jos Boys, 149-67. Routledge, 2016.

Rodas, Julia Miele. "Identity.” In Keywords for Disability Studies, edited by Rachel Adams, Benjamin Reiss, and Davis Serlin, 103-5. New York: New York University Press, 2015.

Samuels, Ellen. "Six Ways of Looking at Crip Time.” Disability Studies Quarterly 37, no. 3 (Summer 2017).

Scarry, Elaine. The Body in Pain: The Making and Unmaking of the World. Oxford: Oxford University Press, 1987.

Siebers, Tobin. Among Men. Lincoln: University of Nebraska Press, 1998.

Siebers, Tobin. Disability Theory. Ann Arbor: University of Michigan Press, 2008.

Siebers, Tobin. The Ethics of Criticism. Ithaca, NY: Cornell University Press, 1988.

Wu, Cynthia. "The Emotional Cost of Diversity Work in the Academy." Asian American Literary Review 7, no. 2 (Fall/Winter 2016): 40-42.

Wu, C. "A Small Act of Resistance." Avidly: A Los Angeles Review of Books Channel, 19 March 2013. http://avidly.lareviewofbooks.org/2013/03/19/a-small-act -of-resistance/ 


\title{
THREE | Cracks Filled with Images: Mental Disability, Trauma, and Crip Rhetoric in Cereus Blooms at Night
}

\author{
JENNIFER MARCHISOTTO
}

In Disability Aesthetics Tobin Siebers calls for an increased consideration of trauma in relation to disability, claiming it will enhance aesthetic representations of disability through an incorporation of "wounds," and better situate disability within evolving global digital communities (102-3). Ultimately, Siebers declares the most important thing trauma studies can contribute to disability studies is the ability to "enlarge the concept of mental disability to include the psychic impairments, psychological injuries, and mental traumas provoked by modern life" (103). Using these claims as a starting point, this chapter focuses on the way trauma necessarily relies on mediation and the manipulation of temporality, or crip time. By extending crip time's emphasis on flexibility to language, I develop a theory of crip rhetoric, in which language and narrative are fundamentally reshaped to accommodate histories of trauma and mental disability.

Siebers is primarily interested in how present or future representations of disability incorporate, either directly or indirectly, histories of trauma. In terms of temporality, he focuses on how traumatic pasts infect present and future aesthetic representations. Synthesizing Siebers's work with recent developments in disability, trauma, and mad studies, I argue trauma surfaces in the present and makes disabled individuals vulnerable to normative expectations of language and temporality. I focus on Cereus Blooms at Night by Shani Mootoo to analyze how narratives are necessarily rearranged to accommodate histories of trauma that encour- 
age more nuanced understandings of present disabled experience, and mentally disabled experience in particular. Through nonlinear narrative structure, and a reliance on the affective, or felt but inarticulate, transmission of knowledge, Mootoo's novel challenges the assumed authority of articulate language as the most precise, and therefore superior, form of communication. Through flexible rhetorical structures that rely on affect rather than words as such, Mootoo shows how incorporating the "wounds" identified by Siebers calls for a rethinking of what qualifies as language. Cereus Blooms at Night forces the past, present, and future together, exposing new ways in which aesthetic representations can incorporate past histories of trauma as essential to present disabled experience, bending time and determining one's ability to narrate that event in the future.

\section{Complex Narrative Embodiment in Cereus Blooms at Night}

Cereus Blooms at Night relies on mediated knowledge as both plot device and epistemological premise, reinventing the trope of a mad Caribbean woman through affective narrative structures. ${ }^{1}$ I define affective narrative structures in terms of animacy. Mel Chen claims "animacy most generally refers to the grammatical effects of the sentience or liveness of nouns" (2). Chen argues that words, and objects, carry meaning through affect, which "potentially engages many bodies at once, rather than (only) being contained as an emotion within a single body" (11). These affective connections help build the narrative in Cereus Blooms at Night. Affect sticks to material bodies (e.g., humans, animals, plants, objects), creating networks of association that are carried across time. For example, throughout the novel Mala collects snail shells. Gradually it is revealed that as a young girl her mother's lover Lavinia taught her to do so, claiming that if Mala protected a snail while it lived, and preserved its home for its spirit, the snail will protect her and those she loves in return (Mootoo, 54). Mala later shares this with Ambrose, the childhood friend and lover she later reconnects with at the alms house. The two bond while collecting and saving snails from other boys looking to torture the snails (92). In what follows Mala and Ambrose have their first sexual encounter. Protecting snails is repeated as a shared and loving experience. When in the alms house, Tyler, Mala's queer male nurse and the novel's main narrator, notes her muttering words that come to refer to memories of her time with Ambrose: "One day, for example, she would go on and on about some gramophone or other, the next day about 
spiders, then about peekoplats or snails" (102). Out of context, in the present moment, the words lack the meaning attached to them through memory. However, as Tyler (and the reader) piece together Mala's history they find that the shells signify not only the thing itself, but Mala's emotional history with them. The snail shells carry with them feelings of love and protection as well as loss, both Lavinia and Ambrose having left Mala in moments of need. ${ }^{2}$ Histories of trauma and mental disability become recognizable as they are told through the simultaneous integration of past and present, maintained through networks of affective association. Interpreting the inarticulate information that sustains these reveals a history saturated in both individual and cultural trauma. ${ }^{3}$

Tyler openly manipulates Mala's history in order to (hopefully) make it recognizable to a future audience-her sister Asha or someone who knows her, embracing his role as intermediary. In foregrounding this mediation and manipulation of temporality Mootoo calls attention to the ways trauma and mental disability call for what Margaret Price and others have termed crip time, which relies on flexibility. ${ }^{4}$ This flexibility has been applied to various timetables, for example, showing up to a meeting, attending class, and the expected time needed to complete a task, among others. Alison Kafer articulates the relationship between time and disabled bodyminds, claiming, "We can then understand the flexibility of crip time as being not only an accommodation to those who need 'more' time but also, and perhaps especially, a challenge to normative and normalizing expectations of pace and scheduling. Rather than bend disabled bodies and minds to meet the clock, crip time bends the clock to meet disabled bodies and minds" (FQC, 27). In the context of trauma, crip time bends the clock as memories of the past event(s) uncontrollably and often unexpectedly surface, forcibly interrupting the normative progression of time. ${ }^{5}$

Mala's present experience of mental disability, because of her history of trauma, can only be understood through the manipulation of time, connecting smaller moments in the present to more significant histories. Framing crip time as "time travel," Ellen Samuels explains, "Disability and illness have the power to extract us from linear, progressive time with its normative life stages and cast us into a wormhole of backward and forward acceleration, jerky stops and starts, tedious intervals and abrupt endings." We see this acceleration throughout Cereus Blooms at Night, as memories of the past continually give meaning to present moments, the text shifting between temporalities based on the association of meaning rather than any linear progression of time. For example, when Tyler hears the elderly Mala singing a song, the narrative then shifts to an event 
from her childhood when Mala plays a game set to the same song with other children but is then abandoned by Boyie and tormented by her peers who had tied up her sister (71-89). The incident shows the community's disdain for Mala while emphasizing her bond with Asha, both points helping to explain not just the origin of the song sung in the present, but Mala's relationship to Tyler, who has similarly been tormented and looked down upon for his sexuality. Mala's past exists alongside her present, her adult life only understood in relation to her childhood.

Readers first meet the protagonist, Mala Ramchandin, when she is sent to an alms house, unspeaking and presumably mad in her old age. Through flashbacks and memories we learn of her childhood and the violent and long-term abuse suffered at the hands of her father. After killing her father following a particularly violent attack of his, Mala withdraws from language and spends decades in isolation before she is taken to the alms house. Overall the novel is framed as a letter written by Tyler. Because Mala no longer uses words, Tyler must infer meaning based on his personal affective connection to Mala and the memories of those who knew her prior to her arrival. Tyler acknowledges his own influence on the narrative's fidelity from the outset but puts the story down on paper and sends it into the world in the hopes that Asha, Mala's younger sister who had escaped her father's abuse as a young girl, will recognize it. Tyler recounts Mala's history in a nonlinear structure, inferring meaning from her limited speech and translating the memories of people from her past. By foregrounding Tyler's fallibility as authority at the center of the novel, Mootoo positions readers as further interpreters of Mala's history, who must rely on linguistic animacy and affect rather than words themselves as sources of knowledge. The voices that make up the narrative intersect and overlap at different points throughout the novel, alongside the reader's experience as interlocutor, together allowing the narrative to be told.

While all fictional representations involve mediation, in cases where the narrative concerns complex embodiment and situations of extreme precarity straightforward narration is inadequate. As Gayatri Gopinath notes, "Mootoo's novel suggests the impossibility of viewing one particular trajectory to the exclusion of others" (185). Mala's history can only ever be heard and interpreted in relation to others-the other histories within the novel itself as well as other histories of mentally disabled Caribbean women. Siebers claims complex embodiment "theorizes the body and its representations as mutually transformative. Social representations obviously affect the experience of the body . . . but the body possesses the ability to determine its social representation as well, and some situations 
exist where representation exerts no control over the life of the body" $\left(D T, 25^{-26}\right)$. This framework illuminates how Mala's intersectional identities (as the female, mentally disabled, daughter of an Indian immigrant to Lantanacamara) shape Tyler's narrative by determining their own affective and temporal representations.

Liam Kruger defines similar circumstances of intersecting oppressive forces as situations of extreme precarity: "multiple exclusions from the political or social sphere on such bases as race, nationality, class, and/ or gender expression, among others" (133). Both Siebers and Kruger note the ways issues of social and political marginalization affect representation, but Kruger more specifically emphasizes the way the complexity of these intersections renders the individual increasingly vulnerable to dominant ideologies, which is essential for appreciating the different violences enacted on Mala. Mala was routinely sexually abused by her father at home. In the community more broadly she was discriminated against because of her race (the daughter of an Indian immigrant) and because of the rumors circulating about her family (rumors of her father's abuse as well as the scandal of her mother running away with another woman). Siebers explains that in relation to theories of intersectional identity, complex embodiment may help navigate different "hierarchies of oppression" when "coming to an understanding of intersecting minority identities demands that one imagine social location not only as perspective but also complex embodiment" (DT, 29). Understanding intersectional identities, in Mala's case but also more broadly, requires attention to the individual's perspective as it exists in a physical, social environment. Complex embodiment and extreme precarity account for experiences in their variability as individuals navigate social ideologies and representations, contributing in varying ways to the violent oppression of different points of one's intersectional identity. Mala's intersectional identity and her traumatic past "determine [their] social representation" through flashbacks paired with present moments and by refusing to articulately re-present the details of her abuse. While this resistance to certainty encourages more nuanced understandings of her experience as a mentally disabled woman, it also lays bare the ways in which Mala's identities make her vulnerable to social disqualification.

\section{Illegible Intersections}

Mootoo's novel relies on illegibility and affectively communicated knowledge as a point of entry rather than a point of dismissal. Siebers claims, 
"Trauma art poses a radical challenge to conventional models of aesthetic explanation. It is at once impersonal and painful-which means it both communicates between cultures and retains an affective power" ( $D A$, 103). Trauma, because of its extreme unknowability, threatens normative conceptions of both self and community. Therefore, trauma art and literature, like trauma itself, cannot be easily assimilated into conventional modes of representation. Despite this challenge, it "retains an affective power," communicating meaning through inarticulate forms of language.

Mootoo's affective narrative structure allows readers to see these valences of identification in the context of Mala, differentiating her from other characters from literature whose madness has long been reduced to metaphor in line with David Mitchell and Sharon Snyder's definition of narrative prosthesis. ${ }^{6}$ Focusing on one of Mala's closest literary predecessors, Bertha Mason from Jane Eyre, Julia Miele Rodas, Elizabeth Donaldson, and David Bolt cite readings by Gayatri Spivak and Sandra Gilbert and Susan Gubar to point out, "The 'madness' of Bertha . . . has most frequently been seen as standing in for some other veiled or unspeakable condition" (3). Rodas, Donaldson, and Bolt explain that "even fictional interpretations of [Jane Eyre], like Jean Rhys's groundbreaking Wide Sargasso Sea, seem to see Bertha's disability as representing something else; in this instance, her 'madness' is reconstructed as the strangulating mask of sexist and imperialist power imposed by an insecure and jealous husband, rather than as an intrinsic quality of Bertha's embodied experience" (3). Both critical and creative readings of Bertha's mental disability understand her disability, in Mitchell and Snyder's terms, as an "opportunistic metaphorical device" (47). Mootoo differentiates Mala by pushing her complex embodiment to the center of the narrative, refusing to let her be assimilated into any easy metaphoric comparison. Mootoo offers a collective retelling of Mala's history that foregrounds the unknowability of specific detail as a starting point through which to imagine new forms of communication that would bear witness not just to Mala's story, but to mad Caribbean women as they are constructed in fiction and in imperialistic figuring of an other. The particularities of Mala's experience, her female, mad, and racial identities that overlap and contribute to her complex embodiment, are exceptionally unique. Where Wide Sargasso Sea attempts to renarrate Bertha's history, claiming it as an identifiable narrative, Cereus Blooms at Night does not offer a contained or clear history. Rather, Mala's past continually evolves, flexible because of Mootoo's withholding of verified specific details.

Mootoo embraces the illegibility often associated with trauma and 
mental disability as a starting point through which to reshape readers' understandings of what it means to inhabit more complex identities. Although this illegibility has often led to reductive readings or dismissal of either trauma or mental disability, Mootoo shows how it can be a space of exchange through which to develop new modes of communication. Catherine Prendergast reflects on the illegibility of mental disability, saying, "I've noticed that if I mention mental illness in the company of many [rhetoric, English literature, and cultural studies] colleagues, I become suddenly culturally unintelligible" (46). Here mental disability constitutes an erasure, the subject itself inciting incomprehension. However, incomprehension, when framed differently, becomes a point of access. Prendergast goes on to argue that "to be disabled mentally is to be disabled rhetorically" (57). Through diagnosis, as well as cultural histories of marginalization, the mentally disabled individual is denied a voice. Prendergast puts it frankly: "If people think you're crazy, they don't listen to you" (57). Prendergast ultimately poses two questions: "Does some kind of al/chemical transformation need to occur before the mentally ill can be heard? And in whom does it need to take place?" (57). She does not have an answer for these questions, and concludes on a note of uncertain possibility, wondering "how a rhetoric that renders mental illness irrelevant can contribute to healing" and "if there will ever be a rhetoric of mental disability that the mentally disabled themselves will have the greatest part in crafting" (58-59).

Rather than force mentally disabled histories to conform to traditionally accepted rhetorical forms, we must shift our understanding of what counts as rhetoric, of what is recognized as language, and therefore effective communication. Doing so pushes us toward what I have referred to as crip rhetoric, which allows for the absolute subjectivity of individual experience and permits meaning to shift according to the affective valences that connect that individual to surrounding bodyminds and communities. ${ }^{7}$ Crip rhetoric results from experiences that resist or even refuse articulate representation. Using Siebers's terms of complex embodiment, these experiences bend rhetoric to accommodate their own representation. In Mala's case, this refers to the way her narrative can only be shared in a particular moment as Tyler moves between past and present to tell her story. It also extends to the novel's reliance on affective forms of communication that remain inarticulate and therefore a-rhetorical. In the tradition of the social model, it is not the individual's responsibility to change, but rather the framework through which we read that individual's experience. Affect theory and trauma studies, both 
of which deal with intangible forms of information and communication, provide a way of working through Mala's complex embodiment. Mootoo places the inarticulable wound of Mala's long-term abuse, and the consequent absence of definitive explanation, at the center of the narrative, representing Mala through the affective relationships she forms with humans, plants, animals, and objects amid and following her experience of trauma.

\section{Trauma and Disability}

Trauma and disability studies have long been at odds due to their divergent temporal orientations, and trauma studies' treatment of individual agency in relation to trauma. However, theorists have increasingly called for alliances between the two fields. Much of the tension between the fields is rooted in their rhetorical framing. Disability studies is often described in terms of gain and futurity-the possibilities of access, crip epistemology, independent living both now and the future. Trauma studies is primarily concerned with loss-of a loved one, an ideal, or a pop-

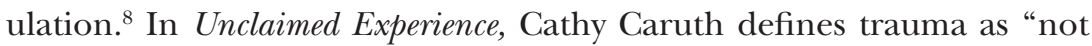
locatable in the simple violent or original event in an individual's past, but rather in the way that its very unassimilated nature-the way it was precisely not known in the first instance-returns to haunt the survivor later on" (4). This phrasing, denying power or agency to the individual in favor of the unknowable event, emphasizes the inability of the individual to claim or maintain agency as a part of his or her own experience.

Trauma studies' focus on loss conflicts with disability studies' focus on futurity and independence. As noted at the start of this chapter, Siebers argues that exploring this connection further would improve disability studies' scope, particularly with regard to artistic engagement with experience. Siebers claims merging disability and trauma studies "will allow us to conceive of wounds as disability representations on a par with those typically considered in disability studies," enhance our understandings of disabled bodies in contemporary global contexts, and improve our considerations of mental disabilities as part of the disabled experience (DA, 102-3). To Siebers, including a more central discussion of loss as part of disability studies can expand understandings of experience in relation to disabilities, and in particular improve conversations about the mental effects of disability. Siebers focuses on how wounds produce mental and physical experiences, disability in particular. Rather than focus on trauma as a loss located in the past, he focuses on trauma as 
it affects the present and future-or, in other words, how it perpetually determines its own representation through crip rhetoric and other aesthetic forms.

To understand how trauma continues to affect the present, we must reconceptualize how meaning is communicated along nontraditional valences that indirectly influence aesthetic representations. Caruth claims "history, like trauma, is never simply one's own ... history is precisely the way we are implicated in each other's traumas" (UE, 24). The effects of trauma cannot be contained within an individual body; its effects extend beyond that individual to wider sociopolitical contexts. Although we can recognize these effects, Caruth's point that the traumatic event "was precisely not known in the first instance" makes understanding those effects an act of interpretation and approximation. By embracing this impossible certainty as essential to the nature of mental disability, and consequently narratives of mental disability, we can develop new forms of rhetorical analysis that consider inarticulate and articulate meaning alongside one another.

In her more recent work, Caruth describes "a new kind of listening" that would bear witness to traumatic experience while knowing that understandings of the event will always be uncertain. Caruth develops this concept through an analysis of Death and the Maiden, a play by Argentinian/Chilean writer Ariel Dorfman. Death and the Maiden is the story of Paulina, who, several years earlier, was tortured by the police during the Dirty War. Death and the Maiden is set in a country, "probably Chile," and tells the story of Paulina, who several years earlier was tortured by the police during a period of violence similar to General Augusto Pinochet's dictatorship in Chile (Dorfman). The action of the play surrounds a chance meeting Paulina and her husband have with a man named Roberto. Upon hearing Roberto's voice, Paulina immediately identifies him as her former torturer, despite never having seen his face. The validity of Paulina's identification is never confirmed. Throughout the play Paulina and her husband stage a trial for Roberto, forcing him to testify to his crimes against Paulina. The play itself, and the staging of Roberto's testimony within the play, constitute performances of possible identification which Caruth argues constitutes "a new kind of listening" (Literature, 55). This "new kind of listening" is only made possible by the identification of Roberto through the recurrence of his voice, which occurs as part of an open system of identification that relies on affective, or felt, knowledge, as opposed to direct evidence. Mootoo similarly encourages this "new kind of listen- 
ing" through foregrounding affect and pairing disparate temporalities. Tyler's admitted fallibility and the indirect narrative style echoes the uncertainty of Paulina's identification. ${ }^{9}$

Understanding the event of trauma while still presenting the original event as in some ways unattainable provides a starting point for moving forward despite uncertainty. By identifying him as her torturer, Paulina places herself in relation to her previously unclaimed experiences. Despite being vulnerable to error and contingent upon the coincidental events that brought Roberto to her door, Paulina's identification allows her to relisten to her past. Whether or not Roberto is truly her torturer, Paulina's encounter with him offers a new form of listening, not to what is definitively true, but to what is identified and performed as such. Ultimately, Caruth argues, the play brings up more questions than answers about Paulina's experience (Literature, 72). Those questions are oriented toward a futurity and the possibility of "a new kind of listening." Caruth claims, "For these stories of trauma cannot be limited to the catastrophes they name, and the theory of catastrophic history may ultimately be written in a language that already lingers, in these texts, after the end, in a time that comes to us from the other shore, from the other side of the disaster" (92). The language of disaster, of the traumatic event, exists in the present and in the future, in terms yet to be discovered. The traumatic event is no longer an event of the past never to be understood, but an event that can be rearticulated in the future, albeit neither straightforwardly nor predictably.

In the context of disability, mental disability in particular, this lack of certainty and predictability encourages more nuanced approaches to absolute subjectivity where the individual's experience actively resists representation. Drawing on her own experiences of unexpected triggers, Alison Kafer uses contemporary debates around trigger warnings as a starting point to theorize strategies for new alliances between disability and trauma studies, similarly emphasizing the need for further consideration of the complex relationship between trauma and disability. Kafer points out that despite efforts to the contrary, we "cannot cleanly separate being disabled from becoming disabled" and that "attending to violence and trauma does not run counter to but is actually an essential part of critical theories of disability. Or, to put it differently, an acknowledgement of loss or a deep reckoning with the aftermath of trauma can co-exist with critical anti-ableist politics" (6). Kafer identifies the deeply embedded complexities of recognizing trauma within disability studies. The separation of being and becoming that Kafer points to is, in the inter- 
est of antiableist representations of disability, a response to histories of representation that defined disability (physical or mental) as something to be feared or pitied, or both. As Kafer notes, by not acknowledging the event of becoming disabled, or persistent pain that might result from a disability, we censure part of the narrative surrounding disability. Moreover, using herself as an example, Kafer points out that triggers are often impossible to predict. Disabled spaces need to allow room for unexpected and uncontrollable triggers that surface in unforeseen ways. ${ }^{10}$

To read the language of disaster, the relationship between being and becoming disabled, one must consider the various registers of aesthetic representation that contribute to the moment which, as Siebers claims, "retains an affective power," which is communicated through the experience of reading written and visual texts, among others. Siebers reflects on the nature of reading itself and what occurs through the process of engaging with different types of texts:

When no language is manifest [in visual artworks such as a painting], readers are obliged to invent one; otherwise, the translation between the "language" of reading and the "language" of the object does not take place, and the object remains unreadable. Perhaps the impulse to read an image is a measure of the desire to control it. Images too complex to be read refuse this control, and they challenge the authority of reading as a privileged activity because they demonstrate a surplus of meaning untranslatable into linguistic terms. $(D A, 122)$

The complexity that prevents some images from being read is not unique to any particular form of aesthetic expression. In the context of trauma, the event itself is marked by its untranslatability. Through the "surplus of meaning," readers can engage with new possibilities, ideas previously beyond normative conceptions of what is possible. This surplus exists within the text itself as well as in the space between reader and text. In Cereus Blooms at Night, there is a surplus of untranslatable meaning in Mala's history that shapes the narrative's overall structure while triggering Mala to withdraw from articulate language for decades. The surplus of affect acts as a structural premise, interfering with the ability of the individual characters to communicate with one another and distances readers from definitive detail. Siebers goes on to claim, "Often, the excess of meaning is perceived as emotion, but there is no reason to deprecate it as unintellectual," calling attention to conventional assumptions that emotion is lesser than reason $(D A, 122)$. However, through 
this emotional excess new meaning, and new strategies for producing meaning, can develop. Siebers echoes Caruth's call for a new kind of listening that attends to the unexpected and unpredictable ways two points affect one another. These associations are unidentifiable in the moment because their association relies on the space of excess meaning that has refused to be assimilated into linguistic terms.

\section{Cripping Rhetoric in Cereus Blooms at Night}

The novel's overall structure echoes Mala's withdrawal from language, and models the flexibility of crip time, whereby objects like the snail shells appear at different points in time, enhancing the narrative through their attached affective histories. In addition to the snail shells, we see this in the reappearance of cereus clippings throughout the novel. Like the shells, the plant is tied to memories of love and loss for Mala-in the moment just before when she and Asha would have escaped with their mother and Lavinia, Mala runs back into the house to retrieve her bag containing a cereus clipping, Asha follows, and they are both left behind with Chandin. The plant reappears throughout the novel, adding to the web of affective associations within the narrative while physically embodying a nonnormative experience of time-cereus plants rarely bloom, and when they do, they bloom at night while other flowers bloom by day. When Ambrose and Otoh first try to visit Mala, the day after she enters the alms house, they bring her a cereus clipping (21-22). Gardening soon becomes one of the first points of connection between Mala and Tyler. The plant reappears in the present moment and facilitates her connection to Tyler after spending decades in isolation. Mootoo shows how relationships to animate and inanimate objects together narrate histories that otherwise could not be spoken. Readers must develop a "new kind of listening" that attends to the web of affective associations imbued in the objects over time.

Mala's withdrawal from language in the decades following her father's death challenges expectations of speech, showing her developing new strategies of meaningful communication that prioritize feeling and affect over words themselves. Mootoo describes Mala's withdrawal from language as both freeing and confining. Lacking the ability to explain her traumatic experiences using articulate language, Mala embraces animalistic noises that more accurately represent her feelings. Through her rejection of language, Mala also rejects gendered conventions of home, creating a new space for herself that counters expectations of civil domes- 
tic spaces. Gopinath argues that Mootoo employs a queer framework to counter colonially imposed "masculinist and heterosexual" standards of domesticity (169). Mala's withdrawal from language is a profoundly personal response to trauma that occurs within an antidomestic space and challenges the broader cultural traumas of colonization. The surplus of affect noted by Siebers supersedes articulate language. In abandoning articulate civilized language, Mala loses contact with the world outside of her own yard. Her withdrawal hovers somewhere between intentional and unintentional, as if she, the words, and the images all possess some form of agency. The tone of the scene describing the undoing of language is emancipatory:

In the phase just before Mala stopped using words, lexically shaped thoughts would sprawl across her mind, fractured here and there. The cracks would be filled with images. Soon the inverse happened. A sentence would be constructed primarily of images punctuated by only one or two verbalizations: a noun tentatively uttered in recognition, a descriptive word confirming a feeling or observation. (126)

While the process by which visual images overtake structured language is introduced as one of agency ("Mala stopped"), in the end those images have taken control. The subject becomes the words and sentences. The narrative voice becomes more passive as the grammatical subjects construct themselves. Being freed from language precipitates further isolation from the world around her. In what follows, Mala moves more and more toward base, bodily experiences, finding language more and more unnecessary. As Mala increasingly conceptualizes her feelings and environment through images rather than words, the surplus of meaning identified by Siebers overwhelms articulate expression. Using Siebers's terms, Mala's traumatic history leads her to embrace the complexities of her past that "refuse the control" of articulate language, "challeng[ing] the authority of reading, [and traditional speech,] as a privileged activity" $(D A, 122)$.

Mala's withdrawal from language emphasizes the physical effects of trauma, describing the shift in language as an embodied experience. Mala's inability to assimilate her experience using traditional language structures aligns with Caruth's definition of trauma as traumatic precisely because it is indescribable. The wound of trauma does not lie just in the event itself but in the inability to assimilate that into everyday life. Readers are never given full access to Mala's experience. Her response to 
trauma is never described in detail, the novel itself echoing Mala's inability to integrate the events and their emotional effects as part of a continuous narrative. We see the effects of her feelings, but not the feelings themselves. The novel's description of Mala's withdrawal emphasizes language's inability to truly represent experience: "verbalization, she came to understand, was not the feeling itself but a name given to the feeling: pretty, an unnecessary translation of the delight she experienced seeing the soaring birds. Eventually Mala all but rid herself of words" (126). Mala sees language's deficiencies, with regards to both trauma and more positive experiences like that of seeing birds.

In releasing her ties to words and the rest of civilized society, Mala turns to more sensorial and bodily forms of expression. Although PTSD, and mental disabilities more broadly, have been figured as psychological experiences, they also have physical, material effects, involving Mala's body as a whole: "Many of her sounds were natural expansions and contractions of her body. She grunted when lifting something heavy. She dredged and expelled phlegm. She sighed melodiously. Cried and belched unabashedly. She coughed and sneezed and spat and wiped away mucus with no care for social graces. . . . She farted at will, for there was no one around to contradict her" (127). Mala's rejection of language and the mind-body hierarchy denounces "social graces," moving to more animalistic or uncivilized behaviors. ${ }^{11}$ Her bodily instincts overwhelm polite, rational behavior, highlighting the physical effects of trauma. This is physically freeing for Mala, releasing her from restrictive standards of polite behavior, but simultaneously moves her further into the realm of irrationality, becoming physical evidence of her perceived mental incapacity.

\section{Conclusion}

When Tobin Siebers "insist[ed] that disability studies include trauma within its definition of disability," he emphasized the significance of not just present experiences of disability, but of past experiences as well ( $D A$, 102). To understand Mala's current experience of mental disability, one must also understand her history of trauma. To continue developing the relationships between disability, trauma, and mad studies we must better attend to the ways crip time manifests, and extend crip time's emphasis on flexibility to rhetoric. Similar to Kafer's claim that "crip time bends the clock to meet disabled bodies and minds," crip rhetoric bends articulate expression to meet disabled bodies and minds $(F Q C, 27)$. Cereus 
Blooms at Night shows the flexibility of both time and language as necessary for making Mala's history communicable in a recognizable way. While mediation is inherent to all communication, Mootoo foregrounds it and shows it as not just inherent in, but foundational to, narratives of mental disability.

Within the novel, communication relies not only on the language of telling, but of the animacy communicated in the moment of telling. The novel orients the reader toward Mala's history by exposing her affective connection to the nonhuman objects surrounding her as sites of experience that carry with them histories of love, pain, and trauma. Mala's experiences are not merely located in the past but are physically kept close through her proximity to these objects. Looking back from the present moment Tyler claims the narrative is made possible through two positions: "one, a shared queerness with Miss Ramchandin, which gave rise to the other, my proximity to the very Ramchandin Nana herself had known of" (48; my emphasis). Tyler recognizes a shared experience of difference or queerness in Mala. Although this shared feeling indirectly allows them to communicate, Tyler's literal proximity to Mala is also necessary. The affective understanding is not self-sustaining; it requires physical presence to support it. In discussing the levels of communication that exist beyond the words themselves Mel Chen identifies that “the 'processing' of language . . . amounts to bringing a listener's unique conceptualization to bear, via 'blending,' on structures or parts of structures alerted by specific linguistic features" (52). Tyler's understanding of Mala's language is composited through her few words and animal-like sounds, as well as his physical proximity to "linguistic features," her mannerisms, facial expressions, and other affective signifiers of meaning. In creating an articulate narrative, Tyler joins the intangible and tangible, a process that will never represent Mala's history according to traditional definitions of fidelity, but which makes it recognizable to others, hopefully Asha, who shared parts of that history and can see themselves in it despite Tyler's influence on its presentation.

Cereus Blooms at Night illustrates the flexibility inherent in crip time and what I have identified as crip rhetoric through its emphasis on inarticulate and affective modes of communication. For Mala, the horror of her abuse falls outside articulate language. Readers access it indirectly, through mediated memories. ${ }^{12}$ In her reading of Alain Resnais's film Hiroshima mon amour, Caruth argues that "seeing" and "listening from the site of trauma" is created through the spectator as mediator $\left(U E, 5^{6}\right)$. The gap left in our comprehension is the point at which witnessing begins: "What we see and hear . . . resonates beyond what we can know and 
understand; but it is in the event of this incomprehension and in our departure from sense and understanding that our own witnessing may indeed begin to take place" $\left(5^{6}\right)$. Cereus Blooms at Night departs from sense and understanding in that it asks readers to accept the potential losses or misrepresentations of mediated information as central to the narrative's ability to be told. It is not told in spite of the risk of mediation, but because of it. While incomprehension lies at the center of traumatic histories, the surrounding impressions and possibilities are still productive. Caruth directly argues that history can be found in the incomprehensible remnants of trauma: "For these stories of trauma cannot be limited to the catastrophes they name, and the theory of catastrophic history may ultimately be written in a language that already lingers, in these texts, after the end, in a time that comes to us from the other shore, from the other side of the disaster" (Literature, 92). Tyler compiles Mala's narrative in a future encounter on "the other side of the disaster." He takes the lingering language of Mala's history and turns it into something new. The "shared queerness" Tyler feels with Mala creates an affective understanding that, while potentially flawed in its ability to represent history, lets him stick the different bits of story together. And, as

the story is offered to the reader, and simultaneously sent into the world in the hopes that Asha will read it and return to her sister, Mala waits, keeping her story with her, "on visiting days [wearing] a garland of snail shells about her neck or a crown of wreaths that we wove with feathers and the wings of expired insects" (247).

Notes

1. I read the protagonist of Cereus Blooms at Night, Mala Ramchandin, as the literary descendent of Bertha Mason from Jane Eyre and Wide Sargasso Sea. Jane Eyre, Wide Sargasso Sea, and Cereus Blooms at Night were published in 1847, 1966, and 1996, respectively. In Jane Eyre, Bertha Mason is the mad wife of the protagonist's love interest, Edward Rochester, who has been locked in the attic and kept secret. She is depicted as bestial, an obstacle to the protagonists' happiness. Jean Rhys's novel is a direct adaptation of Bertha Mason and tells the life story of Antoinette Causeway (as Bertha is called in Wide Sargasso Sea) in Jamaica and Domenica leading up to the events of Jane Eyre. Bertha and Mala are both controlled by the violence of men, and both ultimately set fire to their homes. However, where Bertha perishes in the fire, Mala survives. Rhys offers Bertha a past, but Shani Mootoo allows Mala a future.

2. See Ahmed, "Happy Objects," for more on how objects accumulate affect over time to become sites of experience that can help individuals orient themselves toward the surrounding world.

3. In “Teaching with Trauma," Angela M. Carter “conceptualize[s] trauma as 
a disabling active structure" and eloquently argues that "approaching trauma as an affective structure that may, or may not, be recognizable as a kind of neurodivergence" can "broaden our understanding of disability." Carter's structure for understanding the material effects of trauma on lived experience closely aligns with my reading of Mala in Cereus.

4. In Mad at School, Margaret Price notes the ways in which mental disability interrupts the normative timelines within the academy. She writes, "Crip time, a term from disability culture, refers to a flexible approach to normative time frames. . . It is this notion of flexibility, (not just 'extra' time) that unites kairos and crip time" (Price, 62-63). Alison Kafer picks up Price's emphasis on flexibility as part of her exploration of crip time in Feminist, Queer, Crip.

5. Daniel Morrison and Monica Casper describe the temporal possibilities of an alliance between disability and trauma studies, claiming, "While disability studies often posits disability as an acute, singular thing, static in time and place, critical trauma studies allows us to examine both pre- and post-wounding conditions and all points in between." Affect helps us navigate these temporal connections by connecting bits of knowledge and mediating between subjectivities, which gives the story shape and makes it recognizable as a history.

6. David Mitchell and Sharon Snyder argue that authors have long invoked disability to represent a moral failing (for example, Captain Ahab of Moby Dick or the titular Richard III), or use it as a convenient plot point to create added interest for the audience (for example, The Steadfast Tin Soldier). Mitchell and Snyder see this pattern throughout literary history, claiming "while stories rely upon the potency of disability as a symbolic figure, they rarely take up disability as an experience of social or political dimensions" (48). Rather than engaging the material experience of disability, texts more often use disability to represent something else, contributing to long-standing stereotypes of disability.

7. The bodymind, a term originating in Western trauma studies and developed by Margaret Price in relationship to feminist disability studies, recognizes the mutually constitutive relationship between the body (the physical) and the mind (the nonphysical). As a term, bodymind encompasses both physical and nonphysical elements of experience: "According to this approach, because mental and physical processes not only affect each other but also give rise to each otherthat is, because they tend to act as one, even though they are conventionally understood as two-it makes more sense to refer to them together, in a single term" (Price, "Bodymind," 269). Price highlights the tie between the physical and nonphysical, pointing out that a consideration of the biological experience must include mental experience.

8. For a longer discussion of the rhetorical conflicts between disability and trauma studies, see Berger, "Trauma without Disability, Disability without Trauma."

9. The lack of certainty that structures Cereus's narrative style is also embedded in the plot itself. When Mala's house burns down, her father's corpse is destroyed. While Mala is taken into custody, suspected of murder, the case is dismissed due to lack of evidence $(7-8)$.

10. For further discussion of the relationship between trauma, disability, and trigger warnings, see Carter, "Teaching with Trauma." 
11. In "Three Women's Texts" Gayatri Spivak argues that in Wide Sargasso Sea Jean Rhys renarrates Bertha's abjection and in doing so retains her sanity and therefore her humanity. Spivak claims that while in Jane Eyre Bertha is shown to be animalistic and therefore less entitled to equal rights, Wide Sargasso Sea troubles this depiction by showing Bertha to be sane, and therefore human $\left(249-5^{\circ}\right)$. However, while Rhys signals an important instance of indeterminacy, significantly challenging the ways political representation is tied to perceptions of animality and insanity, in Cereus Mala freely exhibits animalistic behaviors without the caveat of sanity. While Wide Sargasso Sea gives Bertha a history where Jane Eyre did not, the text as a whole relies on traditional masculinist binaries of sanity and madness, human and animal. Rhys troubles the dynamics of Bertha within Jane Eyre, but that unsettling does not account for larger issues of oppression and marginalization.

12. There are possible exceptions to this. Throughout the novel an unspecified narrator seems to take over, filling in details impossible for Tyler, Otoh, or Ambrose to know. This includes the scene describing Chandin raping Mala in graphic detail. The narrator and source of the information are unclear, still implying some form of mediation, but the visceral description of the event is such that it is more immediately affecting than other moments in the novel.

\section{Works Cited}

Ahmed, Sara. "Happy Objects." In The Affect Theory Reader, edited by Melissa Gregg and Gregory J. Seigworth, 29-51. Durham, NC: Duke University Press, 2010.

Berger, James. "Trauma without Disability, Disability without Trauma: A Disciplinary Divide." In "Trauma and Rhetoric," special issue of JAC 24, no. 3 (2004): 563-82. jstor.org/stable/20866643

Brontë, Charlotte. Jane Eyre. 1847. New York: W. W. Norton, 2016.

Carter, Angela M. "Teaching with Trauma: Trigger Warnings, Feminism, and Disability Pedagogy." In "Interventions in Disability Studies Pedagogy," special issue of Disability Studies Quarterly 35, no. 2 (2015). Dsq-sds.org/issue/view $/ 144$

Caruth, Cathy. Literature in the Ashes of History. Baltimore: Johns Hopkins University Press, 2013.

Caruth, Cathy. Unclaimed Experience: Trauma, Narrative, and History. Baltimore: Johns Hopkins University Press, 1996.

Chen, Mel. Animacies. Durham, NC: Duke University Press, 2012.

Donaldson, Elizabeth J. "Corpus of a Madwoman: Towards a Feminist Disability Studies Theory of Embodiment and Mental Illness." In The Madwoman and the Blindman: Jane Eyre, Discourse, Disability, edited by David Bolt, Julia Miele Rodas, and Elizabeth J. Donaldson, 11-31. Columbus: Ohio State University Press, 2012.

Dorfman, Ariel. Death and the Maiden. 1991. New York: Penguin Books, 1994.

Foucault, Michel. History of Madness. 1961. Edited by Jean Khalfa, translated by Jonathan Murphy and Jean Khalfa. New York: Routledge, 2009. 
Gopinath, Gayatri. "Nostalgia, Desire, Diaspora: Funny Boy and Cereus Blooms at Night." In Impossible Desire: Queer Diasporas and South Asian Public Cultures, 161-86. Durham, NC: Duke University Press, 2005.

Hutcheon, Linda. A Theory of Adaptation. 2nd ed. New York: Routledge, 2006. Kafer, Alison. Feminist, Queer, Crip. Bloomington: Indiana University Press, 2013.

Kafer, Alison. "Un/Safe Disclosures: Scenes of Disability and Trauma." Journal of Literary Ẽ Cultural Disability Studies 10, no. 1 (2016): 1-20. muse.jhu.edu/ar ticle/611309

Kruger, Liam. "Gestures of Belonging: Disability and Postcoloniality in Bessie Head's A Question of Power." In "Cripping Modernism," special issue of Modern Fiction Studies 65, no. 1 (2019): 132-51. doi:10.1353/mfs.2019.0006.

Larson, Stephanie A. “I Be Dawg': Intellectual Disability and the Animal Other in the Works of William Faulkner." Disability Studies Quarterly 34, no. 4 (2014). Dsq-sds.org/article/view/3999/3794

Mitchell, David T., and Sharon L. Snyder. Narrative Prosthesis: Disability and the Dependencies of Discourse. Ann Arbor: University of Michigan Press, 2000.

Mootoo, Shani. Cereus Blooms at Night. New York: Grove Press, 1996.

Morrison, Daniel R., and Monica J. Casper. "Intersections of Disability Studies and Critical Trauma Studies: A Provocation." Disability Studies Quarterly 32, no. 2 (2012). Dsq-sds.org/article/view/3189/3073

Prendergast, Catherine. "On the Rhetorics of Mental Disability." In Embodied Rhetorics: Disability in Language and Culture, edited by James C. Wilson and Cynthia Lewiecki-Wilson, 45-6o. Carbondale: Southern Illinois University Press, 2001.

Price, Margaret. "The Bodymind Problem and the Possibilities of Pain." In "New Conversations in Feminist Disability Studies," special issue of Hypatia 3o, no. I (2015): 268-84. doi.org/10.1111/hypa.12127

Price, Margaret. Mad at School: Rhetorics of Mental Disability and Academic Life. Ann Arbor: University of Michigan Press, 2011.

Rhys, Jean. Wide Sargasso Sea. 1966. New York: W. W. Norton, 1982.

Rodas, Julia Miele, Elizabeth J. Donaldson, and David Bolt. "Introduction: The Madwoman and the Blindman." In The Madwoman and the Blindman: Jane Eyre, Discourse, Disability, edited by David Bolt, Julia Miele Rodas, and Elizabeth J. Donaldson, 1-9. Columbus: Ohio State University Press, 2012.

Samuels, Ellen. "Six Ways of Looking at Crip Time." Disability Studies Quarterly 37, no. 2 (2017). Dsq-sds.org/article/view/5824/4684

Showalter, Elaine. The Female Malady: Women, Madness, and English Culture, I830I980. New York: Penguin Books, 1985 .

Siebers, Tobin. Disability Aesthetics. Ann Arbor: University of Michigan Press, 2010. Siebers, Tobin. Disability Theory. Ann Arbor: University of Michigan Press, 2008.

Spivak, Gayatri. "Three Women's Texts and a Critique of Imperialism." Critical Inquiry 12, no. 1 (1985): 243-61. jstor.org/stable/1343469

Yergeau, Melanie. Authoring Autism: On Rhetoric and Neurological Queerness. Durham, NC: Duke University Press, 2018. 


\title{
FOUR | Ghosts of Disability in Naomi Shihab Nye's Transfer
}

\author{
THERÍ A. PICKENS
}

In what follows, I explore the ghosts of disability within Arab American poetry. Broadly speaking, ghosts feature as a trope within Arab American literature, symbolizing and working within a liminal space that muddies the demarcations of past, present, and future and, often, intervening in characters' or speakers' lives to wild effect. Given the tradition's emphasis on memory-historical and cultural — this particular trope gains political resonance as a way to reckon with or launch a critique. Ghosts of disability are an intriguing form of said trope since they insist not only on the murkiness of temporality and memory but also question the unimpeachability of disability as corporeal. To be clear, ghosts of disability are distinct from disabled ghosts-those rattling chains for madness's sake or those haunting the places or people responsible for a crucial (possibly fatal) physical or mental injury; that is, ghosts of disability are those that lived with disability such that their memories or their legacies would be incomplete without incorporating the complexity of disability into their narrative. These ghosts create afterlives of disability then, where despite disability being noncorporeal, it remains complex, mercurial, and influential. I examine Naomi Shihab Nye's poetry collection Transfer (2011) for how Nye's father, Aziz Shihab, a displaced Palestinian who died of cardiac and renal failure, becomes a ghost of disability and, withal the unruliness that entails, shifts the poetics of the collection itself.

I want to clarify the distinction between disabled ghosts and ghosts of disability. The disabled ghost commonly indicates a haunting, a spectral 
presence that inspires fear based on disability, preying upon the fear of disability. Such a ghost erases the lived experiences of the disabled and mocks their embodied realities as individualized aberration rather than beholden to systemic and institutional structures. Michael Gill and Nirmala Erevelles reject disabled ghosts in their article "The Absent Presence of Elsie Lacks: Hauntings at the Intersection of Race, Class, Gender, and Disability." They read against the grain of the New York Times bestseller, The Immortal Life of Henrietta Lacks (2010) by Rebecca Skloot, to discuss the forgotten or discarded life of Henrietta Lacks's daughter, Elsie Lacks.

Elsie Lacks's forced institutionalization and unethical treatment in a mental asylum parallels Henrietta Lacks's story, linking both to histories of debasement and mistreatment of Black people by the medical establishment. Gill and Erevelles move Elsie Lacks from penumbral secondary character to the center of an analysis that examines how her experience buttresses that of the ostensible protagonist, her mother. They link this history to that of supposedly haunted spaces on their respective university campuses, pinpointing how ghost stories that rely on disability to inspire fear elide the material conditions of institutionalization and other socially disabling forces. They write, "these erasures of the histories of lives lived [...] are now supplanted by tawdry tales of ghosts that haunt the spaces in which we live and work," but they also, following the theoretical intervention of Avery Gordon, "recognize[e] the ghost as a social figure who holds in its elusive form both the absence and presence of its history" (Gill and Erevelles, 133-34). What Gill and Erevelles open up is the possibility of a ghost of disability-one whose life and death makes meaning based on disability as a complex social location.

As one can imagine, a ghost of disability presents some challenges to disability studies. First, one of the foundational tenets of disability studies is to be leery of discussions about the origins of an impairment: scholars in the field veer away from conversations about origins in part because they tend to reify a medical model or a comic plot narrative ${ }^{1}$ in which the impairment, once acquired, can be described, diagnosed, and dealt with. Instead, disability studies prefers to approach impairment as a more neutral category of being that, in consonance with the social and cultural models, acquires meaning based on the valuation given to it in the wider world. Race and disability scholars challenge this model, rightly emphasizing that the origins of impairment for people of color often index larger issues of structural oppression. Moreover, hauntings often require that one go back to the beginning and reckon 
with the past including but not limited to the origins of a disability. The past not only provides insight regarding structural oppression but also allows the ghost to perform recuperative or reparative work regarding the past. Second, disability studies has also been (and I think appropriately so) concerned about the futures of disability. In Alison Kafer's Feminist, Queer,Crip. (2013), she avers that the prevailing understanding of disabled futures is one of science fiction, so often is disabled future thought of as oxymoronic. Her monograph foregrounds and explores the multiple and, at times, conflicting conundrums and possibilities for disabled futures, clarifying that disability is not a "limit without possibility" (Titchkosky, 82). The political and theoretical impulse motivating the meditations on futurity are clear: the material conditions of disabled people the world over requires an imaginary that envisions disability as part of the future. We must consider what it means to live with conditions of disability, welcome the disability to come without attempting to inscribe it into compulsory able-bodiedness (McRuer). A ghost of disability troubles the possibility of a disabled future since it represents a truncated story. Yet, the ghost's afterlife often proves instructive about the future even if it does not have one itself.

Third, a ghost of disability, because it is noncorporeal, remains in the nebulous space between materiality and metaphor. On the one hand, disability studies insists (rightly so!) on the materiality of disability, the import of discussing bodies, minds, and people because of the default erasure of disability. On the other hand, scholars like Sami Schalk and Dennis Tyler Jr. remind us that for people of color with disabilities the metaphors about disability often do critical social work that allows disability to be imaginative, expansive, and complexly rendered. That is, disability metaphors index the possibilities of a disabled consciousness, one that refuses disability as shorthand for simplistic, usually ableist narratives, but rather uses disability as the place of creative possibility and nuanced world making. Here, the ghost of disability offers a place of capacity where disability is both embodied and metaphorical such that one has to rest with disability as a social location that makes meaning regardless of corporeality.

Examining ghosts of disability within the tradition of Arab American letters is not a moment of intellectual whimsy. Ghosts surface as a common trope within the tradition, existing as more than disabled ghosts: merely scary spectral presences or as manifestations of grief. They are not exclusively reminders of the past, but rather they often act as interlocutors about the present, taking care to not keep their opinions to 
themselves. Within fictive texts, this tends to take the form of characters who do not behave as spirits ought. In prose, William Peter Blatty's The Exorcist (1971) is one of the most famous examples. The haunting there is more suggestive about the priest that performs the exorcism than the devil himself. Blatty's less well-known work including I'll Tell Them I Remember You (1973) depicts the ghost of his mother whose presence intrudes on her son's life, becoming a voice of conscience who reminds her son not to forget or diminish his Arab heritage. Recently, Frances Khirallah Noble's The New Belly Dancer of the Galaxy (2007) features a snarky mother who mocks her son's indecision. These texts, among others, share an insistence on the ghost as an exacting presence, not one requiring skepticism, and the ghost as invested in the lives of the characters who live on.

In poetic texts, the ghosts appear differently: they form a hauntological presence that shapes the narratives possible in content and form. For instance, the ghosts of Abu Ghraib in Philip Metres's Sand Opera (2015) are not those who have died as a result of torture. Instead, the ideals that undergird nationalism and freedom haunt the poetic text such that the descriptions of torture and confinement require the spectral presence of Americana for ideological heft. These ghosts show up in the erasures and redacted text, including the title itself: Sand Opera is a redaction of Standard Operating Procedure. The cover of the first version of the chapbook was made from recycled army uniforms, an artistic choice that relies on the remains of the uniform to drive home the thrust of the poetic project. Within Suheir Hammad's breaking poems (2008), the ghosts of women, often experiencing some form of impairment, wander within the poetic text such that their transnational subjectivities as displaced Palestinians critique the notion of citizenship. Hammad's practice, within the collection, of breaking apart words resonates with the multiple metaphorical uses of breaking in the collection. In other words, there are multiple ghosts in this tradition, some of which do not appear as noncorporeal manifestations of dead people, but who also imply the ghostliness of a set of ideas or beliefs that will not relinquish its hold on the present or the text of which they are a part.

In reading Nye's Transfer, I became fascinated by how the deceased father figure, Aziz Shihab, shapes the poetics of her collection. Aziz Shihab, a displaced Palestinian, dies from complications of chronic illness, specifically renal and cardiac conditions. In terms of content, his voice surfaces in poems Nye created out of the titles within his notebooks and the words within them. He also appears as a figure in poems 
Nye constructs about him, where the poetic voice is the daughter and he, the subject. An author in his own right, Aziz's voice emerges within the poetry as the one who is principally concerned with his experiences as a displaced Palestinian and the politics of his exile. Mostly, it is the daughter speaker who connects the experiences of chronic illness, disability, and exile. The entire collection gains its emotive thrust from his absence and his presence, regardless of whether the poems discuss him directly since politics, grief, and mourning animate the work. Aziz, as figure and as presence, functions as a ghost of disability: a reminder and remainder of how disability circulates without disabled bodies. Coming from within a tradition of Arab American poetics, Nye's Transfer suggests that the ghosts of disability are not without their social locations even in death. The collection demands a consideration of disability as lived and created within a particular social context, in this case, that of the Israeli/ Palestinian conflict.

In terms of form, the collection seeks to capture Aziz's voice and legacy. It is divided into five sections of mainly lyric poetry, preceded by a dedication and introduction (upon which I will focus the majority of my critical attention). The first section consists of eight poems that meditate on wrapping, burial, and unfolding as processes that facilitate memory. The second section includes eleven poems whose titles are all culled from Aziz's notebooks. Some titles reflect his journalistic style; others, his meditative interests. The third section of twenty-two poems speaks to the daughter's wrestling with grief, not just about her father, but about William Stafford and about Palestine. The fourth section carries an epigraph—a poem about writing with ash—that frames the seventeen poems' interest in writing and recording. The final section of twenty-one poems is the most explicit about its interest in the multilayered idea of transfer and its vectors. Nye's collection hinges on a poetics that yokes the origins of disability (past) with the disability yet to come (future) as it honors the complexity of having lived with disability (materiality) and embeds within it a discussion of living after disability (metaphor).

Following the impetus of this collection to build on Siebers's work, I look for a method that leaves room for a noncorporeal body, or a paradigm in which the disabled body exerts pressure on others. The social model of understanding disability would not suffice alone as a methodology, nor would Tobin Siebers's concept of complex embodiment. Both the social model and the theory of complex embodiment leave open this possibility in that each allows for the social and cultural institutions of narrative and text (here, poetics) to exert pressure on others as well as 
considers how representations of disability can operate in complex ways. The social model divvies up disability and impairment, emphasizing the institutions that create and maintain barriers for people with different bodyminds. Complex embodiment asks us to contemplate the "economy between social representations and the body not as unidirectional as in the social model, or nonexistent as in the medical model, but as reciprocal" (Siebers, DT, 25). The theory of complex embodiment usefully builds upon the reading strategies of the social model by crystallizing how much medical models operate discursively. However, the cultural model of disability allows for two critical stances that become integral to considering a disability afterlife poetics: suppression and resistance. As Sharon Snyder and David Mitchell describe it, "The formulation of a cultural model allows us to theorize a political act of renaming that designates disability as a site of resistance and source of cultural agency previously suppressed" (10). I read Naomi Shihab Nye's collection as a space where disability becomes a site of resistance because cultural agency has been suppressed. Aziz's social location as a disabled, displaced Palestinian reverberates with political exigency after he dies. It would be inadequate to read him as a ghost of disability that haunts out of fear or anger, as typical ghosts do in ableist tellings of haunting, or to read Transfer as merely a collection about grief. Instead, disability and its afterlife-how disability circulates as transnational, raced, and interdependent despite a lack of corporeality-animates how to address the deep difficulty of Palestinian displacement.

Another methodological impulse animates my usage of the cultural model: namely, Nirmala Erevelles's understanding of "becoming disabled / becoming Black" (Erevelles). Without mapping Erevelles's reading of a particularly Black experience onto Arab American cultural context wholesale, I find it useful for this discussion to think through this simultaneity of becoming racially marked and disabled. Moreover, as Michelle Hartman and I agree, the long history of Black-Arab relations mandates a critical armature that is underpinned by the productivity of mutual engagement. ${ }^{2}$ Erevelles reads Hortense Spillers's influential essay “Mama’s Baby, Papa's Maybe: An American Grammar Book," arguing that enslaved bodies in the Middle Passage become disabled simultaneous to becoming Black. Here, thinking of the Middle Passage as a historical event that creates disability and Blackness abets a critical thinking strategy that allows for the simultaneity of suppression and resistance. Erevelles's reading offers the space to think about the transnational con- 
texts of displacement and violence that Arab Americans often live within (certainly applicable in the case of Aziz Shihab) and a set of circumstances in which the acquisition or lived reality of disability exists alongside that of being and becoming ethnically and racially marked.

Perhaps most important for this discussion, being/becoming disabled is a historical process that bears implications for transnational subjectivities. Since Arab American experience in the contemporary moment includes a set of transnational and transcultural subjectivities, then we have to consider how disability, as the result of oppressive practices, shapes said subjectivities. Erevelles's model here becomes crucial since the transatlantic slave trade is foundational to modernity, and her discussion of the Middle Passage attends to how disabled and raced subjecthood is formed as abject without acquiescing to that abjection. In the case of Aziz Shihab, his disability (chronic illness because of renal and cardiac conditions) appears to be an individualized concern in a Western nation. Yet his disability remains historically contextualized as acquired under the conditions of living as a displaced Palestinian. Typically, we consider the relationship between transnational disabilities as uneven and often causally related: the access available in more affluent nations creates impairment in less developed nations or the politics of wealthier nations creates and sustains impairment in less developed nations, or both. In the case of Aziz, his renal and cardiac conditions do not appear to have a causal relationship with Palestinian displacement writ large and they may not be caused by his experience of displacement. In a broader sense, the availability of care for his renal and cardiac conditions may have abetted conditions of poverty in other geopolitical spaces. Though the collection does not address either of these possibilities directly, it does set up a relationship between his chronic illness and his experience such that both his social location as a displaced Palestinian and a disabled man must be considered as co-constitutive, historically situated identities. As a result, Erevelles's reading of Spillers proves once again instructive: we must read the acquisition of disability within the context in which it occurs, wherein the subject is raced as they are disabled. Further, the cultural model, since Snyder and Mitchell discuss it in the context of eugenics, subsumes transnationalism as part of the discussion. When the two cohere as method, they allow for the reading of a historically situated, raced transnational subject who acquires disability under oppressive conditions and who, because of those conditions, may not always be corporeal. In the readings that follow, I attend to how 
these three concerns-be(com)ing disabled, transnational subjectivity, and being racially marked-surface within the poetics of the dedication, introduction, and the first two sections.

$$
* * *
$$

Nye's Transfer opens with Aziz Shihab's death, casting him as a liminal figure who suffuses the collection in both form and content. Prior to the table of contents, there is a dedication that reads as an epitaph. It is one of two discursive spaces (the dedication and the introduction) that transform as a result of Aziz's haunting wherein his ghostly presence brings to bear the difficulties of having lived as a transnational, disabled subject. I look to the dedication and introduction as a way to understand how Aziz's presence as a disabled, chronically ill, displaced Palestinian shapes the collection's poetics. Consider his presence in the dedication as that which opens and guides the entire collection, a lingering, liminal figure who refuses easy categorization and favors disruption. The dedication follows the conventions of most: it appears before all other text, is center justified, and begins with "In Loving Memory of Our Father, Aziz Shihab." Yet, because of its length, and narrative, it transforms a usually pithy dedication into an epitaph: functioning both as a commemorative inscription and a brief poem in praise of a decedent. Each of the four stanzas gives another perspective on Aziz's life, even as they trouble those points of view. That is, inasmuch as this epitaph mourns and defines Aziz, it also marks the collection as a gravesite for him. This poetic burial ground is unstable, however, since Aziz's transnational Palestinian identity calls into question the possibility of clearly understanding geopolitical belonging in a context of settler colonialism. The poem directly addresses an outsider first, naming Aziz both "our father / who was always our father / not always our father" and "refugee / not always / once a confident schoolboy / strolling Jerusalem streets." Here, the poem equivocates about who Aziz could be even as it defines him as a liminal figure. In defining him as such, the poem sets up the tension that pervades the rest of the collection through the conflicts that surface personally and geopolitically. He is a father. But not. He is a refugee. But not. The multiple, conflicting temporal markers- "always," "once"not only oscillate between past and present, but they also index another equivocation between what is discrete and what is ongoing. Juxtaposing the two allows that what is discrete either personally or geopolitically may exist simultaneously with what is ongoing. Further, in the fourth stanza, the speaker asks about Aziz's homeland and where he is now, questioning: 
Is Palestine peaceful in some dimension

we can't see?

Do Jews and Arabs share the table?

Is holy in the middle?

Holy could be in the middle of the two people groups or the phrase "the table." The idea of "holy in the middle" also plays on the fact that the text is centralized on the page, implying that remembering Aziz is linked to or constitutive of that which is holy or wholly (given the homonymic reference) central to the text. The purpose of "holy" is to straddle a space that has yet to be defined or understood or resolved. Holiness could certainly be ecclesiastic here, but that's not quite the concern of the collection. The invocation of holiness adds to the haunting presence of Aziz himself: where the oscillation and double entendre suggests an ephemerality that restructures the poem and shifts the content.

In addition to the dedication, the introduction also transforms from its traditional purpose into a prose poem. Defining it as a prose poem, I realize, is rather a tricky endeavor. But, as Robert Hass says, "there may still be great value in a term impossible to define" (386). In Nye's introduction, the great value surfaces in what Hass terms the prose poem's "expressive possibilities," a set of characteristics or tools with which the poet works to craft the work. The paragraph, for instance, promises unity in a way different from the stanza. Nye's paragraphs suggest a narrative unity; in particular, the narrative of her reckoning with her father's posthumous writerly presence. Another expressive possibility usually unique to the prose poem is its tension between unity and non sequiturs, which Nye's introduction takes advantage of in its vacillating between her mind and her perception of her father's. Bear in mind that her access to her father's interiority is limited, therefore speculative. So, her prose jumps-takes intuitive leaps-between her body and mind and his. Nye also "fills [her introduction] full of the devices that people identify as lyrical as a kind of alchemy to transform prose and the world of prose with poetry" (Hass, $387-88$ ). She does so with the monostich, the muscularity borne out of shifts in grammatical mood, the disruption of syntax (usually in the form of fragments), and the extended metaphor of dialysis (which I will take up now).

Here, the ghost of disability can be consistently disruptive to poetics. As Nye writes, Aziz's presence troubles the possibility of strict formal poetics and his presence makes writing itself arduous. What emerges is a meditation on what it is to be or become raced and disabled. Embedded within a traditional discussion of how the collection came to be, Nye 
melds the story of the father's inability to create dialogue with his experiences of dialysis. Of his writing as an exchange, she asks "where is the back and forth?" (11). Within the context of the introduction poem, the back and forth lies in the image of dialysis, the blood exchange process that filters toxins and stabilizes blood pressure usually provided for short-term or long-term renal failure. Here, the dialysis functions as a prompt for creating dialogue: "He was already on dialysis. I would have done anything he wanted" (11). Yet the speaker cannot fulfill that desire since the father wants to have a dialogue that he does not allow for within his writing. The image of dialysis surfaces here as a way to understand how the exchange truly works. Dialysis is not really a blood exchange; it is a way for a machine to operate in the same way one's kidneys would inside the body and return the filtered blood back to the body. Yet the machine cannot always approximate the machinations of the body. As a result, the process is useful, but consistently flawed. The same is true for the exchange between the father and daughter figure. The dialogue is thwarted-interestingly enough, not by death-but by refusal. The father refuses not only to discuss Palestinian displacement in ways that allow exchange-"AMERICANS GET OUT. / People would begin to count . . . but what about ... / And he would say GET OUT!"even as his conversations and interactions with others demonstrate a desire for a particular kind of parity (13). He calls people "his friend," vomits out of sympathy when someone else does, and, as the speaker says, "Everything depended on mutual respect" (12-13). The resulting exchanges described within the introduction function very much like the dialysis that coerces the speaker to comply: they are a series of starts and stops, equal exchanges, and thwarted ones. The grieving speaker, particularly in the introduction, cannot hold on to the narrative of pity (i.e., "I would have done anything he wanted") since both the introduction and the dedication cum poems shift the loci toward the resistance inherent in dialysis and in considering resolutions for the Israeli/ Palestinian conflict.

Aziz's presence as a chronically ill displaced Palestinian disrupts the typical structure of both the dedication and the introduction, reminding the respective speakers that living with disability can be an alienating and frustrating process. The two spaces link his exilic experience with his embodied one without having one erase or overwhelm the other. In the process, the two spaces transform from being merely prefatory matter for the poetic collection into poetic additions to the collection in their own right. The multiple and multiplying functions index a peculiar 
facet of a disabled afterlife in poetics: namely, they hold within them the possibility of proliferation. In the spirit of a corporealized disabled subjectivity, that proliferation occurs without regard for convenience or clarity. For instance, the dedication attempts to trace his life, but cannot do so completely since understanding his living is wrapped up in understanding his displacement. The introduction attempts to chronicle how he thought, but cannot fully do so because of his politics of refusal. His disabled and displaced subjectivity appears to thwart the primary function of these genres, even as it multiplies the possible functions available. That is, the dedication and the introduction become poems in addition to performing their traditional roles, and the dedication marks the collection as a gravesite since it functions as an epitaph as well. The introduction starts the collection, acquaints the reader with Aziz, and also eulogizes him. In each, disability operates as a resistant spectral presence that suffuses the text and troubles the easy alignment of his chronic illnesses with death and/or stagnancy, his displacement with despair, and the collection itself with grief.

Current conversations about how disability influences form tend to focus on the usually (though not exclusively) able-bodied viewer and the disabled artist and how their embodied subjectivity manifests in the art object. Lennard Davis in Enforcing Normalcy (1995) and Tobin Siebers in Disability Aesthetics (2010) have discussed how disability forms the requisite basis for engagement, either disgust or intrigue, with art whether viewers are aware or not. So, examining art from the perspective of disability changes the interpretation of the art object itself, such that Venus de Milo becomes an amputee, for example. In the groundbreaking collection Beauty Is a Verb: The New Poetry of Disability (2011) edited by Jennifer Bartlett, Sheila Black, and Michael Northen, the editors agree "to look at poetry influenced by an alternate body and how this intersection forms a third language" (15). Though they "include not only poets who created and embrace the disability/crip poetics movement but also those who might resist such a classification and have never been considered in that exact context" (15), their collection's viewpoint of disability poetics relies on a notion of disability that prioritizes the embodied disabled person. Nye's collection, on the other hand, since it hinges on a ghost of disability might usher in a conversation about what happens after disability, after death as a result of disability. This is not about the grieving process of the nondisabled in the wake of death, but is a thanatological concern of a different sort: what the ghost of disability ushers in is the possibility of interpreting the interaction between nonnormative 
and normative, corporeal and noncorporeal, where ableist narratives do not overwhelm remembrance. As I mentioned before, the ghost of disability issues an interpretive challenge to disability studies in its messy insistence on remaining between materiality and metaphor.

For instance, Nye's introduction refuses to spectacularize disability, preferring instead to narrate it as part of the mundane nature of Aziz's life, even if it has changed the speaker's relationship to Aziz himself: "He was already on dialysis. I would have done anything he wanted" (11). This suggests that the dialysis garners pity because it is tragic and anticipates his death, but that emotive space exists alongside the emphasis on dialogue the speaker tries to create. Grief animates the introduction and any mention of disability is subsumed under that discussion.

Nye writes:

Who would ever have guessed a vibrant skinny man of optimism and energy, who disliked all medical procedures, would end of having heart attacks, diabetes, kidney failure, dialysis? He pricked his finger to check his blood sugar for years. He grew comfortable with bleeding.

Why do you have diabetes, Grandpa?

I think because I used to put sugar in my coffee. (12-13)

The dialogue between nonnormative and normative surfaces here as the speaker muses about the unexpected presence of disability, its disruptive nature, its surprise. What's more, the interplay between Aziz's disability and his Palestinian identity also emerges in the comfort with bleeding. It hints at an open set of wounds in the vein of Gloria Anzaldúa: literal, because of the reality of the glucometer and the violence of displacement and, figurative, given the pervasiveness of trauma as not just embodied but also in the zeitgeist. Even though the lived disability was disruptive, it remains mundane since he grew comfortable with it. This sentiment is also echoed in the italicized dialogue that follows: "Why do you have diabetes, Grandpa? / I think because I used to put sugar in my coffee?" (13). The introduction relies on the interplay between Aziz as a deceased figure or absent presence and the speaker as a grieving person. Herein lies the capacity of a ghost of disability to shift the poetics so that disability is limned in complex ways. Disability is disruptive and ordinary. It requires space adequate for grief and honor and, yet, has moments of irreverence. It mobilizes disability as metaphor given dialysis, but eschews pity and medical models as overarching narratives. It exudes a politics of acceptance as well as a politics of refusal. 
Diabetes drives this point further since it too sits at the nexus of materiality and metaphor. On the one hand, it explains some of the quotidian nature of Aziz's life: specifically, the need to check one's blood sugar by pricking one's fingers. It also is the subject of a conversation between Aziz and his grandson. Diabetes operates as a disability metaphor, which, according to Sami Schalk, is "more extended and central to a text's meanings" (141). In the way of Dennis Tyler Jr.'s methodology, the figurative language can be understood without "flattening out the various intersections of blackness and disability" (187). In the passage above, diabetes and the experience thereof parallels that of being displaced such that both metaphorize the other. That is, the relationship between vibrancy, optimism, and energy that gets drained in the angst of displacement and exile mirrors that of the bloodletting diabetes requires. Both drain the subject of energy and demand a comfort with that which is not comfortable. The leap between narrative and dialogue drives this point home. After all, the answer to the grandson's question may be neither accurate nor satisfying even if it suffices for the moment. What the answer does do, however, is leave room, with a wry sense of humor, for the unknown origin of disability to crash into the memory and afterlife of its existence. Further, the exchange, since it metaphorizes discussions about Palestine, complicates current understanding about those conversations. That is to say, the answers are neither definitive nor satisfying, even if they are discussed with wry humor, even if one grows accustomed to bleeding. The narratives of pity are not useful, nor do they command the bulk of attention. If anything, they function as a discursive red herring, a distraction from the more nuanced narratives at stake. The conversation as recollection crystallizes the eventual comfort Aziz had with bleeding while clarifying that the reality was not entirely comfortable. This is a reassertion of the "once" and "always" of the dedication as simultaneous. The discrete acts of dealing with diabetes and the ongoing nature of those acts continue to craft how Aziz is remembered both as andividual and as part of a larger displaced Palestinian collective.

$* * *$

Thus far, I have discussed how Aziz as a ghost of disability shifts the poetics of Nye's collection, such that the dedication and introduction become poems in addition to fulfilling their traditional roles. Because the ghost of disability haunts the space between corporeal and noncorporeal, material and metaphor, it not only changes the way one encounters form but also multiplies the possibilities of interpretation vis-à-vis 
disability. I turn briefly to the first and second sections of Transfer to examine where the ghosts of disability create interpretive possibility. In the first section, the poetry troubles the commonplace narrative about what I have elsewhere called disabled ghosts, specifically that they are anxiogenic and malevolent. "Valley" meditates on the difficulties of language. To be clear, this is not about Aziz's impairment in particular, but rather the structures that made living with disability difficult. If we are to consider that commonplace narratives assume anger or fear of the presence of disability especially after one has died as a result of complications related to disability, then we have to reckon with how this speaker constructs this experience. On the one hand, it is a source of anxiety, but not because disability makes it so. Instead, it is that disability creates an urgency that the speaker cannot surmount. In "Valley," the speaker desires to reach the father before he dies, but cannot because of travel, the inability to transfer. Driving the urgency of the poem is an obsession with words that echo each other-vice and advice; clatter, clutter, and chatter-as the speaker muses, "I carried a lonesome person's acute cognizance of words- / 'vice' suddenly tucked into 'advice' making more sense" (25). Because these words tuck inside each other, the poem cultivates an interest in language that envelops other language, language that disappears inside itself becomes more clear. It begins:

The ear is a purse

into which I dropped all the words I heard

on $25^{\text {th }}$ Street, Ogden, Utah,

the night I knew my father would die. (25)

Yet it isn't only the language that is enveloped or tucked in the content of the poem. The first metaphor of the ear as a purse and both as containers animates this idea. The specificity of where the speaker experiences that language remains far from where the speaker wants to be, a point emphasized by the finality of the stanza's end line: "the night I knew my father would die." The speaker is wrapped in a space from which they cannot escape, "held and bound," they remark, from rushing to the father's hospice bedside. Disability, then, gets tucked into the poem, dropped in media res, and though remarked upon, remains unremarkable. The poem, narrated in past tense, does not convey anger or fear regarding disability, even as the speaker notes that others do not seem to have it as part of their lives. They have "daily lives that weren't dying yet, their many pleasures" (25). What appears to be a slightly resentful 
commentary allows for the exceptionalization of disability-not everyone experiences it-as well as its normalization-that it is part of the experience of the speaker among others. What haunts the speaker then is not disability or dying from it or the treatment thereof, but the structural limitations engendered as a result of it, the inability to get to the bedside, for instance. This says nothing of the haunting of those details that emphasize the emotional resonance: the flattening of the newspaper, the restlessness of waiting.

Another poem, "Bats," indexes a discourse of disability and haunting that reorients the common narratives about malevolence. The poem does not solely function as a metaphor for bloodletting although, in conversation with the poems that mention dialysis or diabetes, the invocation of bats may allow for such a reading. Instead, I opt to read this poem as a way to recast how burial, preservation, and haunting can be spaces of surprising comfort. The poem includes multiple images: the speaker interacting with an animal, bats circling a yard and a group of boys, and a series of meditations on animacy. Within the poem, the speaker references wrapping multiple times. The poem begins with it as an action: "I wrapped the dying squirrel in an old sweater" (19). At the end of the final stanza, wrapping is a verb and a noun, functioning as a material since the wrapped seeds are a "new voice in paper folded / so it looked like clothes" (19). The wrapping not only covers the dead or the dying, but it also encloses and protects that which could be living or growing like the seeds or the boys in the yard. The poem reads: "The boys / were scared, but I wrapped them into my dream" (19). Multiple instances of wrapping tease out how the covering makes meaning as both an avenue to bear grief (i.e., a burial shroud) and allow for what is new (i.e., what comes from the seeds). As a result of this thread, the bats draw on their typical role as harbingers of malevolence, but that association cannot hold completely. Like the meaning and function in the dedication and introduction, the meaning and function of the bats proliferates: they are also as innocuous as a flock of birds, ones that momentarily scare schoolchildren. The speaker voices a preference for them, along with the image of an avian figure often thought of as lonely or dangerous, or both: "Take your large and panting dogs. I'll keep / the owl high in the eaves." Two instances of animacy, the owl and the bat, invoke and dismiss their common association with danger and mystery, especially since their presence is juxtaposed with the dog. The avian and marsupial references complicate the idea that burial completes a process solely after wrapping and preservation. Instead, the concept of burial as conclusion is 
troubled by the bat continuing to fly or the owl perching in the tree. The burial, the wrapping anxiously happens over and over, not because the speaker cannot complete the action, but because the action seems to require repetition as an avenue of grief. Metaphors of thwarted burial also echo the function of the dedication as epitaph, marking the collection as a gravesite for a ghost of disability that refuses to stay buried. The malevolence inherent in the owl and bat images communicate foreboding, but do not deliver on that promise since they and the act of wrapping also seem to provide some small measure of comfort.

In the second section of poems, "Just Call Me Aziz," the titles are culled from Aziz Shihab's notebooks and invoke his journalistic voice. His presence as speaker allows for greater emphasis on his social position as one whose disability is not solely a manifestation of that "third language" to which Bartlett, Black, and Northen refer. These poems spotlight that his disability exists as part of a set of historical processes that are contingent on and interrelated with his transnational subjectivity. Disability surfaces explicitly in two poems: "Many Asked Me Not to Forget Them," and "When One Is So Far from Home, Life Is a Mix of Fact and Fiction." Useful for our conversation here is the fact that disability emerges again as an ordinary fact of the speaker's existence rather than a spectacularized dying. In this way, the poetics also allows for disability to haunt, without fear, and to become a facet of the speaker's existence. This ordinariness is part of the poetics that conceptualizes disability as nuanced, critical to understanding the grieved and the aggrieved, but not overdetermined by narratives that are clichéd or ableist.

When disability does calls attention to itself in "Many Asked Me Not to Forget Them," this poem uses it to trace the speaker's desire and need to remember those who lost homes in the establishment of the state of Israel. The speaker wants to remember those people and their homes as they were before Palestine became a set of occupied territories. Nevertheless, the speaker notes the deep difficulty of remembering and the impossibility of making others understand. The mention of disability is the fulcrum point of the poem, the volta where the speaker notes the ironic twist of Americans' inability to concentrate on the Palestinian conflict and the speaker's inability to concentrate on Africa. The poem reads, "Wished them happiness and peace. / Peace in the heart. No wonder we all got heart trouble" (33). This free association between peace and heart gives way to a morbid ironic declaration that creates a causal link between the Palestinian conflict and cardiac failure. On the one hand, this kind of link is medically plausible and, certainly, a socially 
acceptable, common narrative about metaphorical heartache and physical debilitation from trauma. On the other hand, the cardiac metaphor creates a set of interpretive possibilities that link the living and the dead through disability metaphor. They are connected through their experiences of the conflict as well as the resultant embodied experience. To be fair, this kind of metaphor does chafe against a radical disability consciousness that eschews cliché narratives that appear to sentimentalize disability. What tempers the sentimentality here is the link to a transnational subjectivity and the challenge issued to the living. In a simple sentimental narrative, the heart trouble halts the possibility for action. Here, it is a lament but not a way to forestall political action. The act of thwarted remembering invoked by the title and the charge of the poem relies upon disability for its dynamism and its interiority. Much like "Valley" and "Bats" gain their complexity from the ghosts of disability, "Many Asked Me Not to Forget Them" too relies on disability as material reality and for metaphorical power. Like the speaker, the nondisabled living carry the responsibility to remember, even if they can only lament: "I always did feel sad / in the back of my mind for places I didn't / have enough energy to worry about” (33).

The ghosts of disability remind us how they came to be as transnational subjects who are raced and disabled as a result of historically situated processes and events. They even unsettle the idea that origins are easily understood or always radically conceived. Instead, they insist upon the messiness of these entanglements as a way to promulgate their critique. In "Many Asked Me Not to Forget Them," the speaker laments not being able to fulfill their obligation to remember, but considers it a natural corollary of being in the world: "I tried to get Americans to think of them. / But they were too involved with their own affairs / to imagine ours. And you can't blame them, really. / How much do I think of Africa?" (33). This lament, though it appears blameless, also assumes a kind of defeat. Africa, given its juxtaposition to America and its nonspecificity, is supposed to function as a vague "over there," an ignored country (not specific continent) in this poem. The speaker's invocation of the continent, particularly as a space of understood abjection and trauma and understandable forgetting, relies on the same kinds of narratives that shape public perception of the Palestinian narrative as hopeless, always already circumscribed by tragedy, and available for dismissal. Palestine and Africa as geopolitical sites of war and oppression carry with them the experiences of disability since war and oppression create impairment. Disability acts as a spectral presence here: we all got heart 
trouble. Yet, the haunting is not about the fear of disability to come nor the fear of disability as present, but disability as fact, tragic fact in fact. This forces us to reckon with the way disability is created as a result of war, poverty, and capitalism. The speaker's lament that they cannot think about Africa alongside the invocation of disability is instructive since the speaker's defeated understanding of their own shortcomings simultaneously acknowledges and bemoans the way disability is created.

Being a ghost of disability does not have to be the chain-dragging, fearsome, malevolent spirit of times past. We need not hold out fear or anxiety about those that haunt us as a result of anger regarding their disability. Instead, we might invite these ghosts in since they have much to bemoan about the processes of living and dying, and the historically situated sites of their creation. I have sketched out how ghosts of disability shift poetics, how they haunt a text without fear or spectacularization, but rather continue to insist on disability as a rich social location, a complex and nuanced space of political and social critique. When witnessed as an interplay between the normative and nonnormative, the corporeal and noncorporeal, a disabled afterlife poetics creates access to an intellectual space that does not stop at death. It haunts. It goes into the light. Or it stays behind.

Notes

1. According to G. Thomas Couser in Recovering Bodies, the comic plot narrative tends to end happily with some significant recovery where the narrators are healed if not cured.

2. See Hartman, Breaking Broken English. See Pickens, New Body Politics and "Modern Family."

\section{Works Cited}

Bartlett, Jennifer, Sheila Black, and Michael Northen, eds. Beauty Is a Verb: The New Poetry of Disability. El Paso, TX: Cinco Puntos Press, 2011.

Blatty, William Peter. The Exorcist. 1971. New York: HarperCollins, 2011.

Davis, Lennard. Enforcing Normalcy: Disability, Deafness, and the Body. London: Verso Books, 1995.

Erevelles, Nirmala. "Becoming Disabled/Becoming Black: Crippin' Critical Ethnic Studies from the Periphery." In Critical Ethnic Studies: A Reader, edited by Critical Ethnic Studies Editorial Collective, 231-51. Durham, NC: Duke University Press, 2016.

Gill, Michael, and Nirmala Erevelles. "The Absent Presence of Elsie Lacks: 
Hauntings at the Intersection of Race, Class, Gender, and Disability." In "Blackness and Disability," edited by Therí A. Pickens. Special issue, African American Review 50, no. 2 (2017): 123-37.

Hammad, Suheir. breaking poems. New York: Cypher Books, 2008.

Hartman, Michelle. Breaking Broken English: Black-Arab Literary Solidarities and the Politics of Language. Syracuse, NY: Syracuse University Press, 2019.

Hass, Robert. A Little Book on Form: An Exploration into the Formal Imagination of Poetry. New York: HarperCollins, 2017.

Kafer, Alison. Feminist, Queer, Crip. Bloomington: Indiana University Press, 2013.

McRuer, Robert. Crip Theory: Cultural Signs of Queerness and Disability. New York: NYU Press, 2006.

Metres, Philip. Sand Opera. Farmington, ME: Alice James Books, 2015.

Noble, Francis Khirallah. The New Belly Dancer of the Galaxy. Syracuse, NY: Syracuse University Press, 2007.

Nye, Naomi Shihab. Transfer. Rochester, NY: BOA Editions, 2011.

Pickens, Therí A. "Modern Family: Circuits of Transmission among Black and Arab Americans." In "Blackness and Relationality: An ACLA Forum," edited by Keith Feldman. Special issue, Comparative Literature 68, no. 2 (2016): 13040. doi:10.1215/00104124-3507912.

Pickens, Therí A. New Body Politics: Narrating Arab and Black Identity in the Contemporary United States. New York: Routledge, 2014.

Schalk, Sami. "Interpreting Disability Metaphor and Race in Octavia Butler's 'The Evening and the Morning and the Night'." In "Blackness and Disability," edited by Therí A. Pickens. Special issue, African American Review 5o, no. 2 (2017): 139-51.

Siebers, Tobin. Disability Aesthetics. Ann Arbor: University of Michigan Press, 2010.

Siebers, Tobin. Disability Theory. Ann Arbor: University of Michigan Press, 2008.

Snyder, Sharon, and David Mitchell. Cultural Locations of Disability. Chicago: University of Chicago Press, 2006.

Titchkosky, Tanya. "The Ends of the Body as Pedagogic Possibility." Review of Education, Pedagogy, and Cultural Studies 34 (2012): 82-93.

Tyler, Dennis, Jr. "Jim Crow's Disabilities: Racial Injury, Immobility, and the 'Terrible Handicap' in the Literature of James Weldon Johnson." In "Blackness and Disability," edited by Therí A. Pickens. Special issue, African American Review 5o, no. 2 (2017): 185-201. 


\section{FIVE Crawling Upstairs: Identity and Ideology in Tobin Siebers's Disability Theory}

THOMAS ABRAMS

The disabled body is not timeless. It has a long history. Whereas dominant understandings of disability as bio-economic loss would suggest that disabled bodies are inherently unproductive, extracting from the economy and away from life, disability studies has argued the exact opposite. Disability is not reducible bio-economic lack, without losing the meaningful, embodied, historical, shared, and political way we live with disability (Titchkosky). In both early social model work, studies of disability identity in the 1990 ond 200os, and the recent turn to assemblage and desire, the disabled body is treated as an outcome of forces-productive, political, and affective-that constitute it as such (Oliver, Politics; Siebers, Disability Theory; Puar; Hamraie and Fritsch). In this chapter, I would like to consider the place of Tobin Siebers's Disability Theory (DT) in this historical progression, while maintaining such a critical approach to the disabled body. Siebers's book places that body within two key processes, ideological construction and the politicization of identity. In contrast to now-commonplace arguments about the fractured nature of disability identity politics, Siebers makes a case for a unified disability identity as the basis of a collective rights project. This argument goes against the grain of popular disability theory, then and now. DT argues that an affirmative theory of disability identity is the best way to consolidate the gains of the disability rights movement, and to oppose ableist ideological frames that deny humanity to disabled bodies and minds. In 1990, identification meant crawling up the stairs of the Capitol building, in the 96 
famous American Disabled for Accessible Public Transit protest. On this $D T$ is clear: we cannot, and must not, crawl back down, lest we lose the rights and recognition we have gained thus far.

This chapter has three aims. First, I want to explore DT's untimely formulation of identity. I will argue, however, that unpacking Siebers's identity politics requires us to unbox some neighbouring terminology, namely the "ideology of ability," which pervades DT and Siebers's work as a whole. Whereas ideology keeps us from a better world, identity will help us get there. Second, while I believe the concept of identity is of extreme importance to this better world, I question the extent that Siebers's use of the term matches others, particularly the "false consciousness model," which I explore below, alongside that of Dorothy Smith and Nirmala Erevelles. I suggest Siebers's use of ideology does not suggest a theory of ideology. Finally, Michel Foucault, Judith Butler, and Donna Haraway don't get a fair shake in DT. They are read under the heading of "poststructuralism," opposing the realist identity politics promoted throughout Siebers's work. They have more in common than he posits; we can do these two projects together. My third goal is to make this case, looking to the case of Foucault, as we pursue an affirmative politics of disability.

\section{Disability Theory}

Rather than read Siebers's book as a past contribution to disability studies, important but outdated, I want to consider its claims on their own merit, as arguments. That stated, Siebers admits that his meditation was out of place: "Identity is out of fashion as a category in critical and cultural theory" $(D T, 11)$. DT undertakes an upstream argument, in contrast to then-dominant disability scholarship. Unfashionable as it may be, a politics of minority identity is the proven path through which disabled persons fought for acceptance and inclusion, with the dominant example being the 1990 Americans with Disabilities Act (ADA). It is and was a path to realize a better world, if only incrementally and selectively. This path has not been easy, in no small part due to the prevailing obstacles facing disabled people. These are represented by more than simply bigoted attitudes, as Siebers makes clear. Courthouses (DT, chapter 6), domestic dwellings (chapter 4), sex in public and private places (chapters 7-8), the art gallery: these are social-and-material spaces where identity, inclusion, and meaning are up for grabs (Siebers, Aesthetics). "Meaning," then, should not be thought to be something immaterial. We find the meaning society attributes to disability realized in rehabili- 
tation practice, workfare economics, and insufficient legal frameworks designed to include disabled persons, in the United States, Canada, and elsewhere. While identity politics might be passé for some, for disabled persons and for disability studies, the stakes are too high to let them go. We neglect them at our (material) peril.

Siebers's identity politics are neither abstract nor ahistorical. They are about access to particular real-world locations, ones that are either admit the wide variety of human embodiments or exclude them. Consider the case of Tennessee vs. Lane. Lane's rights were achieved by literally crawling up the stairs to the Polk County Courthouse, and challenging his arrest for failing to do so again (DT, chapter 6). Or recall the famous case of the ADAPT protest introduced above. The challenge here is both material, with activists dragging their bodies up government property, and dominant media narratives accusing ADAPT of sympathy-mongering $(D T, 106)$. Finally, take the accessibility to architectural space, as in Le Corbusier's Modular (DT, 86). Who inhabits this social body? "Nimble six-footers, with an intuitive sense of dark spaces, acute hearing, and a love of staircases" (DT, 88). This is identity politics in the material world-each example is literally concrete.

Disability identity appeals not to a particular sort of bodies, but to a particular sorting of bodies, one that excludes disabled persons from public and private livelihood. We must revisit the politics of identity linked to bodily kinds, to one addressing disability as complex embodiment. Even to take the "public" and "private" realms themselves as preestablished spaces, whereby particular activities take place, is to pass over another sorting problem. Public and private spaces, and public and private acts, are contingent on a real-and-yet-still-constructed politics of access (see also Titchkosky and Michalko). Not all bodies are allowed to act privately. The two chapters in DT (and one in this collection) on the politics of disabled sexuality attest to this. The capacity to pursue intimate acts, in public or private, alone or together, even at all, is determined by fundamental questions of access, questions that identity politics can and must address.

Siebers locates his identity politics between both realism and constructivism. Identities are real. But this appeal to a "real world," Siebers argues, is not to embrace a naïve relational epistemology.

By "realism" I understand neither a positivistic claim about reality unmediated by social representations, nor a linguistic claim about reality unmediated by objects of representation, but a theory that 
describes reality as a mediation, no less real for being such, between representation and its social objects. Rather than viewing representation as a pale shadow of the world or the world as a shadow world of representation, my claim is that both sides push back in the construction of reality. The hope is to advance discourse theory to the next stage by defining construction in a radical way, one that reveals constructions as possessing both social and physical form. (DT, 30)

Identity is one such mediation, real as the stairs one is forced to reckon with, yet constructed because it is designed to admit a particular cohort of bodies. The ambiguity of "physical" and "social" construction is, of course, intentional. "When handicapped entrances to buildings are located in the rear, next to garbage cans, a social construction must be read" $\left(D T, 3^{2}\right)$. To speak of disability experience is to address both poles at once. "Disability provides a vivid illustration that experience is socially constructed, but it exposes just as vividly that identities created by experience also contribute to a representational system whose examination may result in verifiable knowledge claims about our society" (DT, 124). Here "representational system" can be read in numerous ways. It might suggest a tentative philosophical compatibility with representational epistemologies. It also suggests a political relationship. If "the real" is a mediation, who gets to describe and account for that reality is a primary political problem. Siebers asks how we can find collective affirmation in this process. The political question is, "Who represents?" To this Siebers would quickly reply, "it must be those of us who identify as disabled."

The conceptual suture linking Siebers's account of oppression and identity is ideology. The ideology of ability binds disability identity and exclusion, "at its simplest the preference for able-bodiedness. At its most radical, it defines the baseline by which humanness is determined, setting the measure of body and mind that gives or denies human status to individual persons" $(D T, 8)$. Ideology is central to the politics of location and access found throughout Siebers's work. The questions about privacy and publicity, about sexual agency, about architecture and material exclusion, these ultimately can be boiled down to the ideological structures that mediate a reality hostile to embodied differences. But with this exclusion comes opportunity, not just for exploitation, but for change:

Ideology creates, by virtue of its exclusionary nature, social locations outside of itself and therefore capable of making epistemological claims about it. [Thus] oppressed social locations create identities 
and perspectives, embodiments and feelings, histories and experiences that stand outside of and offer valuable knowledge about the powerful ideologies that seem to enclose us. $(D T, 8)$

The ideology of ability, too, is real. It takes concrete form, in built environments and institutional structures, and social form, in prevailing attitudes toward disability as medical and economic deficit, "the lesser the ability the lesser the human being." $(D T, 10)$. The dossier unfolding throughout DT shows, in part, how entrenched the ideology of ability is, in both simple and radical forms. That collection of press clippings shows the ideological apparatus at work, in full force and yet ripe for contestation. It is an unabashed form of identity politics, documenting the nastiness of ableism, pinpointing sites for direct and collective action against it.

Siebers's concrete examples of the ideology of ability are not restricted to offensive passages in the newspapers. Much of the theoretical work in $D T$ is devoted to showing how particular approaches within the academy resonate with the self-justifying ideological structures described above. Here the targets are poststructuralist theories of discourse and right and left critiques of identity politics as "self-victimization" $(D T, 11)$. Regardless of the source, the effect is the same: disability is either obliterated or, worse still, used as justification against collective identity. Of particular importance to disability theory, Siebers isolates the influence of Michel Foucault and Judith Butler, who can only see identity as a site of subject formation, at the whim of disciplinary institutions. "In short, contemporary theorists banish identity when they associate it with lack, pathology, dependence, and intellectual weakness. Identity in their eyes is not merely a liability but a disability" (DT, 13; emphasis mine).

"Body Theory" measures Judith Butler's Bodies That Matter and Donna Haraway's cyborg thinking against his theories of identity (DT, chapter 3). Neither can take seriously the reality of pain, the materiality of the disabled body. In Siebers's reading, Butler's answer to her own question, "Does anything matter in or for poststructuralism?," is unsatisfactory, because of her lopsided emphasis on psychic pain, exclusion, and repression (Butler, 28). How does this account for pain felt by disabled people?

Notice that pain in current body theory is rarely physical. . . Pain is most often soothed by the joy of conceiving the body differently from the norm. . . Rare is the theoretical account where physical suffering remains harmful for very long. The ideology of ability requires 
that any sign of disability be viewed exclusively as awakening new and magical opportunities for ability. (DT, 62-63)

Though Siebers is more charitable to Donna Haraway's "rightly influential" cyborg theory, it is the object of similar critique $(D T, 62)$. Cyborgs, "theorized and fabricated hybrids of machine and organism" are many things-but "the cyborg is not disabled" (Haraway, 150, and DT, 63, respectively). When disability is considered therein, it is as a space of modification, of transgression, experimentation. "Haraway is so preoccupied with power and ability that she forgets what disability is" (DT, 63 ). Unintentionally, Haraway's theory aligns neatly with the ideology of ability. To simply associate identity with poststructuralist notions of subject formation, whereby disability is reduced to an outcome of governing dispositifs and biopolitics, then, is quietism (Foucault, Biopolitics). It gives up our best tool to collective rights, out of the fear that identity might be oppressive because it is a discursively constituted category that organizes thought and action. It can potentially be a tool of oppression but that is no reason to give up any possibility of identity politics because of that danger. Disability identity has taken us this far, why give up on it now?

As I will make clear in the following section, I believe that Siebers's reading of poststructuralism is incomplete, both in addressing the field of disability theory when he wrote DTand in the current theoretical landscape. While I have done my best to capture the character of Siebers's arguments in this section, in the next I will request some minor revisions. This means asking for an adjusted take on the ideology of ability, too.

\section{Two Objections}

My first claim is that when we return to the varieties of ideological thinking, we find that Siebers's book, and its emphasis on identity, is an outlier. This has two components that I will explore in succession. I begin by outlining various approaches to ideology, as the concept is applied in a variety of ways. I look to Marx and Engels, Dorothy E. Smith, Mike Oliver, and Nirmala Erevelles. Second, I locate Siebers's work within that spectrum, building on my reading of DT. I will show that Siebers displays a different account of ideology than these thinkers do, to the point that I do not believe him to be a theorist of ideology.

We begin with Marx and Engels. We know Siebers was very familiar with this source material, citing both The German Ideology and Engels's correspondence to Franz Mehring in a lukewarm review of Eugene 
Goodheart's The Reign of Ideology (Siebers, "Review"). I quote two famous passages in The German Ideology.

1. As individuals express their life, so they are. . . Hence what individuals are depends on the material conditions of their production.

2. The ideas of the ruling class are in every epoch the ruling ideas: i.e. the class which is the ruling material force of society is at the same time its ruling intellectual force. . . . The ruling ideas are nothing more than the ideal expression of the dominant material relations, the dominant material relations grasped as ideas. (Marx and Engels, 37, 67)

Siebers's ideology of ability is more nuanced than a typical "false consciousness" reading of these passages would offer; there is more going on than simply a series of economic forces determining all conscious life. Such a conceptualization would betray Siebers's anti-representationalist realism introduced above. Siebers wants to retain the material reality of exclusion, of pain, and marginalization, at the same time as he wants to indicate that the preference for particular types of bodies resonates throughout that same reality. Ideology is a complex mediation of reality, not simply an inversion of it. Identity, too, is a complex mediation of reality, and not simply an inversion of it. Siebers's ideology is not a story of false consciousness.

$D T$ s theorization of the ideology of ability is not a departure from Marx and Engels's founding path, because Marx and Engels do not present a coherent theory of ideology. Writing thirty years apart, Dorothy Smith and Stuart Hall confirm this. Smith: "While Marxism has theories of ideology, Marx does not" (454). Hall: "The problem of ideology is to give an account, within a materialist theory, of how social ideas arise. No such theory exists, fully prepackaged, in Marx and Engels's works" (29). What Marx and Engels do offer is an historical and economic analysis of the conditions under which bourgeois ideas about the economy and in philosophy developed. It is not a theory of ideology, explaining the genesis of all ideas in a neat-and-tidy fashion, but a problem to be explored.

This same problem underpins the sociological method that Dorothy Smith has employed throughout her career, from early standpoint epistemology to institutional ethnography. It is a method that social scientists (or anyone else) can follow, to the social relations found in and abstracted from everyday practice. 
It is an epistemology that constructs a deep connection between the categories through which we know the world as social scientists and the social relations organizing our everyday experience. It insists, however, that we do not adopt a referential practice of reading from category to phenomenon. Rather, we have to recognize that it is the social relations of people's actual lives, expressed or reflected in the categories that are, or should be, the objects of our inquiry. (Smith, 458)

This is consistent with Hall's position, to give an account of how social ideas arise (29). A critique of ideological processes-rather than a theory of false consciousness - takes us from abstract concepts and toward everyday life, whereby ideas about ability and competency are shaped. It is not that ruling ideas are ideological that matters, or that they are held by the ruling classes, rather it is how they abstract from the social lives of marginalized peoples, and how we can establish a method to combat this abstraction. Hence its utility for disability studies.

Marx and Engels's goal in The German Ideology was not to give an account of how all knowledge is false. Their goal was to demonstrate that their contemporaries were captive to a philosophical system that replaced the living, breathing sensuous life around them with abstract categories. They mistook material history for World Spirit, bracketing the material struggle going on right in front of them. This exact same approach-a critique of totalizing categories that obliterate sensuous life-is found in Siebers's book. His concept of the ideology of ability takes direct aim at the "disability is worse than death" trope (see also Reynolds), the belief that the only value in disability is overcoming it, and the pervasive belief that accepting disability as a positive attribute is a sign of psychological distress or resignation to failure. In each of these cases the goal of disability politics is to challenge abstraction with reality. Disabled people enjoy living as much as anyone else (DT, 10-11). We overcome barriers, it is true, but those are far more often from without than within. These barriers are not inherent. Finally, we have claimed disability as an identity not out of psychological damage, but because of those barriers and the need to remove them.

My point, in looking back to Marx and Engels, and to their more recent interpreters, involves two related positions. First, a softer claim that (a) we can pursue an account of ideological thinking without recourse to the false consciousness argument; and second, a stronger argument that (b) ideological thinking is incompatible with the argument found in DT. The traditional ideology as false consciousness argument is found 
most explicitly in the work of Michael Oliver. His materialist reply to Wolf Wolfensberger's normalization principle, for example, explicitly appeals to the false consciousness position and argues that normalization appeals to capitalist norms rather than to barrier removal (Oliver, "Capitalism"). Normalization-or any other approach to disability that locates the problem of disability in the individual-is false consciousness because it ignores the structural production of disability.

Erevelles's Disability and Difference in Global Contexts similarly employs ideology. Erevelles applies the anti-abstractionist argument held by Hall and Smith in her critique of feminist disability studies, "limited because of its overreliance on metaphor rather than materiality" (129). In feminist disability theory-here she refers most frequently to the work of Rosemarie Garland-Thomson-the focus is too often on discursive interventions rather than the "materiality of structural constraints that actually give rise to the oppressive binaries of self/other, normal/disabled, us/them" (129). She too takes objection to Haraway's influence in disability studies, asking, "How can cyborg subjectivities be celebrated when the manufacture of prostheses and assistive technology is dependent on an exploitative international division of labor?" (130). In this manner, Erevelles reads those theoretical perspectives as idealist that do not foreground the material conditions that give rise to their objects. This is not a theory of ideology as false consciousness. Rather, it is an argument situating the objects of our knowledge and the space of our practical activity within transnational capitalism.

Erevelles evaluates the alternatives to her materialist approach, turning like Siebers to in-vogue theoretical work, here posthumanism. Mirroring her commentary on Haraway, Erevelles argues that posthuman theories of becoming and desire fail to situate their intertwining objects of analysis-be they disability, race, gender, or another form of difference-in the historical conditions that made them what they are. They take us "away from fore-grounding the modes of production, productive forces, and relations of production" (54). For support Erevelles looks to the history and historical legacy of the transatlantic slave trade. In doing so, she situates the history of race alongside the history of disability, but distances herself from a causal association: "Rather than posing a simple causal effect (namely that colonialism produces disability), I argue, on the other hand, that both disability/impairment and race are neither merely biological nor wholly discursive, but rather are historicalmaterialist constructs constitutive of the historical conditions of transnational capitalism.” By this I read that Erevelles is not arguing disability 
or race is an ideological creation with capitalism as its cause, but that transnational capitalism facilitated the conditions whereby race and disability emerged as they did and continue to exist.

Through questions of causality we can distinguish the theorizations of ideology presented thus far, and, subsequently, evaluate their utility for the project of DT and of disability studies more generally. Marx and Engels do not provide a casual theory of ideology because, as Smith and Hall have indicated, they do not have a theory of ideology. They have offered inspiration for various approaches to the problem of ideology, and its relation to material conditions. Oliver establishes a strict causality: capitalism produces disability, and ideology is the result of material conditions. Here, ideology is false consciousness. Smith suggests that the hints left by Marx and Engels produce not just false ideas, but a wholescale epistemology, originating in and departing from the structures of everyday life. This has grounded her and others' standpoint theory and institutional ethnography. Erevelles takes a middle road between Oliver's and Smith's readings, which locate disability within the global political economy, but not fully caused by it. We have a spectrum, then, with Oliver on the one side, Erevelles in the middle, and Smith on the other. The crucial question is, where do we locate Siebers in all of this?

While Siebers uses "ideology" and "the ideology of ability" throughout DT, he does not use the term to suggest that all thought is contained by an inescapable mode of thought, lacking any opportunity for escape. We are not fully captive to the ideology of ability-it offers "social locations outside of itself," explored throughout DT (8). Nor, as Oliver suggests, does Siebers think that ideology is a causal outcome of the dominant material conditions. He would be closer to Erevelles, though her use of "the material" refers more to economic structures than the realism of the body, of design, and of artwork. Oliver and Erevelles read Marx and Engels much more closely than he does. Siebers's ideology of ability is closest, in my reading, to that proposed by Smith and Hall-insofar as he aims to give an account of ideas about disability that we can challenge through collective identity. It is not so much a theory of ideology, but is more a method of problematizing groups of ideas about disability as deficit, abled-bodiedness as natural, and about the baseline against which we judge bodies to be human or not $(D T, 8)$. His ideology is not "false"beliefs about the unworthiness of disabled bodies are as real as it gets. Collective identity is the means to challenge this set of ideas. If this is all we mean by ideology, then Siebers certainly is a theorist of it. What if we 
mean the way that Oliver, Erevelles, or other Marx-influenced theorists of ideology do? By my count, he is not.

My second objection to Siebers's project comes in his reading of poststructuralism. Recall that Siebers's charges against poststructuralist thinkers in DT are threefold. Foucault's discursive frameworks incorporate disability only as a problem of something. It is always captive to biopolitics, to liberal governmentality, to discipline. Judith Butler doesn't sufficiently address the materiality of the body as she purports to, as seen in the case of pain. Donna Haraway's cyborg theory ultimately supports the ideologically underpinned belief that disability must always be shadow to ability. The cyborg is never really disabled. Rather than focus on the entirety of poststructuralism, I focus on Foucault.

My reading of Foucault differs from Siebers's reading. His reading of Foucault is one that gives primary efficacy to the linguistic component of the discursive apparatuses so central to his thought. Siebers reads him as a theorist of language, of descriptors, of abstract discourse. Foucault did, of course, emphasize the space of discursive formation in his early archaeological work, whereby particular statements are incorporated "within the true" (Foucault, "Discourse," 16). DT takes Discipline and Punish as emblematic of Foucault's work, suggesting that its history of carceral institutions presents an underlying need to reclaim an older, more original, entity (Foucault, Discipline). In Discipline and Punish, "Foucault's account is a not so subtle reading of the fall in which wellbeing and ability are sacrificed to enter the modern age" $\left(D T, 5^{8)}\right.$. It is a story of lost innocence.

I suggest that by looking to Foucault's adjacent work, and reading him as a historian, the picture changes. Take The Birth of The Clinic (Foucault, Clinic). Foucault's interest there is to uncover the shifting conditions through which disease can be known and acted on. For most of the eighteenth century, the truth of disease was found in meticulous charts and lists, observed through but distorted by the body it inhabited. Following the French Revolution, we find a practical location of illness within tissues, the stuff of the clinic and the pathology lab. But in charting transformations of medicine, is Foucault necessarily advocating a return to the classical age? No, not any more than Erevelles is advocating a return to the political economy of slavery. Both are at first historical positions, which we can evaluate as beneficial or horrific in hindsight, and adjust our current practices accordingly. Important historiographical concerns remain, about the role of the historian in her tale, and the voices allowed in and left out. Notwithstanding, to read Foucault only 
as a romantic theorist of the Fall is to forget the historical vein running through his work.

With this adjusted reading of Foucault, I suggest that he offers numerous concepts that are of use to Siebers's project. Both thinkers are fundamentally concerned with the contested politics of naming in collective action. A particularly good example comes in Anne McGuire's War on Autism. McGuire's object of inquiry is not solely the various ways that we have addressed autism historically, and in the historical present, but also an exploration of the kinds of voices we hear in the name of autism. We hear, on a daily basis, the bio-economic loss "caused by autism," taking out of lives and pockets, and the public health "crisis" it causes, the "epidemic" that must be stopped. These are the claims of advocacy against autism, fixing minds and brains, charting a future free from autism. McGuire's goal is to temper this totalizing discourse with the work of self-advocates, who, alone and in tandem, are challenging narratives of bio-economic loss with those centred on the living, breathing, neuro-diverse lives they are living, and in which they might flourish on their own terms if allowed. This claiming, disputing, granting, and denial of identity is extremely similar to the project Siebers pursues in $D T$. The difference lies in the reading of Foucault.

\section{Conclusion}

Tobin Siebers's project in disability theory (both the book and the theory) was to tie together various theoretical positions and make a case for collective identity. While I have taken minor objection to some of the concepts used in his narrative, the goal remains the same: to take stock of the field of disability studies and to provide a grounding for future work and future disability politics both in theory and practice. Siebers was and remains correct that the ultimate goal of action-in-concert must remain in our sights, while also telling us that a careful reading of antiquated theory can get us there. Identity politics might be out of fashion, but that does not matter. While I have questioned exactly how ideological the ideology of ability was in comparison to the alternatives-more than some, less than others-identity and collective politics are the means to overcome it. If this is the goal, then sharing concepts with fellow travelers in poststructuralism can only be of benefit to the project, so long as potential collaboration exists. My belief is that it does.

Throughout Disability Theory Siebers consistently argues that the ideology of ability is real. It is not an illusion that distorts a more real under- 
lying structure. It is as real as an accessible entrance next to the garbage cans "just around back," to legal provisions that end at "unreasonable burden" as they do in Canada and elsewhere, and as real as advocacy groups that can only see disability as a bio-economic burden to be made the object of awareness, fought, and then beat. The preference for able bodies is as real as it gets, not simply in our heads or disability studies textbooks, should we be able to afford them. The line between who can be human (and who cannot) is not only the stuff of mental exercise. Where it is located and who it includes is the real problem facing disability studies and its collective political project. To this end, DT is not solely a thing of the past, but a powerful tool needed to continue our upstairs crawl.

\section{Works Cited}

Butler, Judith. Bodies That Matter: On the Discursive Limits of "Sex." New York: Routledge, 1993.

Erevelles, Nirmala. Disability and Difference in Global Contexts: Enabling a Transformative Body Politic. New York: Palgrave Macmillan, 2011.

Foucault, Michel. The Birth of Biopolitics: Lectures at the Collège de France 1978-79. Translated by Graham Burchell. New York: Palgrave Macmillan, 2008.

Foucault, Michel. The Birth of the Clinic. Translated by Alan Sheridan. New York: Pantheon, 1973 .

Foucault, Michel. Discipline and Punish: The Birth of the Prison. Translated by Alan Sheridan. New York: Vintage, 1977.

Foucault, Michel. “Orders of Discourse." Social Science Information 10 (1971): 7-3o.

Hall, Stuart. "The Problem of Ideology-Marxism without Guarantees." Journal of Communication Inquiry 10, no. 2 (June 1986): 28-44.

Hamraie, Aimi, and Kelly Fritsch. "Crip Technoscience Manifesto." Catalyst: Feminism, Theory, Technoscience 5, no. 1 (2019): 1-34.

Haraway, Donna. Simians, Cyborgs and Women: The Reinvention of Nature. New York: Routledge, 1991.

Marx, Karl, and Friedrich Engels. The German Ideology: Including Theses on Feuerbach. Amherst, NY: Prometheus Books, 1998.

McGuire, Anne. War on Autism: On the Cultural Logic of Normative Violence. Ann Arbor: University of Michigan Press, 2016.

Oliver, Michael. "Capitalism, Disability, and Ideology: A Materialist Critique of the Normalization Principle.” In A Quarter-Century of Normalization and Social Role Valorization: Evolution and Impact, edited by Robert J. Flynn and Raymond A. Lemay, 163-72. Ottawa, ON: University of Ottawa Press, 1999.

Oliver, Michael. The Politics of Disablement. Macmillan, 1990.

Puar, Jasbir K. The Right to Maim: Debility, Capacity, Disability. Durham, NC: Duke University Press, 2017.

Reynolds, Joel Michael. “I'd Rather Be Dead Than Disabled'—the Ableist Con- 
flation and the Meanings of Disability." Review of Communication 17, no. 3 (July 2017): 149-63.

Siebers, Tobin. Disability Aesthetics. Ann Arbor: University of Michigan Press, 2010.

Siebers, Tobin. Disability Theory. Ann Arbor: University of Michigan Press, 2008.

Siebers, Tobin. "Review of Eugene Goodheart, The Reign of Ideology." Modern Philology 96, no. 4 (1999): 56o-63.

Smith, Dorothy. "Ideology, Science and Social Relations: A Reinterpretation of Marx's Epistemology." European Journal of Social Theory 7 (2004): 445-62.

Titchkosky, Tanya. "The Cost of Counting Disability: The Production of a NonEconomic Remainder.” In Critical Readings in Interdisciplinary Disability Studies, edited by Linda Ware, 25-5o. Cham, Switzerland: Springer, 2020.

Titchkosky, Tanya, and Rod Michalko. "The Body as the Problem of Individuality: A Phenomenological Disability Studies Approach.” In Disability and Social Theory: New Directions and Developments, edited by Dan Goodley, Bill Hughes, and Lennard Davis, 127-42. New York: Palgrave Macmillan, 2012. 
PART III

Aesthetics 


\title{
SIX | Words and Images: Networks of Relationality in Deaf, Blind, and DeafBlind Aesthetics
}

\author{
REBECCA SANCHEZ
}

This chapter is about words and images, about the sites where the distinction between them is unstable, and about the insights into novel forms of relation to both aesthetics and other humans that such sites of slippage engender. In Disability Aesthetics, Tobin Siebers repeatedly frames words and images as distinct and in conflict: "in the battle between word and images, images are always found excessive or defective"; "visibility and the disabled body are closely linked"; "in the war between word and image, the image plays the role of disabled soldier. It loses the battle every time" $(122,127,133)$. Across the contexts in which these arguments emerge, Siebers importantly calls attention to connections that have long been made between visual images and disability or deformity. But the firm distinctions established in these claims do not hold in many disability contexts. Deaf, Bind, and DeafBlind people, for instance, often find themselves translating and transmediating between visual, audio, and tactile information.

Such reconfigurations of sensory and other physiological apparatuses to process information and perform tasks in nonnormative ways are central to what is perhaps Siebers's most frequently quoted passage:

The disabled body changes the processes of representation itself. Blind hands envision the faces of old acquaintances. Deaf eyes listen to public television. Tongues touch-type letters home to Mom 
and Dad. Feet wash the breakfast dishes. Mouths sign autographs. Different bodies require and create new modes of representation. (Disability Theory, 54)

These "new modes of representation" demand new analysis of the relation between word and image. They also demand and produce new (or undertheorized) forms of relationality-between humans, between humans and aesthetic works, and between humans and their environments. In Disability Aesthetics, Siebers invites us to "apply to words the theories and methods of visual studies" (122). In what follows, I'd like to take up that project by considering a range of works by Deaf, Blind, and DeafBlind artists and writers that illustrate the complex theorization of the relation between words, images, and bodies that has long been occurring in sites where the movement between visual, audio, and tactile information is a project of both aesthetics and access.

Signed languages themselves present one rich example of such intersections. In signed languages, words are both images in motion, perceived either visually or tactilely, and grammatical units (each consisting, in their visual forms, of five parameters). It's not just that words in signed languages can describe images ekphrastically (though they may sometimes be used in this way); they can embody images, make them present in four-dimensional space. Words and images also interpenetrate in image and audio description, wherein visual information is encoded in words that may be listened to or read tactilely.

Much signed language art self-reflexively engages the implications of this overlap. The Flying Words Project's ars poetica "Poetry," for instance, defines poetics as a series of images in motion: a beating heart that morphs into the ASL sign "poetry," a bullet that travels around the world, a forest full of trees and bushes. At one point in the text, the poetic signer paints a portrait, portraying both the artist and the image on the canvas as it emerges from the brush strokes. Poetry, the poem argues, is the particular way in which signed languages bring images into being, the way ideas are imaged in signs and visual vernacular; the texture, pattern, and motion of the trees and bushes in the forest the signer creates, the rhythm of flapping bird wings.

Significantly, those images are not only in motion but embodied by the poetic signer (and, literally, the poet). As I've argued elsewhere, the interpenetration of text and author (Peter Cook, who signs the poem, embodies both the painter in the scene and the painting, forest, and bird) has ethical implications (Sanchez). By presenting objects as ani- 
mate, audiences develop connections to them. When the artist in the poem crumples his creation and audiences watch the painting struggle against impending oblivion, the moment is surprisingly touching. By animating the painting, the poetic signer creates an opportunity for audiences to affectively connect to entities across levels of animacy. As Mel Chen has argued, there are numerous relational and ethical implications we might derive from sites where the "fragile division between animate and inanimate" is not so "relentlessly produced and policed" (2). As one example, "Poetry," in addition to presenting the relation between humans and nonhuman beings in novel ways, also offers a human subject that is intriguingly permeable, an assemblage of image, word, poem, poetic signer, and poet.

Where Peter Cook and Kenny Lerner give us the word as painting, as image, in "Two Books," the British Sign Language (BSL) poet Paul Scott gives us image as text. In the poem a shopper enters a bookshop and is met with books that come alive, revealing their contents in BSL and attempting to convince the shopper to purchase them. "For deaf people," Scott elaborated in correspondence with Rachel Sutton-Spence and Ronice Muller de Quadros, "I am the book" (546). Through a language inseparable from his body, Scott translates the written contents of the books into linguistic images. A vital component of that translation is role shifting, a grammatical feature of signed languages that indexes who or what is providing the perspective of a particular bit of signing. Signers shift body position, eye line, and other nonmanual signifiers to indicate the differences between subjects or objects involved in direct address. Scott's statement points toward the ways that operating in languages that involve conditioning people to imagine scenes from the perspective of other subjects (as well, as demonstrated in "Poetry," as entities occupying a range of animacy levels) may offer a new understanding of the human subject. "I am the book" is both a literal and figurative truth about the role of the poetic signer or narrator in signed literature and an assertion of an alternative understanding of animacy hierarchies. I am the book, the book is me, the book is animate. Or, put differently, part of the effect of "new representational strategies" as they emerge at crip sites where words and images are entwined seems to be an understanding of the human that is enmeshed in its environment.

This kind of expanded sense of self, which we might describe in terms of distributed agency, is similarly central to the DeafBlind literary practices John Lee Clark presents in "Order," quoted below in its entirety: 
We break our story into eight parts because there are eight of us to tell it tonight. It is our job to be one-eighths of ourselves. We break our audience into eight clusters. We shift from cluster to cluster. We don't do rows. We don't do circles. What we do is cellular structure. We are a living biology. Every part is different each time. Each cluster is different every time. The story is the same. We have been broken so many times we are unbreakable. We have been forced apart so many times we are always whole. That is our story. We are growing smaller and smaller and larger and larger at the same time. It doesn't matter in what order we get everything. It only matters that we get everything.

Like Scott's understanding that "I am the book," Clark's poetic "we" is the story, each person comprising both one-eighth of it so as to be able to communicate ProTactilely one to one, without distance, their part to an audience member. Here, the individual subject is interpenetrated both by the story and by the other tellers, with whom she makes up the story's whole. In that individual tactile contact, through the processes of producing language in and on another's hands, on their body, the individual subject is simultaneously specifically_complexly_embodied and also more porous, "larger and larger" than the individual self.

The process disrupts the conventional linear movement of spoken and written language, insisting on a cellular, rhizomatic, structure. The "we" is the story, the linguistic content of which is inseparable from the extralinguistic information transmitted by bodies in contact including, potentially, the size and shape and roughness of one's hands (which may encode additional information about age and occupation), the fabric of one's clothes (which may indicate something about one's gender presentation, age, socioeconomic class), the dialect and fluency of one's signing (which may suggest one's educational background, area of geographic origin, and access to the Deaf community), the familiarity with ProTactile language (which may indicate one's connection to the DeafBlind community). But it is also the case that, as in all "oral" (storytelling) cultures, the story moves beyond the individual; "Every part is different every time. Every cluster is different every time. The story is the same." Without losing track of the concrete realities of particular bodies, individual humans are also decentered as just one part of the network that is the story.

As Clark's poem demonstrates, sites of word/image interpenetration reveal the overlap between human and text as well as that between humans themselves. These boundary blurrings are not confined to 
embodied languages like ASL, BSL, and ProTactile, but can also be observed in textual and aural language that emerges in contexts of transmediation such as audio and image description. Audio description aims to capture significant visual information in a moving scene (as image description does for static ones)-film, television, dance, theater-and to translate that information into text, which is usually accessed through a recorded track (though it is sometimes provided in formats that can also be rendered in digital Braille).

The increase in production of such description in recent years (and the professionalization of the field of audio describers that has accompanied this) has led to the standardization of certain presumed best practices in description recording that are deeply revealing of our assumptions about human sensory perception and the relationship between types of sensory information. Perhaps the most controversial of these is the call of neutrality in description. The American Federation of the Blind's audio description project, for instance, explains that a describer should "describe what you see without interpretation or personal comment."

This attempt to minimize interpretation or intervention on the part of the describer that might interfere with the transmission of the "content" of the visual images closely parallels a model of signed language interpreting known as the "machine model" that, until quite recently, was the de facto theory of signed language interpretation in the United States. The machine or conduit model arose as a reaction to the prior dominance of what is sometimes called the "helper" model, in which interpreters attempted to add or subtract information to the content they were interpreting in order to bring the message in line with their assumptions about deaf clients' level of understanding and cognitive abilities. ${ }^{1}$ The machine model was intended to remove such paternalism from the process by emphasizing the importance of relaying informational content as received and nothing more, as though interpreters were not themselves humans existing in the linguistic space of the exchange, whose own embodiment (as with the complex embodiments of the conversational participants) always already alters the meaning of the message.

Both the audio description as neutral and the machine model of interpreting draw heavily on what in communication studies is described as the "transmission model of communication." The transmission model is widely criticized as overly simplistic precisely because of its failure to register the complexities of communicative exchange (from which the "content" of a message can never be wholly separated), critiques that are 
instructive for the ways we ethically frame the realities of interpersonal communication as they emerge in the context of disability. "Language inevitably comes with connotations and associations that differ from speaker to speaker," Georgina Kleege argues, and it is on these grounds that she pushes back against the fetishization of descriptive neutrality (101). "The insistence on objective neutrality seems to come from an assessment that sighted viewers enjoy an autonomous, unmediated experience of visual media, which is more or less the same from viewer to viewer," she notes. "I . . . have to quibble with the notion that absolute objectivity is possible or even desirable" (101). Similar to critiques of high formalist iterations of close reading-interpret the text and nothing but the text-Kleege's intervention grounds us in the importance of the particularities of individual bodies to interpretive practices. There is no access to images or words that is not mediated by human sensory perception. And, as demonstrated in the contexts of word/image overlap I considered above, increasing rather than reducing our attentiveness to those processes enables us to better consider the complexity of meaningmaking processes surrounding words, images, and bodies.

Part of what occurs when one's access to images is mediated through the description of someone else is that one inhabits a kind of shared intellectual space wherein the content that emerges and that is remembered as constituting the image is derived both from the description user's knowledge and perspectives and those of the describer. For examples of different kinds of knowledges that can be shared in this way-and the different ideas about what constitutes the meaning of an image that follow from them-I will consider Park McArthur and Tina Zavitsanos's description of the painting The Family of Henry VIII (ca. 1545) and Haben Girma's description of a family photo. The McArthur and Zavitsanos description reads as follows:

A painting of King Henry VIII and his family in the center of a large, ornate hall. At each end of the hall, archways that lead outdoors frame the court fools. The family looks forward, posing for their portrait. The king's fools, William and Jane, frown and look away. A monkey is on William's shoulder. All figures appear to present as white and are dressed in the binary gendered clothing specific to their role in the court. (237)

McArthur and Zavitsanos are not experimenting with the form of image descriptions here; there is no explicit pushback against the principle 
of providing a "neutral" account. Because of that, the description is particularly useful in highlighting Kleege's point about the impossibility (and questionable desirability) of neutrality in description. The details McArthur and Zavitsanos note as significant (the direction the figures are facing, the presence of the archways) are things that may well not have occurred to another person viewing the painting. Some information (the names of the court fools, the context for the clothing the figures wear) constitutes a sharing of knowledge that might not be widely known. Encountering such a description (with or without having independent visual access to the painting) enables us to inhabit, for a moment, a shared perspective space with these writers, one that offers insight into their own knowledge, ways of reading images, and priorities.

The time spent encountering this work of art (this visual image) through the description, that is, is time spent in the company of other minds. Through description, images are staged as sites of interpersonal interaction, the meanings of which are inseparable from images themselves. These processes challenge our assumptions about the boundedness of the art object itself. Haben Girma's description of the family photos that accompany her memoir, Haben: The DeafBlind Woman Who Conquered Harvard Law, demonstrate a similar process. Girma's descriptions provide both visual and nonvisual information, highlighting the extent to which photographs of function not just to create an "objective" record of what a person looked like, but to stir a memory, to tell a story. They exist in contexts and providing more of that context in a description is not superfluous to the image's "real" meaning, but essential to it.

In one example from the text, Girma describes a photo of her cousin: "The way Yafet embraces lotion is exactly how he embraces life. My fouryear-old cousin's face is slathered in it, with globs of lotion all over his face, hands, and pajamas." Rather than offering a pretense of neutrality, this description is explicit about its situatedness, offering insight into Girma's relationship with her cousin as well as her own particular use of metaphor (and her sense of humor). Girma's descriptions do not separate out the visual as privileged or wholly distinct from other ways of knowing, other ways that images signify (ways that can, for instance, be converted into text, into words). The description contextualizes both the photo and its subject in networks of relations that expand outward, off the page, and that implicates audiences, whose own interpretations of the image (whether they have independent visual access to it or not) become enmeshed with Girma's.

The deployment of access forms as a means of exploring the poten- 
tial for thinking more broadly about sensory information and the ways it shapes relationality can also be observed in work that experiments with captioning. Captions are traditionally understood to provide access to the dialogue and, at times and inconsistently, additional relevant auditory information in a film or show. As with audio and visual description, creative uses of captions that break away from assumptions about the kinds of information captions can convey (and the kinds of information that are useful for individuals reading them) repeatedly point toward a vital blurring between categories of sensory perception.

This experimentation is foundational to the short film Ode to Pablo, which was directed by Adelina Anthony and produced as part of the 2019 PBS digital film festival. The film tells the story of an encounter between Pablo, a queer, Deaf AfroLatino teenager, and three other young men who join him on a basketball court for a game. The narrative of the film progresses through captions, which transcribe not only the spoken and (at one point) signed dialogue of the characters but push on our understanding of what sound is (the film's soundtrack is distorted so that even hearing audiences must access information at least in part through captions). Pablo's crip presence, to return to Siebers, demands and produces new forms of representation. And what that specifically involves in this film, as in many of the other examples discussed in this chapter, is a synesthetic movement between visual, auditory, tactile, and emotional information in ways that challenge us to reevaluate the ways we conceptualize their relationship.

The captions in Ode to Pablo index a variety of things, some of which are common to the form and others of which are not, providing a selfreflexive commentary on the medium itself. Some captions transcribe background noise, some represent Pablo's thoughts, some highlight things Pablo sees, and some convert the spoken dialogue of other characters into text. Mirroring the camera work, which moves between offering the subjective perspectives of Pablo and Julian (a character with whom Pablo shares a romantic encounter) and an apparently more detached perspective, the captions at times provide access to Pablo's interiority while at others offer audiences information to which he does not have access (for instance, the spoken dialogue of other characters).

Yet other captions more abstractly capture emotional states, explicitly indicating the form as not "merely" compensatory but as offering access to information that would otherwise not be accessible to anyone. "Low rumble" is the caption when the three young men approach Pablo for the first time. "Low rumble with high-pitch ringing" and "low rumble 
continues" after Julian knocks Pablo to the ground to avoid gunshots fired from a passing car. "(Low rumble ends)" is the caption when Julian brings Pablo his phone and headphones, asking why he has the earbuds in if he can't hear the music (Pablo's typed response: "earbuds= passing in your hearing world"). When Miguel (who seems to have a romantic or sexual relationship with Julian) pulls Julian away from Pablo as the the two share a kiss, the caption reads "(panicked low rumble)"; "(low rumble continues)" when Julian attempts to win Pablo back after the altercation with Miguel; and "(low rumble ends) (silence)" when Julian finally walks away after Pablo signs to him (the lines are captioned for nonsigning audiences but are illegible to Julian).

Notably, all of those different kinds of information captured in the film's captions are things that deaf filmgoers normally have to decode based on captions, which typically provide very little beyond dialogue and basic music cues. By experimenting with both the capacity of captions (What visual and emotional information can be captured in words?) and of the genre of short film (What changes about narrative when presented in captions rather than with a standard soundtrack?) Ode to Pablo both critiques limitations in captions as usually deployed and suggests the potential of captions or words, processed visually (or tactilely), to capture information beyond what is traditionally conceived of as auditory.

This expanded understanding of sound can also be observed in Christine Sun Kim's piece "close readings," exhibited in London and Milan in 2015 to 2016 . Kim, a sound artist who is Deaf herself, asked four Deaf friends to provide captions for five famous moments from the films 20or: A Space Odyssey and Disney's The Little Mermaid. Each image is reproduced four times, the screens hung next to one another with the images partially blurred to direct focus to the text of the captions, and each captioner's interpretation was displayed on a separate screen. As in Ode to Pablo, the captions reflect the overlap between auditory and other sensory and spatial information that might be included in the decoding of a sound. In one interpretation of an image from The Little Mermaid, in which there is a close-up of the face of a pouting Ariel and the film's own caption reads "[Sigh]," the added caption reads "(the sound of a problem that is not a problem)." In one close-up of HAL, the caption indicates "(the sound of a light that does not flicker)." These captions, which both are and are not textual representations of sound, make explicitly legible the range of meanings attached to sounds and invite us to think more expansively about the ways we go about making those meanings accessible. 
Just as there is no such thing as neutral image or audio description, there is no such thing as neutral captioning. Such a concept is a misapprehension of the nature of images, sounds, and words, particularly as they intersect and are produced and interpreted by complexly embodied humans. Sounds and images, all of the sites considered in this chapter demonstrate, are not neatly divided out and are not straightforwardly in competition with one another. "Aesthetics," Siebers argues, drawing on the work of Alexander Baumgarten, "tracks the sensation that some bodies feel in the presence of other bodies" (Disability Aesthetics, 7). That grounding of aesthetic theory in embodiment, like the engagement with access forms above, returns us to the centrality of the communicative reality that, to quote Marshall McLuhan, "the medium is the message" (7). And what that involves in Deaf, Blind, and DeafBlind interactions and aesthetic practices that self-reflexively experiment with and comment upon the overlap between words and images is an invitation to reconsider what we thought we knew about words, images, and the ways in which we might relate to them and, through that engagement, to one another.

Note

1. For more information, see Baker-Shenk's "The Interpreter."

Works Cited

"Audio Description Project." American Federation of the Blind. https://www .acb.org/adp/guidelines.html

Baker-Shenk, Charlotte. "The Interpreter: Machine, Advocate, or Ally?” National Consortium of Interpreter Education Centers. 2014. http:/ /www.interpreter education.org/wp-content/uploads/2014/04/The-Interpreter-Machine.pdf

Chen, Mel. Animacies: Biopolitics, Racial Mattering, and Queer Affect. Durham, NC: Duke University Press, 2012.

Clark, John Lee. “Order.” Poetry International Online. https://poetryinternationa lonline.com/roundtable-discussion-on-deaf-poetics

Cook, Peter, and Kenny Lerner. "Poetry.” American Sign Language poem. https:/ / www.youtube.com/watch?v=JnU3U6qEibU\& $\mathrm{t}=129 \mathrm{~s}$

Girma, Haben. Haben: The DeafBlind Woman Who Conquered Harvard Law. New York: Hachette, 2019.

Kim, Christine Sun. "close readings.” Exhibited at the Carroll Fletcher Gallery, London, from 2015 to 2016 and at Galleria Zero in Milan in 2016.

Kleege, Georgina. More Than Meets the Eye: What Blindness Brings to Art. Oxford: Oxford University Press, 2019. 
McArthur, Park, and Constantina Zavitsanos. "The Guild of the Brave Poor Things." In TrapDoor: Trans Cultural Production and the Politics of Visibility, edited by Reina Gossett, Eric A. Stanley, and Johanna Burton. Cambridge: MIT Press, 2017.

McLuhan, Marshall. Understanding Media: The Extensions of Man. 2nd ed. London: Routledge, 2001.

Ode to Pablo. Dir. Adelina Anthony. AdeRisa Productions. 2019. https://www.pbs .org/filmfestival/2019-festival/ode-to-pablo/

Sanchez, Rebecca. Deafening Modernism: Embodied Language and Visual Poetics in American Literature. New York: New York University Press, 2015.

Scott, Paul. "Two Books." British Sign Language poem. https://www.youtube .com/watch?v=DQtpgVSmbOE

Siebers, Tobin. Disability Aesthetics. Ann Arbor: University of Michigan Press, 2010.

Siebers, Tobin. Disability Theory. Ann Arbor: University of Michigan Press, 2008.

Sutton-Spence, Rachel, and Ronice Muller de Quadros. "I Am the Book'-Deaf Poets' Views on Signed Poetry." Journal of Deaf Studies and Education 19, no. 4 (2014): $54^{6-58 .}$ 


\section{SEVEN | Musical Modernism and Its Disability Aesthetics}

JOSEPH N. STRAUS

\section{Siebers's Disability Aesthetics}

Tobin Siebers contends that modern art espouses a disability aesthetics, finding new sorts of beauty in bodies that are fractured, disfigured, and otherwise extraordinary in comparison to bodies that are presumptively normal. According to Siebers (3), the representation of disability is one of modernism's "defining concepts": "Disability aesthetics refuses to recognize the representation of the healthy body-and its definition of harmony, integrity, and beauty - as the sole determination of the aesthetic. Rather, disability aesthetics embraces beauty that seems by traditional standards to be broken, and yet it is not less beautiful but more so, as a result." 1

Whether one thinks of the still shocking depictions of wounded World War I veterans by Otto Dix, or Pablo Picasso's cubist portraits of fractured bodies, or the asymmetrical, disfigured bodies in the Viennese expressionism of Egon Schiele and others, or the large number of paintings and sculptures in the first half of the twentieth century that depict strange or distorted bodies, it does seem as though Siebers is right to ask, "To what concept, other than the idea of disability, might be referred modern art's love affair with misshapen and twisted bodies, stunning variety of human forms, intense representation of traumatic injury and psychological alienation, and unyielding preoccupation with wounds and tormented flesh?" (Siebers, 4). 
For Siebers and other scholars of modernism in the arts, disability functions as an artistic resource: a source of images and an impetus for narrative. Disability is not a deficit to be filled, an obstacle to be overcome, or a deviation to be avoided; rather, it is a desirable and defining artistic quality. To put it most simply, disability enables artistic modernism. Disability scholars and activists speak of claiming disability, that is, of destigmatizing it and choosing it as an affirmative political, social, and cultural identity. ${ }^{2}$ In that sense, modernist art claims disability as an aspect of its disability aesthetics.

Modernist art aestheticizes disability into new forms of beauty. Aestheticizing disability does not mean prettifying it, or normalizing it to conform to traditional standards of beauty, however. Rather, it means the significant broadening and, in some cases, the radical subversion and disruption of traditional notions of beauty. Artworks that exemplify an aesthetics of disability may thus "turn traditional conceptions of aesthetic beauty away from ideas of the natural and healthy body" (Siebers, 134) and toward bodies that are deformed, disfigured, fractured, fragmented, and thus disabled. In short, modernist art bends beauty in the direction of disability.

Siebers claims bluntly that "the modern in art manifests itself as disability" (140). Is it possible to make a similar claim about modernist music? Can we say that the modern in music manifests itself as disability? Can we say that modernist music has a fundamental interest in representing the disabled human body? Can we say that modernist music claims disability?

In what follows, I will argue the affirmative for each of these questions. The sorts of qualities that make music distinctively modern-forms made of discrete blocks, stratified textures, immobile harmonies, radical simplification of materials, juxtaposition of seemingly incommensurable elements, extremes of internal complexity and self-reference-can be understood as representations of disabled bodies. Modernist music does many things, of course, and for many different reasons, but it maintains a fundamental interest in disability. In moving disability representation from a stigmatized periphery to a valorized center of artistic expression, modernist music claims disability. ${ }^{3}$

Modernist music claims disability by making it a central concern and drawing on it as a valuable source of new kinds of musical combinations and musical effects. But the specific manner in which it stakes that claim varies quite a lot. The claim of disability is made amid-sometimes in defiance of and sometimes in compliance with-traditional stigmatizing 
attitudes toward disability, given added weight during a eugenic era. As a result, modernist representations of disability are often complex, riven with conflicts and internal contradictions. Amid these crosscurrents, however, we often find in modernist music some sense of pleasure in and celebration of the disabled body.

\section{Locating Cultural Modernism within the History of Disability}

In the very broadest historical terms, there are three ways of conceptualizing disability, each of which is deeply intertwined with representational regimes in literature and the arts, including music. First, in the religious model, which begins with the first recorded discussions of disability and persists to some extent to the present day, disability is understood as an outward mark of divine disfavor or sinfulness or, in some cases, of transcendent spirituality.

Second, in a medical model that gathers force through the nineteenth century and achieves epistemological hegemony in the early twentieth century, disability is understood as a pathological condition that inheres in a body or mind, and which it is the task of medical professionals (physicians or psychiatrists) to diagnose and, if possible, to normalize or cure. Within the medical model, two apparently contradictory, but actually complementary, approaches came to dominate thinking about disability in the first half of the twentieth century. On one hand, this period coincides with what Henri-Jacques Stiker calls "the birth of rehabilitation.” In response especially to the carnage of the Great War, medical science and medical institutions turn their attention increasingly toward the normalization and possible cure of physical and psychic wounds. On the other hand, a eugenic approach achieves unprecedented influence. As a result, people with disabilities, especially cognitive and emotional disabilities, were widely understood as a menace to the health of the community and nation, and were incarcerated in institutions, sometimes sterilized, and often left to die of neglect in appalling conditions. ${ }^{4}$

Cultural modernism emerges in an eliminationist, eugenic age, and its disability representations often bespeak a corresponding horror and fear of the nonnormative body or mind. As Siebers observes, "eugenics weds medical science to a disgust with mental and physical variation" (27). These apparently contradictory responses, both aspects of the medical model of disability, are two complementary features of what Rosemarie Garland-Thomson (2004) calls the "cultural logic of euthanasia": the imperative either to normalize disabled bodies (through 
medical intervention) or to eliminate them (either by sequestration in institutions or in more direct ways) — "cure or kill," in a widely used phrase. Rehabilitation points toward normalization or cure, eugenics points toward elimination, and both involve a desire to see disability and disabled bodies disappear.

A third model, with roots in the earlier twentieth century and a dramatic flowering beginning in the 1970 ond 1980 os, sees disability as a social and cultural formation. In this model, disability is valorized rather than stigmatized, and may be affirmatively claimed as a personal and political identity. The decline of cultural modernism coincides with the end of the eugenic age, symbolized by the late twentieth-century deinstitutionalization of people classified as mad or feebleminded. The sociocultural model of disability has flourished in a postmodern cultural world, after the passing of high cultural modernism. Nonetheless, in its incipient embrace of disability aesthetics, the origins of a valorizing attitude toward disability may be traced right into the heart of cultural modernism in all of the arts, including music.

Cultural modernism expresses a deeply ambivalent attitude toward disability. On one side, we find the medical model of disability and the cultural logic of euthanasia. At the same time, modernist artists, writers, and composers are aware of disability as a resource for artistic creativity, simultaneously a liberating way of shattering conventions and of establishing radically new canons of beauty. In modernist art as in the societies from which it arose, disability is thus simultaneously a focus of pity (leading to normalization or cure), horror (leading to segregation and institutionalization), and fascination (leading to valorization and celebration). These contending impulses are apparent in all forms of cultural modernism. The affirmative claim of disability always contends with the cultural logic of euthanasia.

\section{Modernist Musical Representations of Disability}

Music consists of nothing but tones and is thus self-evidently nonrepresentational. And yet music has been widely understood as involving actors, agents, and characters in an unfolding drama. Music, even untexted, instrumental music, can tell stories and can make meanings. Indeed, the inference of narrative and meaning from purely musical sounds is an ancient tradition. Inevitably, those stories and those meanings will be somewhat fragile and insubstantial, untethered by language or visual images, and their interpretation will necessarily be metaphori- 
cal, as we transfer knowledge from the musical to the linguistic domain. But we can achieve some degree of stability if we draw on metaphors that have commonly accreted around music in the published theoretical or popular literature. One particularly common and relevant metaphor understands musical works as bodies, as living, sentient beings with form and motion, and often with blood, organs, limbs, and skin as well. In some cases, the bodies at issue may seem to incorporate disabilities.

Within modernist music generally, very much including nontexted instrumental music, the musical body is frequently understood as disabled by, or representative of, five disability conditions: deformation/ disfigurement, paralysis/mobility impairment, madness, idiocy ("feeblemindedness"), and autism. This list is not exhaustive or definitive, and many of the musical phenomena I discuss might well be described under more than one of these rubrics. Two of these disabilities are primarily of the physical body (deformity/disfigurement and mobility impairment) and three are primarily of the mind (madness, idiocy, and autism), but all are disabilities, understood as culturally stigmatized differences from established norms in appearance or functioning, or both. Modernist music is replete with and distinguished by its representation of these five disability conditions.

\section{Deformity/Disfigurement}

For most of recorded human history, deformity and disfigurement have been understood in religious or spiritual terms, as a punishment for sin and an outward mark of an inner evil. Beginning in the early nineteenth century, and greatly accelerated by the appearance in the public space of wounded veterans of increasingly devastating wars, bodily deformities are increasingly medicalized, to be remediated through surgical or other medical interventions or normalized with prostheses.

At the turn of the twentieth century, coincident with the rise of cultural modernism, the history of deformity/disfigurement observes both impulses within the cultural logic of euthanasia, toward normalization (cure) or elimination (kill). First, in response to the shocking severity and pervasiveness of combat-related wounds inflicted during World War I, society proposes a regime of rehabilitation, of medicalized eradication of deficiency. As noted above, this is what Stiker (2000) refers to as "the birth of rehabilitation." He observes, "The war-injured will take the place of the disabled; the image of disability will become one of an insufficiency to be made good, a deficiency to eradicate" (124). The second decade of the twentieth century thus marks a culmination of the 
medicalization of deformity/disfigurement, with a broad societal commitment to normalization via rehabilitation, understood as a medicalized regime to eradicate bodily deficiency.

At the same time, the early decades of the twentieth century witness a sharply negative, stigmatizing response to visible bodily anomalies. Starting in the second half of the nineteenth century, various cities in the United States enacted what were known as "ugly laws." Partly in response to wounded veterans from a previous, devastating war, the American Civil War, San Francisco in 1867 banned from its public spaces "any person who is diseased, maimed, mutilated, or in any way deformed so as to be an unsightly or disgusting object." Similarly, in 1911, Chicago prohibited "exposure of diseased, mutilated, or deformed portions of the body." ${ }^{5}$ Cultural modernism thus arises at a time of deep societal antipathy toward deformed bodies.

Deformity and disfigurement enter modernist music as the shattering of traditional norms of formal continuity: the modernist musical body is fractured, deformed, and grotesque. ${ }^{6}$ The extensive literature on modernism in the arts identifies "fragmentation" as a central, defining feature. Many modernist works prefer a collage-like juxtaposition of discrete parts to the more continuous forms of the classic-romantic tradition. Works like that have a feeling of being shattered, fractured, or dismembered. In Igor Stravinsky's music, for example, this phenomenon is called "block juxtaposition" or "splinterdness," and this fracturing of musical form is widespread in modernist music, with its apogee in the music of Charles Ives and Edgard Varèse. ${ }^{7}$

In the real world, deformation and disfigurement usually evoke pity or horror, and the same is true to some extent in the arts, including music. Modernist artists of all kinds have used deformity and disfigurement for their shock value and to scandalize a bourgeois audience. Representations of disability in modernist music frequently draw on familiar and stigmatizing tropes. But formal fragmentation and deformation often have a positive aesthetic value in modernist music. By deploying its fractured forms and fragmented textures as a sign of liberation from conventional restrictions, modernist music often claims deformity and disfigurement as a valuable and aesthetically desirable resource.

\section{Paralysis/Mobility Impairment}

The history of mobility impairment closely tracks the history of deformity/disfigurement, but now we are talking about bodily functioning rather than appearance. This disability, traditionally understood in 
religious terms ("the halt and the lame"), is increasingly medicalized throughout the nineteenth century, spurred by the wounds experienced by the combatants in increasingly destructive wars. With the Great War, Stiker's "birth of rehabilitation" signals the hegemony of the medical model, with its emphasis on normalization (in part through the use of increasingly sophisticated prostheses). And we find the same eugenic-era bifurcation of attitudes of pity and fear.

The idea of motion - usually toward climaxes or cadences-plays a central role in traditional canons of musical beauty. But modernist music very frequently prefers harmonies that are relatively static, turning in on themselves, lacking a sense of direction, circular rather than teleological (Claude Debussy, Stravinsky). The time of modernist music is relatively nonlinear, preferring a sense of simultaneity to a sense of one thing leading purposefully toward a logical successor: instead of one chord leading to another, their notes may be commingled. ${ }^{8}$

In modernist music, which usually avoids both the resolution of dissonance as a means to impel motion and the traditional linear progression as a means to direct motion, the harmony may appear relatively immobile. In the music of many modernist composers, harmonic immobility is related in part to a preference for inversional symmetry, that is, for chords that are mirror images of themselves, with the same intervals from top to bottom as from bottom to top-palindromes in register (Stravinsky, Béla Bartók, Arnold Schoenberg, Anton Webern). Just as deformation results from an apparent deficit of (formal) symmetry, immobility may result from an apparent excess of (inversional) symmetry.

The relative immobility of modernist music has inspired a strong reaction of horror among anti-modernist critics. Heinrich Schenker is the most extreme example-he repeatedly describes the inhibition of musical motion toward predefined goals as a form of "paralysis." 9 Observing a cultural logic of euthanasia, they have argued that if this music cannot be cured of its defects, it should be eradicated entirely from the corpus of great music. But for modernist composers, the disability of mobility impairment has often seemed a valuable artistic resource. If sounds are freed from their conventional obligations, no longer compelled to move in foreordained ways toward prescribed goals, they can be enjoyed on their own terms rather than as part of a directed continuity. Stasis (nonlinearity, simultaneity) then becomes a source of liberation and a cause for celebration. In that sense, with its static (often inversionally symmetrical) harmonies, modernist music claims mobility impairment as a valuable resource and a mark of its disability aesthetics. 


\section{Madness}

Throughout human history, some people have "heard voices," that is, have heard verbal utterances in the absence of any actual external source. ${ }^{10}$ Traditionally, such voices were understood within a religious framework, as something either divine or demonic, and associated with madness in either case. In the mid-nineteenth century, however, in tandem with other disabilities, this experience falls increasingly under the control of medical science. Under the medical model, the experience of hearing voices was pathologized as "aural hallucination," and understood as a symptom of mental illness, especially schizophrenia (a diagnostic category created by Eugen Bleuler in 1908). ${ }^{11}$ Indeed, one might argue that the category of schizophrenia was created, in part, to provide a diagnostic home for the phenomenon of hearing voices.

As with physical disabilities, mental disabilities are brought fully under the medical regime during the first decades of the twentieth century. This is the period when the idea of "mental illness" is consolidated-the culturally contingent idea that affect and behavior that deviate from normative standards are disease entities that require diagnosis and remediation from medical professionals. This is also the eugenic era of psychiatry, marked by a transition from the hope of cure via "moral education" to the pessimism of large institutions designed primarily for segregation of an undesirable population. Just at the moment that rehabilitation gains momentum for physical impairments, it is increasingly abandoned as an ideal for psychiatric disorders, for which horror increasingly trumps pity in the broader societal response.

Both schizophrenia and modernist art and music are centrally concerned with the splitting of consciousness, of which hearing voices is the epitome and conspicuous outward mark. Modernist art and literature frequently explore multiple perspectives, with a cacophony of competing narrative voices and extreme heterogeneity of style and content. In modernist music, quotation practices that involve an ambient atonality and the sharp intrusion of traditional tonal references give a vivid impression of heard voices (Schoenberg, Alban Berg, Ives).

In modernist music, these heard voices involve different sorts of disability representations and elicit different sorts of responses. The voices may seem threatening in some way, a sign of some deep disturbance. Certainly they have been apprehended in eugenic mode by critics who hear in the voices a threat to the treasured coherence of the musical work. Music theorists and analysts have been particularly concerned with 
containing the threat posed by the heard voices, and demonstrating the ways in which they are subsumed and normalized musically. But while heard voices may sometimes be understood in eugenic mode, the music often makes possible a different approach. The voices often appear welcome in some way-not a threat to be contained but the bearers of wisdom. Or, the voices may originate from the beloved dead, and may be heard nostalgically. The urge to normalize these voices-to cure them as though they were a sickness of some kind-is common in critical commentaries, but modernist music often makes possible hearings in which the voices, and the division in consciousness they signal and enforce, are celebrated on their own terms, as a manifestation of disability aesthetics.

Even in the absence of quotation, modernist music frequently stratifies the musical texture into discrete layers (Stravinsky, Bartók, Ruth Crawford-Seeger). These layers are often identified by different, clashing centric tones (an effect sometimes referred to as bitonal), and are further differentiated by distinctive internal rhythms and a lack of rhythmic coordination among the layers. Furthermore, neither layer functions as a ground for the other's figure, or as a norm for the other's deviation; rather, the layers are heard as independent and self-sufficient, and the piece that contains them is irrevocably divided. In some cases, the division is felt as a disabling wound that elicits a response in eugenic mode: emotional horror and a desire to normalize or somehow eliminate. More commonly, however, such bifurcations of musical consciousness elicit a more realistic response: these divisions represent difference, not deficit, and are among the new forms of beauty provided by musical modernism. That is the sense in which musical modernism claims madness-as a way of overthrowing stultifying traditions and as a source of new forms of beauty.

Stylistically, many modernist musical works incorporate an apparent jumble of contrasting musical styles, with jarring juxtapositions of low and high, as folk or popular music mingles with more learned styles. This stylistic heterogeneity produces stratified musical textures, just as formal splinteredness and discontinuity produce fractured forms. When one of the layers is made up of quoted material, this "heard voice" may provoke in analysts a therapeutic urge, a desire to rationalize it in relation to its surroundings. Analysts have often tried to insist that, despite their apparent source outside the frame of the piece, these quotations are nonetheless organically integrated into the fabric of the piece.

Other times, however, the music seems to suggest that different voices may coexist without the need for reconciliation or cure, as a valu- 
able component of a new modernist aesthetic of divided consciousness. The heard voices signal a radical divergence from the hegemony of a unified Romantic organicism, and have the potential to help rewrite familiar scripts of mental disorder. In some works, the heard voices may have a dark and menacing quality, eliciting a response in eugenic or exotic mode. But more commonly, modernist music uses its divided consciousness, realized in stratified textures, often reinforced with bitonal effects and extreme quotation practices, to claim madness as a valuable resource and a new source of beauty.

\section{Idiocy}

Over the course of the nineteenth century, idiocy was gradually split off conceptually from madness: both are characterized by a deficiency of reason, but madness came to be understood as acquired and temporary, while idiocy was inborn and permanent. In nineteenth-century literary representations of idiots, the most prevalent type is the Holy Fool, whose intellectual deficiency is compensated for by a purity of understanding and a deeper, if inarticulate, wisdom. In works by William Wordsworth, Charles Dickens, and Fyodor Dostoevsky, idiot characters are associated with a series of literary tropes: they are authentic and sincere; uncivilized and primitive; prelinguistic and prerational; natural and animal-like; childlike and innocent. They inspire pity and an impulse of care.

In the eugenic age of the early twentieth century, there was widespread concern with a perceived "menace of the moron," a fear that idiocy-literally a breeding ground for criminality and promiscuitywould undermine and demoralize an otherwise healthy social body. The result was a proliferation of institutions for the "feebleminded," designed to segregate rather than to remediate. In modernist literary representations like William Faulkner's Benjy and John Steinbeck's Lenny (note the diminutive quality of these names), while some vestiges of the Holy Fool trope remain, the idiot now projects an aura of menace or violence, especially sexual violence, and inspires horror and an impulse to kill or incarcerate.

In modernist music, idiocy is represented by an extreme simplification of melody, harmony, rhythm, and texture (Erik Satie, Stravinsky, Virgil Thomson). As in literary representations, idiocy in music may connote a wise simplicity (in association with the natural, the pastoral, the folk, the childlike) or, more darkly, the menace of the feebleminded (in association with the primitive). 
The normally abled musical body maintains a reasonably high level of intellectual complexity (especially in its counterpoint and voice leading). The disabled modernist musical body is deliberately emptied out, stripped of its contrapuntal complexity; it is static and repetitive. As a result, it has often seemed to its detractors to be comparatively simpleminded (Theodor Adorno's terms for this sort of simplification in Stravinsky's music are "primitive," "childish," "regressive" and "infantile.") But modernist composers have found in idiocy a rich compositional resource, both as a way of deflating the grandiose pretentions of late nineteenth-century Romanticism and as a source of directness, authenticity, and sincerity, and, more darkly, as a window into the "primitive mind." Insofar as it is interested in extreme simplification, with a corresponding emphasis on the natural, the childlike, the folk, and the primitive, modernist music claims idiocy as a valuable resource and thus affirms a disability aesthetics.

\section{Autism}

The term "autism" originated in 1908 with Eugen Bleuler, as part of his constitution of the diagnostic category of schizophrenia, with autism understood as "detachment from reality, together with the relative and absolute predominance of the inner life" ("Dementia Praecox," 354). In 1943, Leo Kanner appropriated the term to refer to a group of children whose behavior he distinguished in two ways from other forms of madness or idiocy. ${ }^{12}$ First, there was an unusual degree of social isolation, which Kanner refers to as "an extreme autistic aloneness that, whenever possible, disregards, ignores, shuts out anything that comes to the child from the outside." Second, there was an unusual rigidity and aversion to any change in habit or routine, what Kanner referred to as "autistic sameness": "[The children shared an] inability to relate themselves in the ordinary way to people and situations [and an] anxiously excessive desire for the maintenance of sameness." Autism has experienced a spectacular rise in diagnostic prevalence since the 1990s, but it has its roots firmly in an earlier period, namely the period of the musical modernism under discussion in this essay. In discussing the music of that earlier period, I rely on contemporary conceptualizations of autism, which may seem punishingly stigmatizing in the present age of neurodiversity and autism activism.

In modernist literature, art, and music, autistic aloneness manifests itself as self-reference, recursion, radical subjectivity, withdrawal from social consensus, withdrawal from consensual language, hermeticism, 
autonomy, subjective self-reliance, and inwardness (all of these qualities are featured in the vast literature on cultural modernism). Modernist musical works are relatively contextual (Milton Babbitt's term): they have a wealth (some would say a surplus) of internal relations but relatively few external ones (Babbitt). Robert Morgan's description of the hermeticism of modernist musical discourse, focused on Schoenberg but with broader relevance, emphasizes its resistance to communal communication and its insistence on private meanings and thus its autistic "aloneness": "Music became an incantation, a language of ritual that, just because of its inscrutability, revealed secrets hidden from normal understanding" (Morgan, $45^{8}$ ). The wealth of modernist music's internal relations often gives the impression of extreme complexity and difficulty (Schoenberg, Webern, Berg, Babbitt, Pierre Boulez). Its autistic aloneness manifests itself as a tough, thorny surface that simultaneously conceals and reveals an unusual complexity of internal, contextual relationships.

The complexity of some modernist music reinforces its aloneness, its isolation from listeners, its relative inaccessibility. In a familiar criticism, modernist music is likened to a built environment (a space, a building, a room) to which normal, conventional listeners cannot gain access. Musical innovations and difficulties, in this view, create an impermeable barrier to access. A thorny, forbidding exterior conceals the inner meaning (in contrast to the more conventional arrangement in which the musical surface reflects and manifests-gives transparent access to-the structural depths). These sorts of metaphors-an impenetrable wall of incomprehensible signs that prevents access to an inner life-are extraordinarily pervasive in the autism literature. ${ }^{13}$ The quality of inaccessibility is thus understood as a feature of autistic aloneness, for both autistic individuals and modernist music.

In some modernist music, including a good deal of twelve-tone music, autistic aloneness (manifested as complex self-referentiality) finds a corresponding autistic sameness (manifested as a compositional commitment to derive everything in the piece from a single source). In most twelve-tone music, everything is related to a single referential ordering of the twelve notes. That row or series comprises a basic shape, and other shapes are derived from it by transposition, inversion, retrograde, and retrograde-inversion, those traditional contrapuntal devices. Indeed, the basis of this music is imitative counterpoint. The basic shape (the imitative subject), although endlessly reshaped, remains the source for all the harmonies and melodies. In that sense, and at a deep level, the music remains always the same. 
These autistic features of twelve-tone composition have elicited a strongly negative response from many listeners, critics, and musicologists. But a more sympathetic response is also possible. Autistic aloneness and sameness, both in music and in individuals, can be understood as differences, not deficits, indeed, as sources of particular strength and interest. There are unquestionably barriers to traditional sorts of sociability and apprehension, but remarkable and distinctively autistic appeal resides within.

Excessive aloneness and sameness have often been stigmatized as pathological conditions, both for musical works and individuals, evoking pity or horror. But taking these works, and these individuals, on their own terms, one might see their high degree of self-reference and their refusal of organicist evolution as defining strengths. Insofar as it makes a virtue of aloneness and sameness, and affirms the values of contextuality and commitment to a single referential source, modernist music claims autism as a valuable resource, and thus affirms its disability aesthetics.

\section{Claiming Disability}

Critics of musical modernism, especially on the political right, have explicitly identified it as disabled: sick, diseased, and mad. This line of criticism reached its culmination in the Nazi condemnation of modern music as "degenerate." In a horrible historical irony, the German National Socialists, whose mass "euthanasia" of people with disabilities set the stage for the Holocaust, were probably the first to understand the centrality of disability for modernism in the arts. As Siebers observes (34-35), "The Nazis were the first to recognize the aesthetic centrality of disability to modern art. . . The Nazis waged war against modern art because they interpreted the modern in art as disability, and they were essentially right in their interpretation, for modern art might indeed be named as the movement that finds its greatest aesthetic resource in bodies previously considered to be broken, diseased, wounded, or disabled."

Proponents of modernist music have also adopted the language of disability, but from the opposite direction. Modernist art is sometimes seen as a cure for a sick culture, a sort of shock therapy administered to a complacent bourgeois audience. For conventional audiences, the music may appear disabled. For the composers and their supporters, it is the audience that is disabled. And it is precisely the music that disables 
them, renders them unable to listen with comprehension and enjoyment. Modernist music both represents disability and disables conventional listeners.

In response to questions posed at the beginning of this chapter, I contend that the modern in music manifests itself as disability, that modernist music has a fundamental interest in representing the disabled human body, and that modernist music claims disability. For modernist composers, disability is a source of enduring fascination, a means of shattering conventions and establishing new structural paradigms and new kinds of beauty, a cause for celebratory delight.

At the same time, modernist music is enmeshed in the history and culture of disability, which it simultaneously reflects and shapes. It thus evinces a deep ambivalence toward disability, as something that should be either cured (normalized, rehabilitated) or eliminated (segregated, institutionalized, sterilized, or killed, following the eugenic imperative). Modernist musical representations of disability often conform to oppressive regimes of representation: disabled bodies are often represented musically in stereotypical ways and elicit stigmatizing responses. In short, the modernist musical response to disability is complicated, abounding in ambivalence, conflict, and self-contradiction, both in the corpus as a whole and in individual works. But even amid a eugenic culture and a tendency toward the exoticization and enfreakment of disabled bodies, modernist musical representations of disability often open up new perspectives on disability. They reveal the aesthetic and physical beauty of disability, and in the process, change our sense of the beautiful.

Notes

1. For related studies of the representation of disability in modern art, see Ann Millett-Gallant, The Disabled Body in Contemporary Art (2010) and Carol Poore, Disability in Twentieth-Century German Culture (2007). For a related perspective on disability and aesthetics, one that takes full account of the modernist dalliance with eugenic ideas of degeneration, see Michael Davidson, "Aesthetics," in Keywords for Disability Studies (2015) and "The Rage of Caliban: Disabling Bodies in Modernist Aesthetics," Modernism/modernity (2015). Like Davidson's discussion of Zemlinsky's opera Der Zwerg, this essay treats modernist music "as a site for studying musical representation of bodily difference."

2. On the idea of affirmatively "claiming disability" as a personal and political identity, see Simi Linton, Claiming Disability: Knowledge and Identity (1998).

3. The chronological span of cultural modernism is calculated differently in the different disciplines. Most of the artworks discussed in Siebers 2010, for exam- 
ple, date from after 1970 . In contrast, the subtitle of Gay 2008, a study of literary modernism, is "From Baudelaire to Beckett and Beyond." It identifies Charles Baudelaire (1821-67) as "modernism's first hero" (5). Musicologists tend to be somewhat narrower in the scope of musical modernism, which is understood to begin with the atonality of Arnold Schoenberg and Anton Webern, the pantonality of Igor Stravinsky and Béla Bartók, and the experimentalism of Charles Ives, Edgard Varèse, and the American "ultra-modernists," beginning around 1910 , and to end around 1970, with the postwar twelve-tone serialism of Milton Babbitt, Pierre Boulez, and others, although with a long tail that extends to the present date.

4. On the coincidence of cultural modernism with the "birth of rehabilitation," see Henri-Jacques Stiker, A History of Disability (2000). On eugenics and euthanasia as central features of disability history and culture, see Rosemarie Garland-Thomson, "The Cultural Logic of Euthanasia: 'Sad Fancyings' in Herman Melville's 'Bartleby"' (2004). For more general historical accounts of eugenics, see Thomas Leonard, Illiberal Reformers: Race, Eugenics, and American Economics in the Progressive Era (2016) and Paul Lombardo, ed., A Century of Eugenics in America: From the Indiana Experiment to the Human Genome Project (2011).

5. On "ugly laws," see Kim Nielson, A Disability History of the United States (2012) and Susan Schweik, The Ugly Laws: Disability in Public (2009).

6. On a related attempt among modernist authors to "de-form" the novel, see Linett 2017.

7. On the "splinteredness" of form in Stravinsky's music, see Richard Taruskin, Stravinsky and the Russian Traditions: A Biography of the Works through "Mavra" (1996). On its "block juxtaposition," see Pieter van den Toorn, The Music of Stravinsky (1983). Jonathan Kramer adduces Stravinsky's Symphonies of Wind Instruments and several works by Ives as early examples of "moment form" in "Moment Form in Twentieth-Century Music" (1978). Matthew McDonald, "Ives and the Now" (2013), offers an interpretation of "The Things Our Fathers Loved" that emphasizes its fragmentary qualities.

8. The idea that the time of modernist music is nonlinear is the central contention of Jonathan Kramer, The Time of Music: New Meanings, New Temporalities, New Listening Strategies (1988). Kern, The Culture of Time and Space (2003), considers simultaneity a principal defining feature of cultural modernism.

9. Schenker develops his sense of musical "paralysis" in two sources: "Further Consideration of the Urlinie" ([1926] 1996) and "Rameau or Beethoven? Creeping Paralysis or Spiritual Potency in Music?” ([1930] 1997).

10. There is a large literature on this topic. The best single source is Charles Ferneyhough, The Voices Within: the History and Science of How We Talk to Ourselves (2016).

11. Although Eugen Bleuler presented his new diagnostic category of schizophrenia in a public lecture in 19o8, the first published account is "Zur Theorie des schizophrenen Negativismus" (1910).

12. Leo Kanner announced his new diagnostic category of autism, which he understood as a kind of schizophrenia, in "Autistic Disturbances of Affective Contact" (1943). 
13. Two early classics of the modern autism literature enshrine the idea of inaccessibility in their titles: Bruno Bettelheim, The Empty Fortress: Infantile Autism and the Birth of the Self (1967); Clara Claiborne Park, The Siege: A Family's Journey into the World of an Autistic Child (1967).

\section{Works Cited}

Adorno, Theodor. Philosophy of Modern Music. Translated by Anne G. Mitchell and Wesley V. Blomster. New York: Continuum, 2003.

Babbitt, Milton. Words about Music. Edited by Stephen Dembski and Joseph Straus. Madison: University of Wisconsin Press, 1987.

Bettelheim, Bruno. The Empty Fortress: Infantile Autism and the Birth of the Self. New York: Free Press, 1967.

Bleuler, Eugen. "Dementia Praecox oder die Gruppe der Schizofrenien." In Handbuch der Psychiatrie. Translated by Joseph Zinkin as Dementia Praecox or the Group of Schizophrenias. New York: International Universities Press, (1911) $195^{\circ}$.

Bleuler, Eugen. "Zur Theorie des schizophrenen Negativismus." PsychiatrischNeruologische Wochenschrift (1910): 12.

Davidson, Michael. "Aesthetics." In Keywords for Disability Studies, edited by Rachel Adams, Benjamin Reiss, and David Serlin, 26-3o. New York: New York University Press, 2015.

Davidson, Michael. "The Rage of Caliban: Disabling Bodies in Modernist Aesthetics." Modernism/modernity 22, no. 4 (2015): 609-25.

Fernyhough, Charles. The Voices Within: The History and Science of How We Talk to Ourselves. New York: Basic Books, 2016.

Garland-Thomson, Rosemarie. "The Cultural Logic of Euthanasia: 'Sad Fancyings' in Herman Melville's 'Bartleby."' American Literature 76, no. 4 (2004): 777-8o6.

Gay, Peter. Modernism: The Lure of Heresy (from Baudelaire to Beckett and Beyond). New York: W. W. Norton, 2010.

Kanner, Leo. "Autistic Disturbances of Affective Contact." Nervous Child 2 (1943): $217-5^{\circ}$.

Kern, Stephen. The Culture of Time and Space, I880-I9I8. Cambridge: Harvard University Press, 1983 .

Kramer, Jonathan. "Moment Form in Twentieth-Century Music." Musical Quarterly 64, no. 2 (1978): 177-94.

Kramer, Jonathan. The Time of Music: New Meanings, New Temporalities, New Listening Strategies. New York: Schirmer Books, 1988.

Leonard, Thomas. Illiberal Reformers: Race, Eugenics, and American Economics in the Progressive Era. Princeton: Princeton University Press, 2016.

Linett, Maren Tova. Bodies of Modernism: Physical Disability in Transatlantic Modernist Literature. Ann Arbor: University of Michigan Press, 2017.

Linton, Simi. Claiming Disability: Knowledge and Identity. New York: New York University Press, 1998.

Lombardo, Paul, ed. A Century of Eugenics in America: From the Indiana Experiment 
to the Human Genome Project. Bloomington: Indiana University Press, 2011.

McDonald, Matthew. "Ives and the Now." In Music and Narrative since I9oo, edited by Michael Klein and Nicholas Reyland, $285-307$. Bloomington: Indiana University Press, 2013.

Millett-Gallant, Ann. The Disabled Body in Contemporary Art. New York: Palgrave Macmillan, 2010.

Morgan, Robert. "Secret Languages: The Roots of Musical Modernism." Critical Inquiry 10, no. 3 (1984): 442-61.

Nielson, Kim. A Disability History of the United States. Boston: Beacon Press, 2012.

Park, Clara Claiborne. The Siege: A Family's Journey into the World of an Autistic Child. Boston: Little, Brown, 1967 .

Poore, Carol. Disability in Twentieth-Century German Culture. Ann Arbor: University of Michigan Press, 2007.

Schenker, Heinrich. "Further Consideration of the Urlinie: II." In The Masterwork in Music, vol. 2, edited by William Drabkin, translated by John Rothgeb, 1-19. Cambridge: Cambridge University Press, 1996.

Schenker, Heinrich. "Rameau or Beethoven? Creeping Paralysis or Spiritual Potency in Music?" In The Masterwork in Music, vol. 3, edited by William Drabkin, translated by Ian Bent, 1-9. Cambridge: Cambridge University Press, 1997.

Schweik, Susan. The Ugly Laws: Disability in Public. New York: New York University Press, 2009.

Siebers, Tobin. Disability Aesthetics. Ann Arbor: University of Michigan Press, 2010.

Stiker, Henri-Jacques. A History of Disability. Translated by William Sayers. Ann Arbor: University of Michigan Press, 2000.

Taruskin, Richard. Stravinsky and the Russian Traditions: A Biography of the Works through "Mavra." Berkeley: University of California Press, 1996. 


\title{
EIGHT | Staging the Asylum: Javier Téllez's Disability Aesthetics
}

\author{
LEON J. HILTON
}

The disabled body changes the process of representation itself. . . . What would it mean for disability studies to take this insight seriously?

—Tobin Siebers, "Disability in Theory: From Social Constructionism to the New Realism of the Body"

The question of ethics is always at the core of representation. Mental illness only exists within the realm of representation: it is a language and our task is to challenge it.

-Javier Téllez, "Madness Is the Language of the Excluded"

La extraccion de la piedra de la locura ("The Extraction of the Stone of Madness") was an installation that the contemporary Venezuelan artist and filmmaker Javier Téllez created in 1996 for the Museo de Bellas Artes in Caracas. Born in the northern city of Valencia in 1969, Téllez moved to New York in 1993 and has spent much of his career living away from his home country. The installation-which borrows its name from the Spanish title of the fifteenth-century painting by Hieronymus Bosch known in English as The Cure of Folly-immersed visitors in a faithful recreation of several rooms of Valencia's Bárbula psychiatric hospital. At one time considered to be among of most progressive and scientifically advanced mental health institutions in Latin America, Bárbula was also where both of Téllez's parents worked as psychiatrists. (The artist himself was born and raised on the hospital's grounds). Téllez's installation occupied several galleries of the Bellas Artes Museum, where he 
had arranged hundreds of objects from Bárbula: rows of original hospital beds, uniforms worn by patients and medical staff; vitrines displaying artworks produced by the hospitals patients; photographs of various group activities from the hospital; and video and sound recordings from Bárbula's archive including the haunting, looped audio track of a recording of a patient singing a plaintive rendition of Charles Gounod's Ave Maria. From the ceiling, Téllez hung colorful crèche-covered piñatas in the shape of psycho-pharmaceutical tablets: looming crèche globes and ovoids bearing the brand names of brands-Valium, Tegretol, Haldol—in colorful papier-mâché lettering. (In an interview with the author, Téllez described these pill-shaped piñatas as "third world brillo boxes," a nod to Warhol.) In La extraccion de la piedra de la locura, Téllez places the viewer in the position of the occupants of the hospital. The spectator is substituted simultaneously as patient and doctor. We come to recognize how social hierarchies are structured and maintained by the careful and deliberate control over lines of sight—of what is allowed and compelled to come into visibility-even as the installation places the spectator in the privileged position of the one who looks.

This substitution of the spectator's gaze for that of the medical expert and the psychiatric patient is a characteristic gesture of Téllez's practice as it has developed over the last several decades. Téllez identifies madness itself as his aesthetic terrain. ${ }^{1}$ This has manifested for Téllez in a body of work that manages to function as an immanent critique of the psychiatric hospital and the art museum as parallel heterotopias, each structured and governed by the same historical mode of rationality. For Téllez, the "museum and the psychiatric hospital are products of the enlightenment project. . . . It is as if the same impulse that created the museum liberated the patients from their chains, marking both the birth of the modern asylum and the public museum" (Faguet and Lehyt). This striking observation was, in many ways, the genesis for the discussion that follows, which has been motivated by a curiosity about how the aesthetic questions and methods that Téllez has been developing over the past several decades might be productively considered in tandem with the critical project of disability aesthetics-a concept that Tobin Siebers used in order to "emphasize the presence of disability in the tradition of aesthetic representation" in order to claim disability as "aesthetic value" in itself-a value that in turn "requires us to revise traditional conceptions of aesthetic production and appreciation" ("Disability Aesthetics," 64). Through readings of canonical works of art history and more recent aesthetic practices undertaken by people with disabilities, Siebers offered 
the groundwork for a new way of thinking about aesthetic experience, deeply informed by the rich vocabularies for rethinking embodiment, history, ethics, and relationality that have emerged from disability movements and cultural practices. Yet Téllez's work poses a number of crucial and provocative challenges for contemporary critics and scholars seeking to carry on the urgent work of theorizing and historicizing the relationship between disability and cultural production.

Before proceeding, it will be important to zoom out a bit. How might the concept of disability aesthetics fit within larger debates about the role of art and aesthetic experience in the historical struggle for political and social transformation? During a conversation with the artist in preparing this chapter, I explained that my premise would be to consider his work in relation to the concept of disability aesthetics as it was described by Tobin Siebers. Téllez expressed some hesitation about having his work categorized in relationship to "disability." Indeed, disability aesthetics can be understood as a concept that has an indirect and critically vexed relationship to both the disabled subject and the complex and fractured historical consolidation of disability as a category of modern social identity. As such, disability aesthetics can be said to circulate in proximity to but not entirely overlap with persons who may or may not be identified (or identify themselves as) disabled in the contemporary usage of this term. This understanding of disability aesthetics draws upon an assertion originally formulated in Siebers's 2001 essay "Disability in Theory: From Social Constructionism to the New Realism of the Body." Here Siebers argues that disability poses a set of challenges for the renewed attention to the social and discursive contingency of embodiment within the poststructuralist theory of the 199os. At the core of his argument is the assertion of an intimate link between the aesthetic representation of disability and the everyday, material processes of social exclusion, marginalization, and disqualification that come to produce disability as both an abstract social category and as a material component of everyday, embodied experience. Siebers does not take for granted a stable or coherent correspondence between aesthetic representation and the social reality; instead, he calls for disability studies to take seriously the ways that the disabled body "changes the process of representation itself" ("Disability in Theory," 738).

In his 2010 book Disability Aesthetics, Siebers expanded his argument by turning to the origins of the modern discourse of aesthetics. Aesthetics, as he writes in the book's opening sentence, "tracks the sensations that some bodies feel in the presence of other bodies" (1) - a formulation 
that Siebers traces to the German philosopher Alexander Baumgarten. It is notable that Disability Aesthetics opens by evoking Baumgarten rather than Immanuel Kant, his more famous contemporary and counterpart in the eighteenth-century origins of the modern philosophy of aesthetics. Kant notoriously criticized Baumgarten for attempting to argue that our private and subjective sensory experiences of pleasure and displeasure could be said to follow rational laws, offering instead an account of the aesthetic as involving judgments of taste that are at once subjectively perceived and universally recognizable by the sensus communis-what might be called the "community of (shared) sense" (20). The Kantian legacy has been inescapable for subsequent critical debates that have attempted to illuminate how art relates to politics, society, and history. Beginning with Baumgarten instead of Kant signals that Siebers will chart a somewhat wayward philosophical pathway in search of alternative accounts of the configuration between aesthetics and the senses. His argument for disability as an aesthetic value in and of itself draws at different points from debates over the politics of representation across a range of postEnlightenment critical traditions. In certain respects, Siebers's attention to the sensory dimensions of aesthetic experience resonates with Jacques Rancière's influential account of the relationship between politics and aesthetics within the "distribution of the sensible" - the arrangement, organization, and partitioning of what is included (and excluded) from common life according to the capacity to be perceived by the senses. Though disability does not appear as an explicit theme or topic of concern in Rancière's work, Siebers's concept of disability aesthetics could be said to help us pose questions about how aesthetics gives shape to what Rancière describes as the "sensible fabric of experience" (Aesthesis, $\mathrm{x})$. As Rancière makes clear, the "fabric" of sensory experience is constantly being woven and rewoven, a product of historical contingencies that are at once political and aesthetic. For Rancière, the aesthetic and the political are always in relationship insofar as art has the capacity to "intervene in the general distribution of ways of doing and making" (Politics of Aesthetics, 13) to forge new configurations of the sensorium. In placing the senses at the center of its account of the connection of aesthetics and politics, the distribution of the sensible has become an influential way of advocating and defending the social function of art within broader histories of emancipatory struggle.

Téllez's work, I will suggest, provokes us to consider the place of mental illness within such an understanding of disability aesthetics. Both Siebers's writing and Téllez's art and film work specifically call attention 
to mental disability and mental illness as historical categories of experience, inseparable from the social institutions and scientific disciplines (e.g., biology and psychiatry) through which these categories are materialized, sensed, and embodied. Consider a passage from one of the most extended considerations of mental disability that Siebers's disability aesthetics provides:

The appreciation of the work of art is a topic that is well rehearsed in the history of aesthetics, but rarely is it considered from the vantage point of the disabled mind-no doubt because the spectacle of the mentally disabled person, rising with emotion before the shining work of art, disrupts the long-standing belief that pronouncements of taste depend on a form of human intelligence as autonomous and imaginative as the art object itself. Artistic production also seems to reflect a limited and well-defined range of mental actions. Traditionally, we understand that art originates in genius, but genius is really at a minimum only the name for an intelligence large enough to plan and execute works of art—an intelligence that usually goes by the name of "intention." Defective or impaired intelligence cannot make art according to this rule. Mental disability represents an absolute rupture with the work of art. It marks the constitutive moment of abolition, according to Michel Foucault, that dissolves the essence of what art is. (Disability Aesthetics, 15)

The passage from Foucault that Siebers refers to in this paragraph is from History of Madness (1964), which famously argued that historical transformations in the experience of madness have been inseparable from the great division between reason and unreason that defines modern rationality - a rationality that Foucault in turn argued has been central to the way we come to know and understand ourselves, which is to say to the production of modern subjectivity (xxxii). In the passage that Siebers references, Foucault is preoccupied by the silence of madness within the historical archive: Madness can only be known as the "absence of an oeuvre" (Foucault, 536). Paradoxically, madness only becomes intelligible (or perhaps we could say sensible) when it is made to speak in the discourse of a modern rationality that obtains legitimacy-which is to say authority to distribute the sensible-by way of the isolation, confinement, and diagnosis of "mad speech." Foucault is not endorsing the view-rather, he is attempting to make visible the historical forces that have produced the conditions in which madness is understood as 
antithetical to the criteria of autonomy and enclosure to which modern rationality subjects both the aesthetic object and the liberal subject.

While Siebers in this passage seems to be in search of a more general category or concept to which madness, "defective or impaired intelligence," and "mental disability" could all be said to belong, Foucault and subsequent scholars have argued that each of these categories has been subject to historical contingency. If these separate yet intertwined histories raise key questions for disability studies, they are also questions that have been at the core of Téllez's aesthetic concerns. Indebted to Foucault, Téllez refuses to grant to mental illness that status of objective or empirical "existence" outside of the representations through which it becomes knowable. Téllez makes it clear that the possibilities for flourishing afforded to people living with mental diagnoses are entirely contingent upon the discourses, images, and other representational systems that give their experiences social meaning and coherency in ways that also undercut their own rhetorical agency and autonomy. Téllez explains:

Most "objective" representations of the mentally ill have been made by the psychiatric institution, in which the discourses of the patients are always categorized as mere illustrations of their diagnoses, not to mention stigmatic media constructions. The experience of madness can be situated historically in between the prohibitions against action and against language; these prohibitions also involve the representation of the body of the mentally ill, observed and catalogued only as a representation of the illness. Fortunately there are also counter discourses articulated by the patients themselves that can be use as models to understand the problem of language. (Faguet and Lehyt, n.p.)

In much of his work, Téllez seems to address the problem that Foucault also identified: The great division of reason from unreason, exemplified in the spatial partitioning of the asylum and the prison cell, produces forms of modern rationality that takes the form of what in History of Madness is described as a "structure of refusal" "on the basis of which a discourse is denounced as not being a language" and hence "as having no rightful place in history" (xxxii). As I will suggest in my discussion of the three works that follow, Téllez has sought to propose a series of aesthetically rich and conceptually searching alternatives to this structure of refusal, working around the historical "prohibitions" that have surrounded and delimited the representational field of mental illness in ways that have often been violent and dehumanizing.

La extraccion de la piedra de la locura uses the sensory affordances of 
installation as a way of producing an aesthetic experience that draws out affinities between the space of the art museum and the space of the psychiatric institution. It also draws attention to the overlooked importance of the politics of mental health to larger histories of emancipatory social struggle in the late twentieth and early twenty-first centuries. I next turn to Téllez's 2001 film and installation You Are Here, which documents a ludic intervention into the everyday habits and routines followed by residents and staff of a dilapidated psychiatric ward in rural Venezuela. You Are Here brings to the fore some of the ethical dimensions of Téllez's collaborations with people living with a range of psychiatric diagnoses in mental health institutions. Téllez's interest in the ethics of representation in these collaborations corresponds with some of the central prerogatives of disability aesthetics, particularly as it relates to what Siebers describes as the process of social disqualification. I propose that disability aesthetics offers an important rubric for considering the question that Téllez says lies at the heart of his collaborative projects: "How might we define a system of ethics capable of moving beyond the dichotomy of the normal and the pathological?" (Faguet and Lehyt, n.p.). In the final part of this chapter, I turn to Téllez's most well-known project to date, a 2005 public performance in Tijuana that culminated in the dramatic launching of "human cannonball" David Smith across the US-Mexico border. Conceived and staged in collaboration with patients from the CESAM State Psychiatric Hospital in the Mexican border town of Mexicali, the grandly theatrical gesture at the heart of this work functioned as a metaphor linking the geopolitical border with the medical/psychiatric border between normal and pathological. I argue that this metaphor suggests the importance of placing disability aesthetics into dialogue with contemporaneous developments in the theory and practice of decolonial aesthetics within global and transnational contexts. Returning to the question of the senses and the sensible as the fulcrum of aesthetics and politics within histories of emancipatory social struggle, I propose that Bala perdida suggests that the politics of mental illness-particularly as it takes shape within efforts to counter the medical pathologization and institutional confinement of "unreason"-must be seen as a central site of struggle within broader critical and aesthetic projects seeking to decolonize, dishabituate, and indeed emancipate the sensorium.

\section{The Cure of Folly}

La extraccion de la piedra de la locura seems preoccupied by the question of how the language of madness can be rendered sensible as a lan- 
guage, as a counterdiscourse. Téllez credits the unusual circumstances of his upbringing with sparking his interest in the hidden, or perhaps repressed, affinity between the psychiatric hospital and the art museum. Describing his childhood and adolescence on the Bárbula grounds, Téllez explains:

I remember that even back then I already found a lot of similarities between both types of institutions: hygienic spaces, long corridors, enforced silence and the weight of the architecture. . . Both institutions are symbolic representations of authority, founded on taxonomies based on the "normal" and the "pathological," inclusion and exclusion. (Faguet and Lehyt, n.p.)

With La extraccion de la piedra de la locura, Téllez produced an uncannily precise reproduction of a vanished time and place that was also a dreamlike re-creation of the world of his childhood spent among mental patients. The installation thus produced a space where memory and delirium were indistinguishable. Piedra de la locura can in this sense be understood as a sort of "autotopography" - the term that the art historian Jennifer González proposes to describe works of installation art that use the format of the museological display of ethnographic objects in order to critique the colonial underpinnings of aesthetic hierarchies and the anthropological gaze. Such practices have been a particularly important aesthetic strategy for artists working within and against experiences of postcolonial, indigenous, and racialized dispossession. González argues that autotopographic installation is an aesthetic strategy that artists have used to claim "ontological rights through the preservation and display of personal objects: the right to exist, the right to tell a story, and the right to a territory, whether imagined or actual, where the psyche of the subject dwells and leaves behind a physical trace" (19).

The idea that objects bear the material traces of psychic life-that the physical detritus and ephemera of daily life can, when placed and put on display in the proper context, become imbued with the capacity to make existential demands that are otherwise denied to those who used them-is particularly pertinent to La extraccion de la piedra de la locura. The reconstruction of Bárbula's object-world is built around an absent center: a void that radiates from the physical absence of the actual patients who used, interacted with, and (in some cases) were subjected to medical treatment by the objects on display in the museum galleries. In the exhibition, the Bárbula patients appeared only in old photo- 
graphs lining the gallery walls that documents daily life in the hospital; their artwork adorns the vitrine; their case histories are narrated in documents hung above the rows of empty hospital beds; their traces are felt even in the ephemeral detritus from the opening celebration (plates of food, scattered confetti from pill piñatas). Yet La piedra de la locura is not simply an autotopography of Téllez's individual childhood experience: the exhibition immerses the viewer in the material remnants and ghostly traces of the vibrant social ecology that formed among the hospital's patients, doctors, and staff.

As a collective autotopography, La piedra de la locura also represents an important corrective to our understanding of the history of radical psychiatric thought and politics, in which Bárbula and its founders had a significant but overlooked role. The hospital was founded in $195^{1}$ by Cristóbal Masia, who had been a student of the visionary Catalan psychiatrist François Tosquelles, who as the director of the famous Saint-Alban psychiatric hospital in France developed an influential (if controversial) approach to clinical psychotherapy that emphasized new and sometimes unorthodox treatment methods designed to address the social basis of psychological suffering. Among the first to bring psychoanalytic theory into institutional psychiatry, Tosquelles also trained numerous influential figures in postwar critical thought, including Jean Oury, who went on to found and direct the experimental psychiatric clinic La Borde in collaboration with Felix Guattari. ${ }^{2}$ In essence, Toquelles and the innovations he undertook at St-Alban were shaped by the Left resistance to European fascism. (Tosquelles himself had been interned in a protoconcentration camp while fighting as a partisan in the Spanish Civil War.) They sought to emphasize the broader political and social context in which mental illness manifests itself and incorporated this insight into the theory and practice of psychiatric treatment by emphasizing the social dynamics of the institution, from the doctors and other staff to the patients. The Bárbula hospital was an important site where the social and political commitments of European institutional psychiatry were adapted within a Latin American and specifically Venezuelan contextprecisely at the historical moment in which Left and revolutionary energies were rapidly developing in Latin America and elsewhere. La piedra de la locura makes clear that Bárbula was a far from idyllic or utopian place. The exhibition put on display clinical tools and objects that were used to physically restrain patients. (An original machine used to administer electroshock therapy provides an especially ominous totem of the psychiatry's hold upon the body.) Yet it also seeks to rescue some of the 
utopian spirit that animated the vision behind the Bárbula's history by producing what the artist describes as a "symbolic contamination" of the art museum - that supposedly hygienic sanctum of aesthetic experience-by the psychiatric asylum (interview with author).

\section{You Are Here}

Following La piedra de la locura, Téllez began to work directly in collaboration with psychiatric patients in mental institutions in his native Venezuela, as well as in Mexico, Australia, Germany, and most recently Rochester, New York. Many of these collaborations led to films that are in turn exhibited in gallery installations containing the objects that the films depict the patients interacting with; often, these films reference the history of cinema and visual art more generally. In Passion of Joan of Arc (2004), for instance, twelve female patients of a psychiatric clinic in Sydney, Australia were asked to supply new intertitles for Carl Dreyer's 1927 silent film classic depicting Joan of Arc's trial (itself an important entry in the history of cinematic representations of mental illness) that reflected their experiences with the mental health system. Scenes from the original film were then intercut with static shots of the women describing their lives directly to the camera and interacting with a marionette reproduction of Maria Falconetti as Joan of Arc. Some of the alternate intertitles that the women wrote channel the voices of doctors and psychiatrists ("Have you stopped taking your medication?" "We have to keep you in the hospital because you are a danger to yourself and others."). One of the Australian patients, Maria, explains: "Mental pain is more difficult than physical pain. It can kill you if you don't treat it. If you don't handle it with care, it's like a poison growing inside of you." Another says: "Most of the time I see having mental illness as a positive thing because you get this illness. It's actually more of a blessing than anything else."

Téllez has occasionally addressed the questions that have been raised about the ethics of creating artistic work with collaborators who have been given diagnoses that imply an impaired or diminished capacity to exercise rhetorical or expressive agency: "I never pretend not to be visible in the discourse, but the work is articulated in the dialogue between my subjectivity and their subjectivities" (Faguet and Lehyt, n.p.). Indeed, Téllez says that he means his work to "create a flexible space where those represented can intervene in their own representation" (Faguet, 50).

The implications of this imperative can be glimpsed by turning to You Are Here (2002), a video installation that depicts scenes of patients gath- 
ered in the walled-in courtyards surrounding a dilapidated Venezuelan psychiatric clinic. One of the installation walls becomes the screen for the projection of the film, which shows the patients, many of whom are in various states of undress, playfully attempting to toss an enormous inflated ball-six feet in diameter and constructed out of multicolored patches of corduroy so as to resemble an oversized soccer ball-across the various courtyard walls that separate the residents into groups and serve to isolate them from one another. In order to launch the ball across the high partitions, the patients work in small groups, occasionally climbing on one another's shoulders or using ready-to-hand implements, including tree branches and crutches. The patients, not Téllez, direct the whole action of the film by propelling the giant ball from one space to the next. As the game gathers steam, the camera follows the ball's slow, mesmerizing torsions as it bounds across the courtyard's labyrinthine layout, turning the architectural configuration of the institution itself into a kind of oversized pinball machine. The film becomes a kind of cinematic cartography of the asylum, with the camera following the trajectory of the ball through and across the high institutional partition walls.

You Are Here continues Téllez's fascination with how modern and Classical spatial forms can be superimposed. In this case, in the mythological architecture of the labyrinth. The ball functions as a kind of passport authorizing forms of movement between and across the hospital's labyrinthine spaces of division that its residents are otherwise denied. The asylum, then, becomes a sort of giant pinball machine. It is hard not to imagine the ball as a manifestation of the patients' own collectively held desire to escape-or to at least forge a new relationship to-the asylum walls. The film culminates in a final shot showing a determined group of male patients triumphantly managing to send the ball soaring beyond the clinic's outer perimeter.

That the ball expresses something about collective desire becomes even clearer in the installation itself, in which the imposing physical presence of the six-foot-tall ball depicted in the film dominates the spatial layout of the room. This is a desire that calls attention to the prescribed and predetermined pathways of the institution and seeks to not only upend but to escape them entirely. Téllez explains that he chose the size of the ball in reference to the American sculptor Tony Smith's Die, a six-sided steel cube that was first created as a model in 1962 and manufactured at scale, six feet on each side, in 1968. Smith's Die has become a touchstone within art critical debates about the scale and abstraction of 
the human form in minimalist art: Robert Morris's influential 1968 essay "Notes on Sculpture" quotes Smith describing the human-sized dimensions of Die by explaining that he did not want the sculpture to be either a monument that would loom over the viewer or a "mere" object that the viewer might regard with passing interest (229-30). In placing the ball within the space of the installation as the film footage is projected on one wall, Téllez acknowledges the legacy of minimalism's ambivalent position within twentieth-century artistic debates about objecthood and autonomy. Smith's brushed-steel cube is austere and industrial. Téllez's ball is multicolored and spherical and shown in the midst of those bodies that interact with it as an object (if albeit an oversized, or at least humansized, object).

The provocative amalgamation of references that this video and installation puts into play blends references to debates about minimalism with the participatory, collective, and radical psychiatric/therapeutic aesthetic experimentation associated with a particular trajectory of Latin American modernism. This aspect of the work can be seen in the film's short scenes of other patients in the same Venezuelan clinic interacting with tennis ball-sized versions of the larger sphere. Some of these patients appear to be in particularly dire straits. Several are lying on the bare cement ground in near catatonia, while others seem nearly emaciated. The palpably distressing conditions that the film documents bespeak the wider crisis that has seized Venezuela's mental health system due to the country's tumultuous and increasingly catastrophic recent history. In some ways, the small, toy-sized versions of the ball seem to recall the "non-object objects" created in the 1970s by the Brazilian conceptualist Lygia Clark, with whom Téllez would seem to share an interest in the maladies of the psyche. Clark understood these objects as (in part) therapeutic - meant to reawaken the body's senses that have been dulled by exposure to the historical trauma produced by social struggle. Clark would schedule private, hour-long sessions with individuals in which she would apply carefully chosen "therapeutic objects"-plastic bags, ping-pong balls, sand-directly upon the body, a technique intended to resensitize the body. "The artist received each person individually for one-hour sessions, one to three times a week, over a period of months, and, in certain cases, for more than one year." Clark's "relationship with the receiver, mediated by the objects, had become indispensable for the realization of the artwork. It was on the basis of her sensations of the living presence of the other in her own "resonant body" that these relational and therapeutic objects were created (Rolnik). Yet unlike Clark's 
objetos, Téllez maintains that his objects were not introduced primarily as a therapeutic gesture. He is committed to maintaining a meticulous separation between artistic methods and the medical or therapeutic mandates that are materialized within the partitioned space of the psychiatric institution. You Are Here documents simple interventions into the patients' everyday habits that produce a momentary transformation in the structure of the collective social body as it is structured and regulated by the institution's rigid, hierarchically ordered partitioning of space. The video and installation document a sudden and transitory "phase shift" in the social atmosphere that also disturbs the modes of sociality that are confined within the clinic's walled-off zones of contact. ${ }^{4}$

Just as La piedra de la locura evoked the denied or suppressed speech of the Bárbula hospital residents as a way of asking historical questions about the processes by which madness is recast into the discourse of mental illness by the rational authority that governs the space of the psychiatric institution, You Are Here and Téllez's other collaborative projects seem to crack open what Siebers will describe as the stubborn linkage between aesthetic judgment and social disqualification. It is clear that Siebers sees an intimate connection between aesthetic representation and the material conditions and lived experiences of people with disabilities in the social world. One of the ways in which he describes this connection is through the concept of disqualification, which he understands as a social process of exclusion that is itself intimately bound up in aesthetic processes. As Siebers writes in Disability Aesthetics, "disqualification is justified through the accusation of mental or physical inferiority based on aesthetic principles" (24). This point seems to take up and expand upon an earlier point that Siebers had made in his 2001 essay "Disability in Theory: From Social Constructionism to the New Realism of the Body," which argues that the "central issue for the politics of representation is not whether bodies are infinitely interpretable but whether certain bodies should be marked as defective and how the people who have these bodies may properly represent their interests in the public sphere" (742). In other words, Siebers continues, representation is a process-or rather, an endlessly complex and recursive series of processes-that has immense political consequences for determining the access that disabled subjects have to the spheres of collective life:

Only by beginning to conceive of the ways that disabled bodies change the process of representation, both politically and otherwise, might we begin to tackle the difficult issues of how access bears on voting rights, 
how current theories of political subjectivity limit citizenship for the mentally disabled, and why economic theories cast people with disabilities exclusively as burdens. (742; emphasis added)

Siebers seems to be responding to a tradition of thought that has understood aesthetic judgment as integral to the production and regulation of collective political life, shifting the emphasis to questions of social inscription ("marked as defective") and the normative formalization of "politics" in relationship to the state ("represent," "interests," "public sphere"). Traces of these processes are certainly palpable in You Are Here. The dilapidated grounds of the Venezuelan hospital testify to the abandonment by the state of the people the film depicts; the physically embodied presence of the patients themselves-many of whom also have serious physical disabilities in addition to their psychiatric conditions-is depicted with a sometimes disquieting frankness. Yet the hospital residents are not presented to the viewer as objects of pity or to appeal to the viewer's sympathy. Emerging, instead, from the encounter between the multiple subjectivities at play in the creation of the work, You Are Here offers one response to a different question that Téllez asks. ${ }^{5}$ This is as much an ethical question for the artist, the viewer, and the pathologized subject who is both represented and an active participant in shaping the formal dimensions of the works in which she appears.

Invoking Emanuel Levinas's insistence on the ethical necessity of forgetting the self in order to enter into proximity with the other, Téllez maintains that ethics "has to be understood as a responsibility to difference. For me this responsibility is manifest in the inclusion of the other as an active participant in the work" (Faguet and Lehyt, n.p.). The artist does not specify whether the other who must be included as a participant in the work is the viewer or the mentally disabled collaborators who both appear in and help to determine the form of the films and installations.

Téllez's call for an ethical system that would be capable of moving beyond the normal and pathological is echoed in the passage from Foucault's History of Madness that led Siebers in Disability Aesthetics to posit that mental disability "represents an absolute rupture with the work of art." Foucault's discussion of madness as the absence or silence of the oeuvre is predicated upon a consideration of works by artists and writers whose flirtations with the delirium of unreason pose a question that at its core concerns what might be called the ethical responsibility to difference: "Why is it not possible to remain in the difference that is 
unreason?" (352). At stake in the dichotomy between the normal and the pathological that modern rationality instantiates-and that enter our discourse via the diagnostic language of psychiatric and medical expertise-is nothing less than the expulsion of mental illness from the consolidation of subjectivity as such. Following the giant soccer ball in You Are Here as it ping-pongs across the labyrinthine walls of the institution, it becomes possible to understand this process as an ethical problem before it is a properly political one. As Lynne Huffer suggests, "With this ethical question Foucault names the cost of Western subjectivity as the silencing of unreason: the mutating of the historical other" (197). Téllez's investment in producing forms of collaboration such as You Are Here across lines of normal/pathological, ability/disability, artist/psychiatric patient "stage" this conundrum—which, Foucault writes, "probably concerns the essence of the modern world" (352) - as an ineffable poesis. Dense with sensory and affective immediacy, these works open up the possibility of an ethics of representation beyond the normal/pathological divide that has been central to the production of subjectivity. This is not a denial of difference, but rather an attempt to lay bare the historical, political, and aesthetic processes by which such distinctions are maintained and reproduced.

\section{No Racismo Intelectual!}

Arriving at the high border fence that runs the length of the main beach of Tijuana's Las Playas neighborhood, a crowd assembles before a stage facing an enormous, almost cartoonishly proportioned blue cannon whose long cylindrical barrel is angled ominously, pointing toward the US territory that lies beyond the tall, pointed steel partitions that trail off like a set of ellipses into the Pacific Ocean. The pack of spectators has been led to this site by following a festive parade of colorfully attired performers, many wearing commedia dell arte-style animal masks. Some play instruments while others hold demonstration-style placards with hand-painted political slogans_-including No racismo intelectual! (No to intellectual racism!) and Vivir sin frogar (Live without building walls). After a series of short performances and musical interludes comes the main event: David E. Smith, an American daredevil performer known as the "Human Cannonball," climbs a ladder and showily waves his US passport to the assembled crowd before descending into the cannon's barrel. After a few moments in which the crowd looks on with breathless 
anticipation, Smith is launched over the fence-landing triumphantly in a net that has been set up on the other side of the wall.

This performance, titled One Flew Over the Void (Bala perdida), took place in 2005 as part of the Tijuana-based inSITE performance festival. The richly symbolic act with which the work culminated was not an idea that Téllez came to on his own. The cross-border human cannonball launch was proposed by his collaborators on the project, which was conceived, produced, and staged by patients of the CESAM State Psychiatric Hospital, located in the Mexican border town of Mexicali, who wanted their collaboration with the artist to reflect their experiences of psychiatric institutionalization within a hypermilitarized border region. Indeed, as Téllez later said in an interview about the piece, Bala perdida "used the geopolitical border between USA and México as a metaphor for another boundary, the boundary between the normal and the pathological" (de Retana). In disability studies scholarship and criticism that attends to questions of cultural representation, the use of disability as a metaphorical trope is rightly met with suspicion-particularly when the formal or aesthetic ends to which a disability metaphor is put diverts from or even undermines attention to the lived, material realities of disabled people. Yet Bala perdida cannot be easily reduced to a simple case of narrative prosthesis. In fact, this piece seems to surpass the boundaries of metaphor, pointing not just to comparisons or parallels but suggesting deep contiguities between the two forms of partitioning it references (nor$\mathrm{mal} /$ pathological, US/Mexico). How, the piece seems to ask, might we come to see this border as being produced and maintained by some of the same modes of rationality that partition the normative (healthy) subject from its (ill, debilitated, or pathologized) other?

Gloria Anzaldúa describes this continent-spanning territorial dividing line as "una herida abierta [an open wound] where the Third World grates against the first and bleeds" (25). A colonial invention, the border is a cut that won't stop bleeding. Anzaldúa's poetic image bears the imprint of her own hardfelt embodiment, evoking la frontera as a tear made by the history of colonialism in the Americas into the body of the earth that also has the power to mark and injure the bodies that traverse and are traversed by it-and even to warp their very consciousness itself. Like Anzaldúa's herida abierta, Bala perdida offers of poetic way of sensing anew the geopolitical border as a symptom of (or perhaps a defense against) the psychic and corporeal liabilities of modern selfhood (something that can itself be understood as a colonial invention). Indeed, these works suggest that a certain kind of disability aesthetics might 
already be at work in what has come to be called decolonial aesthetics. The decolonial theorists Rolando Vazquez and Walter Mignolo propose that the discourse of aesthetics as it emerged in European thought since the Enlightenment must be understood as "the regulator of the global capability to 'sense' the beautiful and the sublime." They insist that decolonial struggle has and must encompass forms of praxis that seek "to decolonize the regulation of sensing all the sensations to which our bodies respond" (Vazquez and Mignolo).

Like the oversized soccer ball in You Are Here, the human cannonball launch with which Bala perdida culminated introduced a break in the "sensible fabric" of social reality, temporarily disturbing the ontological illusion that sustains the geopolitical reality of an international border bisecting an otherwise uninterrupted stretch of rocky beach. If You Are Here stages a momentary interruption and transformation of the everyday that is at once produced and confined by the partitioned spaces of the psychiatric institution, Bala perdida attempts a similar transformation of the US-Mexico border itself, overlaying and blurring the distinction between two forms of separation and division. Bala perdida allows for new ways of sensing the contiguities between the powers of confinement associated with psychiatric institutions and the hypermilitarized surveillance and policing of movement that characterize the US-Mexico border zone. The carnival-like atmosphere leading up to the cross-border human cannonball launch produced a momentary interruption in the administrative procedures that typically determine the flow of bodies at this site. Téllez and the festival organizers had worked to obtain special clearance from both the local Mexican and US customs and immigration agencies, and even then, it is notable that Smith, a white US citizen, was the one chosen and granted permission to perform the stunt.

Bala perdida also seems to obliquely resonate with the recent attention within disability studies to the limits of liberal, rights-based models of disability politics when considering the complex and uneven ways that bodily and mental impairment are lived in different geopolitical contexts. ${ }^{6}$ The work invites viewers to consider how the life experiences of people diagnosed with mental or intellectual disabilities are determined and constrained by the geopolitical and economic fractures between Mexico and the United States, and indeed more generally between the Global North and Global South. In so doing, the piece interweaves disability and decolonial aesthetics by way of a highly theatricalized gesture that throws into crisis the position of the spectator, compelling us to question our own implication in the work we are viewing. Though 
launching the human cannonball over the border gained the work its notoriety, I would suggest that an equally vital insight into the work's ambitions is in fact suggested by the presence of the placard bearing the phrase "No Racismo Intelectual!" This concise formulation-framed in the performative idiom of the political protest march meets carnivalesque parade-places decoloniality and disability within a common horizon of emancipatory struggle.

Who watches? Who flies? Who moves? Whose movement is constrained? How are we asked to imagine or reimagine what we mean by something like vision? When asked in a 2014 interview with the Latinx online cultural journal Remezcla whether he considers his work political, Téllez responded:

All work is political. Every art object has political content. I identify myself with a radical thought. I love what Swiss artist Paul Klee said: "Art does not reproduce the visible, it makes things visible." Making something visible is a political concept. Working with those who are excluded, and somehow, incorporating them into the public discourse. (de Retana)

Téllez identifies himself with a tradition of radical thought that understands aesthetics as being capable of producing new visibilities- - a different praxis of struggle" (30) that seeks to define emancipation as a struggle over creation of new forms of perception, new ways of seeing. This is also a tradition within which Siebers's disability aesthetics might be positioned. Yet when Téllez insists that "making something visible is a political concept," it is also clear that making something visible is not sufficient. Rather, it is the larger context in which visibility is produced that allows for the aesthetic to accrue political force. Following the trajectory in Téllez's work from Piedra de la locura through You Are Here and Bala perdida reveals the emergence of an ever more collective and emancipatory aesthetic praxis: one that lays bare the ethical underpinnings of representation as a historical structure of relationality inseparable from the larger histories of exclusion, confinement, and social disqualification that are as spatialized and materialized in the art gallery or cinema as they are in the architecture of the psychiatric hospital. In each case, the aesthetic emerges as a modality for interrogating the rupture between madness and the aesthetic oeuvre that Foucault—in a passage that seems to have galvanized both Téllez and Siebers-identified with the establishment of alterity as a fundamental structure of modern knowing, sensing, 
and perceiving. By returning us to the site of this foundational division within modern rationality, Téllez and Siebers imagine new modes of relation between looking and perceiving, knowing and speaking, watching and acting.

Notes

1. See Wendorf and Dimeo.

2. On Tosquelles's influence on the development of twentieth-century thought, see Robcis. On the history of La Borde and institutional psychotherapy, see Oury and Roulot.

3. In the same interview, Téllez acknowledges that this form of "inclusion obviously takes place within a framework that includes the conditions and distribution of the art system."

4. The concept of incorporeal transformation is drawn from Deleuze and Guattari.

5. See also, e.g., Levinas.

6. See, e.g., McRuer and Puar.

Works Cited

Anzaldúa, Gloria. Borderlands/La Frontera: The New Mestiza. 4th ed. San Francisco: Aunt Lute Books, 2012.

Deleuze, Gilles. Foucault. Translated by Sean Hand. Minneapolis: University of Minnesota Press, 1988.

Deleuze, Gilles, and Felix Guattari. A Thousand Plateaus. Translated by Brian Massumi. Minneapolis: University of Minnesota Press, 1987.

de Retana, Iñaki Fernández. "Filmmaker Javier Téllez on That Time He Shot a Human Cannonball across the Border.” Remezcla, 25 October 2014, http:// remezcla.com/features/film/javier-Téllez-on-film-making-that-time-he-shot -a-human-cannonball-over-the-border/

Faguet, Michèle. "El sueno de la raizon produce monstruos: On the Work of Javier Téllez." Afterall: A Journal of Art, Context and Enquiry, no. 18 (Summer 2008): 46-53

Faguet, Michèle, and Cristóbal Lehyt. "Madness Is the Language of the Excluded: An Interview with Javier Téllez.” C Magazine, no. 92 (Winter 20o6). n.p.

Foucault, Michel. History of Madness. Edited by Jean Khalfa, translated by Jonathan Murphy. London: Routledge, 2006.

González, Jennifer A. Subject to Display: Reframing Race in Contemporary Installation Art. Cambridge, MA: MIT Press, 2008.

Huffer, Lynne. Mad for Foucault: Rethinking the Foundations of Queer Theory. New York: Columbia University Press, 2009.

Kant, Immanuel. The Critique of Judgement. Translated by W. S. Pluhar. Cambridge, MA: Hackett, 1987. 
Levinas, Emanuel. Otherwise Than Being or Beyond Essence. Translated by Alphonso Lingis. Amsterdam Kluwer Academic Publishers, 1978.

McRuer, Robert. Crip Times: Disability, Globalization, and Resistance. New York: New York University Press, 2018.

Morris, Robert. "Notes on Sculpture.” In Minimal Art: A Critical Anthology, edited by G. Battcock. New York: E. P. Dutton \& Co., 1968.

Oury, Jean, and Danielle Roulot, Dialogues à La Borde: Psychopathologie et structure institutionelle. Paris: Hermann Éditeurs, 2008.

Puar, Jasbir K. The Right to Maim: Debility, Capacity, Disability. Durham, NC: Duke University Press, 2017.

Rancière, Jacques. Aesthesis: Scenes from the Aesthetic Regime of Art. Translated by Zakir Paul. London: Verso, 2013.

Rancière, Jacques. The Politics of Aesthetics: The Distribution of the Sensible. Translated by Gabriel Rockhill. Continuum, 2004.

Robcis, Camille. "François Tosquelles and the Psychiatric Revolution in Postwar France." Constellations 23, no. 2 (2016): 212-22.

Rolnik, Suely. "The Body's Contagious Memory: Lygia Clark's Return to the Museum.” Translated by Rodrigo Nunes. 2007. http:/ / eipcp.net/transversal $/ 0507 /$ rolnik/en/print

Siebers, Tobin. "Disability Aesthetics." Journal for Cultural and Religious Theory 7 , no. 2 (Spring/Summer 2006): 63-73.

Siebers, Tobin. Disability Aesthetics. Ann Arbor: University of Michigan Press, 2010.

Siebers, Tobin. "Disability in Theory: From Social Constructionism to the New Realism of the Body." American Literary History 13, no. 4 (Winter 2001): 737-54.

Téllez, Javier. Interview with author. New York City, October 2017.

Vazquez, Rolando, and Walter Mignolo. "Decolonial AestheSis: Colonial Wounds/Decolonial Healings.” Social Text Periscope, 15 July 2013. https://so cialtextjournal.org/periscope_article/decolonial-aesthesis-colonial-wounds decolonial-healings/

Wendorf, Anna, and Carlos Dimeo. "La extraccion de la piedra de la locura (Instalaciones de Javier Téllez)." Arte de America Latina (Polish Institute for Research in Global Art), no. 2 (2012): 187-219. 


\title{
NINE | Disability Aesthetics: A Pedagogy for Teaching a Revisionist Art History
}

\author{
AMANDA CACHIA
}

\section{Introduction: Calling Out Art History}

The work of the late disability studies scholar Tobin Siebers has long played a critical role in the development of my own thinking, research, and curating on the topic of disability aesthetics. When Siebers's book Disability Aesthetics was published in 2010, I was relieved when he "called out" art history, because he indicated that disability is, in fact, everywhere present in contemporary art, because nondisabled contemporary artists "see" the aesthetic merits of "disability" in art, ranging from the work of Pablo Picasso to Francis Bacon. ${ }^{1}$ It was Siebers who put a name to this fact- "disability aesthetics" — and it was Siebers who began to center disability within canonical art history. Siebers was thus one of the first to offer a studied, documented, and historical trajectory of where disability studies and contemporary art productively intersect.

This chapter will provide case studies from my own academic work through specific classes I have taught in order to shed light on how disability can be centered in the pedagogy for teaching art history. I then provide some reflection on how I have applied disability aesthetics to my previous employment as an art history instructor. Like Siebers, I have aimed to rethink the very frameworks of how art history and art discourse in general judge bodies and by extension the work of certain kinds of bodies. Conventional art history has not accounted for the reality of disabled subjects and their bodies, or rather, where misshapen forms have not been discussed in a disability-positive manner. In all of the art history 
classes I took, both in my native country of Australia and then when I completed my PhD coursework at the University of California at San Diego (UCSD), art historians continued to teach that the ostensible "normative" male and female body is an aesthetic ideal going back to Leonardo da Vinci's Vitruvian Man and other classical aesthetics from the Greeks, the Romans, and the Egyptians. None of this was untrue, but it was simply that the art-historical aesthetic ideals of perfection, proportion, and beauty found in classical sculpture and modernism, and in architecture through the golden section, went unquestioned. The art historians who taught me these aesthetic traditions never offered provocative critical questions around these so-called ideals, and how these ideals should and could be interrogated by examining a disability-centered discourse. This is because there is an internalized, almost unconscious assumption of able-bodiedness in art theory and praxis-if the assumption becomes "disrupted" by nonnormative corporeal forms, then these forms have historically been rejected and marked as pathological, diseased, and "other." I am certain that most of the art historians I came across had never encountered disability studies discourse, let alone thought about how disability studies ideas could be applied to an art history pedagogy.

One example of how one image in a Powerpoint was presented to me in a conventional art history survey was where several statues and inscriptions of the Egyptian pharoah Akhenaten was described as having a long thin neck, sloping forehead, and elongated skull, among other things. This has led to claims that the king suffered from various disorders, or even that he was female owing to the large hips and belly (this in itself is problematic because it also alludes to how art history makes conservative judgements toward the so-called correct male and female form). To quote from a standard art history survey textbook, Gardner's Art through the Ages, Akhenaten is described as "ugly, misshapen man struggling with his own mental and physical abnormalities." 2 Some art historians have even gone as far as suggest that his abnormal form indicated the state of flux and disarray that Egypt found itself in once Akhenaten was in power, for the pharaoh decided to change allegiance to the gods and overturned the religious systems that previously had been in place in the country for hundreds of years. This theory suggests that disability embodies not only aesthetic characteristics in which perfection can compare and oppose itself on a scale of beauty versus ugliness, but it also acts as a symbol for negativity in general, where it can be applied to negative events, chaos, and disorder in a society at large. Clearly these descriptions continue to perpetuate a judgement toward the aesthetics 
of disability within a narrow, and negative, category. I would like to delve into my case studies to see how alternatives may be offered to students.

\section{The Lived Experience: A Philosophy of Teaching}

I'd like to begin my sharing with you my general philosophy of teaching that is informed by a disability activism. As an outcome of my work in art history, disability studies, and social justice, I set a tone of activism in the classroom. Being $4^{\prime} 3^{\prime \prime}$ tall, I demonstrate visual and audio access by creating an inclusive learning environment by requesting that all the students sit in a large circle when I teach seminars. In lecture-based courses, I use my portable custom-made podium, which has been designed by various people including Sara Hendren of the Accessible Icon project and fits my stature. I had initially developed the idea of my podium when I had to deliver a lecture based on my thesis when I was a master's student in Visual and Critical Studies at the California College of the Arts in San Francisco. I refused to use the average-height podium and wanted one for myself. When Hendren designed my podium, she actually used the project as a case study for one of her design and disability classes at Olin College of Engineering in Boston. I was invited to fly to Boston to work with the students as they developed a unique object to fit the needs of a short-statured body. Thus, this object demonstrates to all the students in my classes how this tool in itself became a pedagogical hands-on exercise in the disability aesthetics and design of architecture. This version of my podium was made from carbon fiber and my students always laugh when I tell them that this is a material that is commonly used in the production of motorcycles and air-space equipment and that I was thrilled that I had my own object with which to launch into space. ${ }^{3}$ Through my podium, I instantly offer commentary for my students on structural and institutional inequality in the built environment, so my goal as a pedagogue is to show students an example of how radical access can be achieved. I ask them to take responsibility for their own access in my classroom both physically and intellectually, because access is important to me. I ask them to change positions in class if they cannot hear or see me, and I ask them to give me constant feedback on my teaching and to be proactive about letting me know if my teaching style is not working for them, or if they respond to learning in a different way so that I can try and cater to their needs.

I also call on students to verbally provide an audio description of any still image on my Powerpoint slides. Audio-description is a practice of 
aurally describing images. This benefits the comprehension of not only visually impaired and blind students but also expands the students' tool box as they grasp skills in visual analysis for talking and writing about art. I have all students provide me with written feedback after each class regarding their experiences with verbal description, and how it contributed to their overall learning. Several times as a teaching assistant at UCSD, I taught a blind student named Jimmy, and he verbally reported to me that accessing the visual material in my class was greatly enhanced by the regular deployment of audio description, and that this was the first time an instructor had offered this as a pedagogical exercise in a college course.

\section{Teaching "Disability Aesthetics" in Action}

Beyond this general philosophical approach toward all my teaching, over the past few years I have had the opportunity to teach the topic of "Disability Aesthetics" several times. The first time I did this, it was for a class I entitled Formations of Modern Art: Disability in Modern Art over the summer break for five weeks at the University of California at San Diego, where I completed my PhD. The course was modeled on a conventional history of modern art course, only I tweaked it so that it provided a broad overview of the presence of disability and its various manifestations throughout various periods of modern art in the nineteenth and twentieth centuries. Questions I presented to my students included: How might we consider an alternative version of neoclassicism, postimpressionism, cubism, Dadaism and surrealism, abstract expressionism, and conceptual art through the lens of complex embodiment? What new information might be uncovered as we examine these popular movements of modern art through the lens of a marginalized identity category such as disability? The course attempted to find the language to build a new framework around how disability might fit into the discourse of modern art, and how disability informs modern art by way of a radical aesthetics of representation that challenges sociocultural norms. I also included lectures on how disability aesthetics informs photography, performance art, outsider art, and curatorial practices. Each week, we examined readings from different periods of modern art in dialogue with writings about disability aesthetics to rethink art history as we know it. The course included thirty-five undergraduate students from different majors and different international backgrounds.

Specific examples of how I attempted to shape traditional modern art 
history lectures into a focus on disability include giving talks on the work of Claude Monet (who had a visual impairment), Henri de ToulouseLautrec (who was short-statured), and Edvard Munch (who had schizophrenia). Linda Ware states that there are no written accounts on the lived experiences of disability for each of these prominent artists, as their disabilities were perceived as irrelevant and invisible. ${ }^{4}$ While it is true that not all lived experiences of disability impact the work of an artist, it is arguable that in the case of Monet, Toulouse-Lautrec, and Munch, their lived experiences certainly fed into their art-making and visual imagery. In his later years, Monet's water lilies became more and more abstract as the artist's vision altered. Clearly he wasn't able to use his vision in the same way, and this led to a profound and generative new way to articulate the visual form of water lilies and gardens that had never before been experienced in the history of Western art. Indeed, Monet's newly "acquired" vision (rather than a "loss" of eyesight) provided us with a precursor to abstraction as an official art movement that would explode later in the twentieth century. My lectures simply pointed out these relationships and how we might consider the artists' works differently under new accounts than those written into the official textbooks.

One of the assignments I developed for this course required the students to visit a contemporary art museum, select an object, and create an artwork or write an essay in response to this work and its reimagined relationship to disability aesthetics. One student, Hannah Heimer, submitted a short video filmed by her friend Sophia Weiss entitled Sensorial Shift, where two dancers (herself and a male friend) voluntarily blindfold themselves and begin to explore space and each other without the privilege of sight. This work was in response to a 1913 oil portrait painting by Lovis Corinth at the San Diego Museum of Art that demonstrates the disabling and ocular-centric nature of the male gaze. In Hannah's video introduction, she narrates over an image of a male face, Alex Nielsen, who is reading a book and then eventually stares into the camera: "Eyes, sight. Most people say it's the last sense they would want to lose. Sight. What would life be without it? No colors, no shapes, no beauty. Eyes. Without eyes what can you see? Those with eyes can't imagine an eyeless world. And so it is the sightful that disable the sight-less." ${ }^{5}$ She then provides a powerful collage of audio bites of different voices talking about their experiences of blindness, of losing their sight, and what they have gained through their altered visions and learning how to see-or "enjoy" vision differently. After these audio clips, Hannah reappears on a large grassy field on the University of California San Diego campus with 
Alex, who was the male face who appeared in the introduction. They both blindfold themselves with yellow caution tape, and begin to fold over one another in gestures of contemporary dance and movement as contemporary music plays in the background. She continues:

It is said there's a right way and a wrong way to see, because sight provides instantaneous access to reality. Instantaneous access to the known. Navigating reality in a sightless world is like stepping into a foreign frontier for the sightful. Frightening and destabilizing. This is what we think, and so this becomes reality. But maybe, maybe lack of sight opens a door to a world of emotions, through energy and touch, breath and feel, body and sound, a sensorial revolution. Think about the freedoms, the freedoms from the walls that your visual world builds. Freedom from the gaze of the other that is often disabling. The gazer decides what the gazee becomes. Both may see, but the one renders one blind to reality. Without sight, the gaze doesn't exist. Communication of the souls reside without the gaze, without sight. The eyes turn inward to understand the self, the body, the environment. If you'd allow, maybe the sightless world could become colorful in other ways and other senses. An enhancement of touch, smell, proprioception, sound. Who knows what the sightful are missing. Eyes, perception, sight, gaze. Even with functioning eyes, are you truly seeing? The eyes are thought to make our realities clearer, but the gaze paralyzes us, transforms the abled to disabled. Lack of sight makes us think there's something wrong. But maybe the only wrong is our judgement of right and wrong. Maybe the sightless are not so disabled. Communication, life, light, love, can happen without the eyes. Without the eyes that make our illusions stronger.

As the screen fades to black, she concludes with the same words from her introduction, in order to reinforce her message, "Eyes, sight. Most people say it's the last thing they would want to lose. Sight. What would life be without it? No colors, no shapes, no beauty. Eyes. Without the eyes, what can you see? Those with eyes can't imagine an eyeless world, and so it is the sightful that disable the sightless." Hannah's work is brilliant for it demonstrated her intuitive, deeply sensitive understanding of the subject matter. As an educator, of course, this is the best possible outcome we can hope to achieve.

In one of my lectures, I asked the students to take photographs on their iPhones during a break in class that they felt were empowering 
self-expressions of their identities. Students chose either to take selfies or more formal portraits taken by fellow students. I then asked them to upload the images onto Facebook and Instagram using a common hashtag (such as \#UCSDsummervisarts2016). We viewed the images together online, where I gave the students the opportunity to reflect on their own and each other's frameworks for understanding the meaning of art about disability within society and in their own lives. At the very end of the course, I asked them to create a two or three minute video about what disability aesthetics means to them. I was very pleased with this video, which gave me an honest assessment of students' grasp of the concept of disability aesthetics. While these concepts varied and even deviated, I was impressed nonetheless with the students' willingness to candidly participate with their thoughts on the subject.

In fall 2016, I was privileged to teach Re-Visualizing Embodiment: Choreopolitics, Design, Access, and Space for the School of Arts and Architecture at the University of California at Los Angeles. At this same time, the UCLA School of Arts and Architecture had launched an exciting new initiative: a series of school-wide courses designed for students from across the school's four departments (Architecture \& Urban Design, Art, Design Media Arts, and World Arts and Cultures/Dance) to create, think, and percolate ideas together. I developed an interdisciplinary course where students could explore how bodies, gestures, materials, and places together reflect and reinforce collective ideas about the rights and responsibilities of both majority and minority individuals. By interrogating and creating physical models of dance, gesture, design, and representation, as well as evaluating issues of access and participation, students explored how embodiment can be deployed to promote social justice. Together we developed a new rhetorical framework for the "choreopolitics" of complex embodiment, where we also attempted to build a new vocabulary and methodology around disability and access in challenging and stimulating ways. Coined by writer and curator André Lepecki, the term "choreopolitcs" is a portmanteau word that fuses the sound and meaning of the words choreography and politics, where politically passive bodies may become mobilized through manifold movement, in juxtaposition with an engagement with other bodies, objects, surfaces, and environments. ${ }^{6}$ I used this concept heavily in my $\mathrm{PhD}$ dissertation and applied it toward this course. We engaged primarily with work that interrogates the social, political, and philosophical stakes of complex embodiment, drawn from fields that have a history of interrogating embodiment in visual culture, such as within the discourses of 
dance, choreography, performance, architecture, and more. We also examined how we might trouble the ostensibly normative narratives in museum and gallery spaces, and consider how access might become a dynamic conceptual and curatorial tool for destabilizing reductive categories. The overarching goal was to engage in dialogue that centers on the creative potential of disabled bodies to generate social transformation within visual culture at large.

Some of the questions that were posed throughout this course included the following: How do bodies and materials work together to create a generative tension in the discussion around the rights and responsibilities of minority representations in order to reshape our world? How can we imagine revised physical models of choreographic form, gesture, and movement that contribute toward an evolving and sophisticated language, knowledge, and politics of complex embodiment? How might the interventions of bodies in public space be directed toward various forms of social justice? How might the landscape of signs, symbols, banners, or "disobedient objects," intermingled with the semiotics of visible and invisible corporeal differences, be made strange, ruptured, or destabilized, so that we might think about the body differently? What began as an opportunity for artists to think outside their disciplines grew into a valuable experience in which students shared their diverse perspectives, exchanged ideas, and approached new solutions through their given medium. At a time when we are hyperconscious of political correctness and when honest conversation between people with differing viewpoints is more important than ever, the students were compelled to outline a working vocabulary in their discussions. The class would often go through the difficult yet valuable process of breaking down the root of certain descriptors to create terminology they found to be useful as a group.

The course included several guest lectures, including by Susan Leigh Foster, author of Choreographing Empathy and a professor in the School of Arts and Architecture at UCLA; the Los Angeles-based hearing-impaired artist Alison O'Daniel, who works with film, sound, sculpture, and mixedmedia installations; and the Pasadena-based designer Hugo Pilate. ${ }^{7}$ Pilate helped me design the third and latest iteration of my custom-made podium, which is a podium that was built for my stature. When he came to present to my class about all the designs he had been involved with in relation to the disabled body, we chose to use this class as a showcase for revealing the design of my latest podium. Pilate presented the object to the students who were able to fold and unfold it to consider how the 
object was providing me with a unique but practical point of access as a person of short stature.

\section{The Future of Disability Aesthetics}

As an art historian and teacher of art history, I'm interested in developing ways to teach canonical art history by consistently offering critical reflections on conventional frameworks. The classes I taught at UCSD and UCLA allowed me an opportunity to really focus deeply on the topics of my PhD dissertation in disability aesthetics. In my other teaching posts, while it is true that I am required to teach conventional art history frameworks from the art history textbooks, I also insist on teaching this material by ensuring that students do have opportunity to question these frameworks, and that perhaps the form of disability offers more generative possibilities and openings than we may previously have been led to believe. For example, when I teach students in my Renaissance to Modern Art History survey class about Leonardo da Vinci's work, I explain to them that the ideal of Vitruvian Man has been questioned through the work of other well-known disability studies scholars such as David Mitchell and Sharon Snyder. On the cover of their book, The Biopolitics of Disability: Neoliberalism, Ablenationalism, and Peripheral Embodiment, there is a commissioned artwork by Selene DePackh entitled Vitruvian Man with CP that offers an appropriation of Vitruvian Man, where an alternative body inhabits the same space that Vitruvian Man once did.

It is fascinating that the iconic image of Vitruvian Man incorporates a perfect concentric circle in a thinly drawn line that represents the cyclical and uninterrupted flow of ostensible normal up and down movement that the arms should make at the side of the body; the legs are engaged in similar gestures back and forth, but it especially demonstrates proportion and symmetry, and that a body in proportion and with symmetry is a body that fits within a pristine circle. This artwork by DePackh critiques the rigidity of perfection of this oppressive circle by literally and symbolically breaking through it with the limbs of a disabled body. Following this, I show my students a video, which is another appropriation of Vitruvian Man. What is so wonderful about this video is that there are many contradictions, and the students are able to engage in a lively debate about the message of the video that might seem to support the disabled body from the outset, but yet still falls into a trap of relying on classical aesthetic and corporal ideals to convey that message. 


\section{Conclusion: A Promising Pedagogy}

In this chapter, I have attempted to demonstrate through my case studies that implementing a pedagogy of disability aesthetics with the goal of offering a revisionist art history has many powerful theoretical and practical applications. I believe that a pedagogy of disability aesthetics offers many promising opportunities for art historians within many types of academic settings, in order to equip students with an enhanced critical awareness and the ability to question embedded ideals. By centering disability within an art history context, through lectures, exhibitions, and beyond, the goal is that students will recognize inherent biases within historical and contemporary trajectories of visual cultures, and realize that they can no longer take traditional forms of knowledge at face value. I remain grateful to the groundbreaking work of Tobin Siebers, who was a passionate and committed teacher as well as a gifted scholar of disability aesthetics. His work and his legacy paved the way for my scholarship, and for all those who have contributed to this volume.

Notes

1. Siebers.

2. Kleiner.

3. For more information, see "The Alterpodium: A Performative Design and Disability Intervention."

4. Ware.

5. Heimer.

6. Lepecki.

7. For more information, see Susan Leigh Foster, Choreographing Empathy: Kinesthesia in Performance.

\section{Works Cited}

www.alisonodaniel.com

www.hupilate.co

Cachia, Amanda. "The Alterpodium: A Performative Design and Disability Intervention." Design and Culture: The Journal of the Design Studies Forum 8, no. 3 (Fall 2016).

Foster, Susan Leigh. Choreographing Empathy: Kinesthesia in Performance. New York: Routledge, 2010.

Heimer, Hannah. "Sensorial Shift." University of California at San Diego, 2016.

Kleiner, Fred S. Gardner's Art through the Ages: The Western Perspective. 14th ed. Vol. 1. Boston: Wadsworth Cengage Learning, 2014. 
Lepecki, Andre. Exhausting Dance and the Politics of Movement, New York: Routledge, 2006.

Mitchell, David, and Sharon Snyder. The Biopolitics of Disability: Neoliberalism, Ablenationalism, and Peripheral Embodiment. Ann Arbor: University of Michigan Press, 2015 .

Siebers, Tobin. Disability Aesthetics. Michigan: University of Michigan Press, 2010.

Ware, Linda. "When Art Informs: Inviting Ways to See the Unexpected." Learning Disability Quarterly 34, no. 3 (2011): 194-202. 


\section{Contributors}

Thomas Abrams is an Assistant Professor of Sociology at Queen's University, Kingston, Canada. He is the author of Heidegger and the Politics of Disablement (Palgrave, 2016) and numerous articles on disability theory, the politics of rehabilitation, and the sociology of inequality.

Amanda Cachia is an independent curator and critic from Sydney, Australia. She received her PhD in Art History, Theory, and Criticism from the University of California at San Diego in 2017. Her research focuses on modern and contemporary art; curatorial studies and activism; exhibition design and access; decolonizing the museum; and the politics of disability in visual culture. Cachia has curated approximately forty exhibitions, many of which contain social justice themes and content. She currently teaches art history, visual culture, and curatorial studies at Otis College of Art and Design, California Institute of the Arts, California State University, Long Beach, and California State University, San Marcos.

Allison Weiner Heinemann is a lecturer in the disability studies sequence at Cornell University's School of Industrial and Labor Relations. Her teaching and research focus on disability law, intersectional approaches to disability studies, and writing pedagogy. She holds a PhD in comparative literature from Yale University.

Leon J. Hilton is an Assistant Professor of Theatre and Performance Studies at Brown University. His research has been supported by a Creative Capital/Andy Warhol Foundation Arts Writers Grant and the Mellon Foundation, and has been published in GLQ, African American Review, the Journal of Literary and Cultural Disability Studies, and TDR/The Drama Review. 
Jina Kim is Assistant Professor of English and the Study of Women and Gender at Smith College. She teaches and writes on the topics of critical disability studies, feminist- and queer-of-color critique, and contemporary ethnic U.S. literatures.

Joshua Kupetz, PhD, is a Lecturer at the University of Michigan where he teaches disability studies, twentieth and twenty-first century U.S. literature, and argumentative writing.

Crystal Yin Lie is Assistant Professor of Comparative World Literature at California State University Long Beach, where she teaches disability studies, health humanities, and graphic narratives. Her research focuses on dementia, contemporary literature and life writing, and the memory of historical trauma. Her work has been published in the Journal of Literary and Cultural Disability Studies.

Jennifer Marchisotto completed her PhD in Literature at the University of California at San Diego (UCSD). Her work focuses on mental disability, trauma, and affect in twentieth-century anglophone literatures. Her work takes up questions of access at the level of language itself, as well as in the context of cultural institutions in emerging global communities. She currently teaches at UCSD.

Therí A. Pickens is a Full Professor who teaches English, African American Studies, and Arab American Studies. She is the author of Black Madness :: Mad Blackness (Duke, 2019) and New Body Politics (Routledge, 2014), and editor of Arab American Aesthetics (Routledge, 2018), a special issue of African American Review (Summer 2017), and a special issue of the College Language Association (2020). You can find her on Twitter (@ $\mathrm{TAPPhD}$ ) and on her site: www.tpickens.org

Rebecca Sanchez is Professor of English and co-director of the Disability Studies Program at Fordham University. Her published works include Deafening Modernism: Embodied Language and Visual Poetics in American Literature (NYU Press) and the republication of Pauline Leader's memoir And No Birds Sing (Gallaudet UP).

Joseph Straus is Distinguished Professor of Music at the Graduate Center of the City University of New York (CUNY). He is the author of numerous books, among them Broken Beauty: Musical Modernism and the Repre- 
sentation of Disability (Oxford, 2018) and Extraordinary Measures: Music and Disability (Oxford, 2011).

Cynthia Wu is a professor of Gender Studies and Asian American Studies and the director of Race, Migration, and Indigeneity at Indiana University. She is the author of Sticky Rice: A Politics of Intraracial Desire (Temple, 2018) and Chang and Eng Reconnected: The Original Siamese Twins in American Culture (Temple, 2012). 


\section{Index}

ableism, 27, 41, 100

ability, ideology of, 12, 24, 25, 28, 34, 97, 99, 100-101, 102, 103, 105, 107

Abrams, Thomas, 16 academic labor, 41-55; it depends, 5455; pain, labor, identity, $48-54$; pleasure writing, $44-48$

Accessible Icon, 163

ADAPT, 98

Adorno, Theodor, 134

Affordable Care Act, 18

Ahmed, Sara, 46; "Happy Objects," $73^{\mathrm{n} 2}$

Alcoff, Linda, 28

alterity, $15^{8}$

American Civil War, 129

American Disabled for Accessible Public Transit, 97

American Federation of the Blind, 117 Americans with Disabilities Act, 25, 53-54, 97

Anthony, Adelina: Ode to Pablo, 120 anti-abstractionism, 104 anticapitalism, 19n2, 47 Anzaldúa, Gloria, 35n4, 88, $15^{6}$ art history, 161-70; lived experience, 163-64; teaching "disability aesthetics" in action, 164-69

ASL, 114, 117

"aural hallucination," 131. See also heard voices

autism, 107, 128, 134-36, 138nn12-13 autoimmunity, 48, $5^{6 n_{5}}$

Avery, Ellis, $49^{-} 5^{\circ}$

Babbitt, Milton, 135, 137n3

Bala perdida, $147,156,157,15^{8}$

Bárbula psychiatric hospital, 141-42, $148-5^{\circ}, 153$

Bartlett, Jennifer: Beauty Is a Verb, 87, 92

Bartók, Béla, 130, 132, 137n3

"Bats," 91, 93

Baumgarten, Alexander, 122, 144

Bellas Artes, 141

Benedet, Janine, 31-32, 36n10, 37n11

Berg, Maggie: The Slow Professor, 4648

biopolitics, 17, 101, 106

Black, Sheila: Beauty Is a Verb, 87, 92

Blackness, 82, 89

Blatty, William Peter: The Exorcist, 8o; I'll Tell Them I Remember You, 8o

Bleuler, Eugen, 131, 134, 138n11

Blind, 113-14, 117, 122, 164, 165. See also DeafBlind

"block juxtaposition," 129, 138n7

"blueprints," 25, 27, 28

bodymind, 19nı, 6o, 64, 74n7, 82

Bohlmann, Hans-Joachim, 14

Bolt, David, 63

Bosch, Hieronymus: The Cure of Folly, 141

Boulez, Pierre, 135, 137n3 
British Sign Language (BSL), 115, 117 Brontë, Charlotte: Jane Eyre, 63, 73n1, $75^{\mathrm{n} 11}$

Brown, Wendy: "Wounded Attachments," 9-10, 19n2

BSL. See British Sign Language

Buck v. Bell, 29, 36n6

built and cultural environments, 3, 11, 42

Butler, Judith, 97, 106; Bodies That Matter, 100

Cachia, Amanda, 17

captions, 120-21

Carter, Angela M.: "Teaching with Trauma," 73n 3

Caruth, Cathy, 67, 69, 7o, 73; Unclaimed Experience, 65, 66, 72

Casper, Monica, 74n 5

Cepeda, María Elena, $5^{2}$

CESAM State Psychiatric Hospital, $147,15^{6}$

Chen, Mel, 59, 72, 115

"choreopolitics," 167

claiming disability, 125, 136-37, 137n2

Clark, John Lee: “Order," $115^{-16}$

Clark, Lygia, 152-53

Cold War, 4, 5

collective autotopography, 149

collective identity, 100, 105, 107

comic plot narrative, $78,94 \mathrm{n} 1$

complex embodiment, 10, 11, 15, 16 , $28,30,33,61,62,63,64,65,81-$ $82,98,117,164,167,168$

conceptualizing disability, 11, 126-27

conduit model, 117

consciousness, 156 ; coalitional, 19n4; disability, 93; disabled, 79; divided, 133; division, 132; false, 97, 102, 103-4, 105; global, 4; musical, 132; public, 17; splitting, 131; spontaneous, $35^{\mathrm{n}} 4$

Cook, Peter: "Poetry," 114, 115

COVID-19, 18

crip rhetoric, $16,58,64,66,71,72$ crip time, $4^{6-48}, 5^{8}, 60,69,71,72$, $74 \mathrm{n} 4$ critique, 19nı, 24, 25, 35, 77, 93; ability, 34; aesthetic hierarchies, 148; anticapitalist, 19n2; captions, 121; citizenship, 8o; cyborg theory, 101; and emancipation, 28-29; feminist disability studies, 104; high formalist iterations, 118 ; identity politics, 100; ideological processes, 103; institutional means of accommodations, 54 ; interpersonal communication, 117-18; medicalization, 29; poststructuralist, 16, 27; psychiatric hospital, 142; racism, $5^{1}$; rigidity of perfection, 169; Siebers of Brown, 10; social, 27, 94; structural, 7; totalizing categories, 103 cultural and environments, 3, 11, 42 cultural modernism, 128, 129, 135, 137n3, 138n4, 138n8; history of disability, 126-27

cyborg theory, 100, 101, 104, 106. See also Haraway, Donna

da Vinci, Leonardo: Vitruvian Man, 162, 169

Davis, Lennard J., 49, 53-55; Americans with Disabilities Act, 53-54; Bending Over Backwards, 2; dismodernism, 53; Enforcing Normalcy, 87

Deaf, 113-14, 115, 116, 117, 120, 121, 122 DeafBlind, 113, 114, 115-16, 122 "defective or impaired intelligence," $113,128,145,146$

deformity/disfigurement, 128-29

Deleuze, Gilles, 159n4

DePackh, Selene: Vitruvian Man with $C P, 169$

dependence, 42, 55

developmental disability, 31, 32, 37n11

Dickens, Charles, 133

"disabled enough," 42, 50, 51, 53

disabled ghosts, 77-78, 79, 90

disability activism, 24, 29, 35 $\mathrm{n1}, 163$

disability aesthetics, 142, 143, 144-45,

147 , 156-57; art history, 161-70; 
future, 169; lived experience, 163-64; modern art, 17, 124, 125; teaching "disability aesthetics" in action, 164-69. See also musical modernism

"disability experience on trial," 23-35 disability identity, 24, 42, 49, 52, 53, $55,96,98,99,101$

disability rights activism, 1, 19n4, 42 disability studies, 49, 58, 96, 97, 98, 103, 104, 105, 107, 108, 141, $143,146,157,161,162,163,169$; autoimmunity, $5^{6 n_{5}}$; emergence, 8-15; feminist, 74n7, 104; futures of disability, 79; humanistic, 3; impairment, 78; looking backward, 3-8; materiality, 79, 88; ontology, 42; proto-, 45; reimagining, 1-37; trauma, $6_{5}-69,71,74 n_{5}$

Disability Visibility Project, 23, 25, 35, $35^{\mathrm{n} 1}$

dismodernism, 53, 55

Dolmage, Jay Timothy, 54

Donaldson, Elizabeth, 63

Dorfman, Ariel: Death and the Maiden, 66

Dostoevsky, Fyodor, 133

Dreyer, Carl, $15^{\circ}$

Dumas, William Jeffrey, 30-31, 36nn8-9

emancipation, 25, 27, 28, 35, $15^{8}$

Engels, Friedrich, 105; The German Ideology, 101, 102, 103

Enlightenment, 3, 7, 142, 144, 157

equal rights, 15,75

Erevelles, Nirmala, 82-83, 97, 101, 106; "The Absent Presence of Elsie Lacks," 78; Disability and Difference in Global Contexts, 104-5

ethical responsibility to difference, 154-55

eugenics, 12, $36 \mathrm{n} 6,83,126-27,130$, 131-32, 133, 137, 137n1, 138n4

euthanasia, 126-27, 128, 130, 136 , $138 n 4$

experiential narrative, $34,35^{\mathrm{n}} 4$
Falconetti, Maria, $15^{\circ}$

false consciousness, 97, 102, 103-4, 105

The Family of Henry VIII, 118

Faulkner, William, 133

Fayette County Superior Court, 30, 32, 36ng

feminist disability studies, 74n7, 104

Fletcher, Ruth, 33-34

Flying Words Project, 114

Foster, Susan Leigh: Choreographing Empathy, 168

Foucault, Michel, 97, 100, $155,15^{8 ;}$ The Birth of The Clinic, 106-7; Discipline and Punish, 106; History of Madness, 145-46, 154

Fox, Marie, 33-34

Future of Minority Studies, $7-8$

Garland-Thomson, Rosemarie, 19n4, 36n5, 49, 104, 126; Extraordinary Bodies, 2

ghosts of disability, 16, 77-94

Gill, Michael: "The Absent Presence of Elsie Lacks," 78

Girma, Haben, 118; Haben, 119

Goodheart, Eugene: The Reign of Ideology, 101-2

Gordon, Avery, 78

Gounod, Charles: Ave Maria, 142

Grant, Isabel, 31-32, 36n1o, 37n11

Great War, 126, 130

Guattari, Felix, 149, 159n4

Hall, Stuart, 102, 103, 104, 105

Hames-García, Michael R.: Reclaiming Identity, 8

Hammad, Suheir: breaking poems, 8o

Haraway, Donna, 97, 100, 101, 104, 106

harm, 4, 34, 44, 100

harmony, 124, 125, 130, 133, 135

Hass, Robert, 85

heard voices, 131-33

Heimer, Hannah, 165

Heinemann, Allison Weiner, 15

Heiner, Dennis, 14

"helper" model, 117 
Hendren, Sara, 163

Hilton, Leon, 17

Huffer, Lynne, 155

human prejudice, 4, 9, 15, 29

identity, 16, 49-51, 96-108; created, 28 ; intersectional, 62; working class, $5^{1}$

identity politics, 10, 16, 19n4, 24, 35, 49, 55, 96, 97, 98, 100, 101, 107

Identity Politics Reconsidered, 8

idiocy, 133-34

ideology of ability, 12, 24, 25, 28, 34,

97, 99, 100-101, 102, 103, 105, 107

illegibility, $62-65$

images, 16, 68, 70, 91, 113, 114, 115, $117,118,119,121,122,125,127,130$, $146,164,167$

immobility, 130

impairment, 11, 18, 43, 8o, 82, 83; Aziz, 9o; intellectual, 42; Kovaleski, 17; mental, 157; mobility, 5o, 128, 129-30; oppression, 93; origins, 78; paralysis, 128, 129-30; partial, $5^{\mathrm{O}-5^{1}}$; physical, 131 ; psychic, $5^{8}$; race, 104; Samuels, 48; visual, 165; war, 93

imperfection, 9, 14

inclusion, 13, 97, 148, 15o, 154, 159n3 incorporeal transformation, $159 n_{4}$ institutional psychotherapy, 159 n2 intellectual disability, 36n10, 37, 157 interpersonal communication, 117-18 intersectional identity, 62

Ives, Charles, 129, 131, 137n3, 138n7

Jones, Beverly, 25

Kafer, Alison, 6o, 67-68, 71; Feminist, Crip, Queer, 2, 74n4, 79

Kanner, Leo, 134, 138 n12

Kant, Immanuel, 144

Karpin, Isabel, 32-33, 34-35

Kerschbaum, Stephanie, 46

Kim, Christine Sun, 121

Kim, Eunjung, 45

Kim, Jina B., 2
Kittay, Eva Feder, 42, 55

Kleege, Georgina, 118, 119

Kleiner, Fred S.: Gardner's Art through the Ages, 162

Kovaleski, Serge, 17

Kramer, Jonathan, ${ }_{13}^{8 n} 7$; The Time of Music, $138 \mathrm{n} 8$

Kruger, Liam, 62

Kupetz, Joshua, 2

La Borde, $149,15^{8 \mathrm{n} 2}$

"lack of fit," $28,36 \mathrm{n}_{5}$

Ladau, Emily, 24, 35

Lane, George, 25-26, 27, 28

language of disability, 136

language of disaster, 67,68

Laski, Gregory, 10

Left, 149

Lepecki, André, 167

Lerner, Kenny: "Poetry," 114, 115

Lie, Crystal Yin, 2

Lindsey, Jaime, $3^{1}$

literary theory, 4, 5

The Little Mermaid, 121

lived experience, $8,11,15,16,18,27$, $28,3^{\circ}, 33,35^{\mathrm{n}} 4,3^{6 \mathrm{n} 10}, 5^{\mathrm{o}}, 5^{2}$, $73^{n} 3,78,153,165$; philosophy of teaching, 163-64; Téllez, 142

machine model, 117

madness, 63, 75n11, 128, 134, 145-46, 153,158 ; absence or silence, 154 ; language, 147-48; musical modernism, 131-33

"Many Asked Me Not to Forget Them," 92, 93

Marchisotto, Jennifer, 16

Marx, Karl, 105, 106; The German Ideology, 101, 102, 103

Masia, Cristóbal, 149

materiality of the body, 11, 41-55, 79, $81,88,89,100,104$

McArthur, Park, 118-19

McCandless, Julie, 33-34

McFadden, Christopher, 30-31, $3^{2}$

McGuire, Anne: War on Autism, 107

McLuhan, Marshall, 122 
McRuer, Robert, 79; Crip Theory, 2 medicalization, 24, 29, 129

medical model, 10, 78, 82, 88, 126, 127, 130, 131

Mehring, Franz, 101-2

mental disability, $15,31,32,37,5^{8}, 60$, $6_{3}, 64,65,66,67,71,72,74 n_{4}$, 131, 145, 146, 154

\#MeToo movement, 23, 24

Metres, Philip: Sand Opera, 8o

Michelangelo: Pietà, 14

Mignolo, Walter, 157

Miller, Herman, 48

Minich, Julie, 55; Accessible Citizenships, 2

misfit, 19n4, 36n 5

Mitchell, David T., 74n6, 82, 83; The Biopolitics of Disability, 169; narrative prosthesis, 63; Narrative Prosthesis, 2

mobility impairment, 50, 128, 129-30 modern art, 17, 124, 136, 137n1, 164 modern/modernist music, 17,125 , 126, 127-28, 129, 130, 131, 132, 133, 134, 135, 136-37, 137n1, 138n8

Mohanty, Chandra, $35^{\text {n }} 4$

Monet, Claude, 165

Mootoo, Shani

Cereus Blooms at Night, 58-59, 72-73, 73n1, 73n 3

animalistic behaviors, $75^{\mathrm{n} 11}$

complex narrative embodiment, 59-62

cripping rhetoric, $69-71$

illegible intersections, $62-65$

lack of certainty, $74 \mathrm{ng}$

trauma and disability, $65^{-69}$

Morris, Robert: "Notes on Sculpture," $15^{2}$

Morrison, Daniel, $74 \mathrm{n}_{5}$

motion, 114, 128, 130

Moya, Paula M. L.: Reclaiming Identity, 8

Munch, Edvard, 165

musical modernism, 17, 124-37;

autism, 134-36; claiming disability, 136-37; cultural modernism within the history of disability, 126-27; deformity/disfigurement, 128-129; idiocy, 133-34; madness, 131-33; paralysis/mobility impairment, 129-30; representations of disability, 127-28; Siebers's disability aesthetics, 124-26

nationalism, 4, 8o

Nazis, 136

neoliberalism, 44, 46, 55

Nietzsche, Friedrich, 10

Nishida, Akemi, 19n6

Noble, Frances Khirallah: The New Belly Dancer of the Galaxy, 8o

normalization, 91, 104, 126, 127, 128, 129, 130

Nye, Naomi Shihab: Transfer, 16, 77-94

O'Daniel, Alison, 168

Ode to Pablo, 120, 121

Ofili, Chris: The Holy Virgin Mary, 14

Oliver, Michael, 101, 104, 105, 106 ontology, 42, 148, 157

oppression, 28, 30, 35, 62, 75n11, 99, 101; structural, 78-79; war, 93

Oury, Jean, 149

outsider, 24, 84, 164

paralysis/mobility impairment, $5^{\circ}$, 128, 129-30

Patsavas, Alyson, 43

perfection, 45, 162, 169

Perry, David M., 31, 32, 36n7

Picasso, Pablo, 124, 161

Pickens, Therí Alyce, 16; Black Madness :: Mad Blackness, 2

Pilate, Hugo, 168-69

pleasure writing, $44-48$

Polk County Courthouse, 28, 98

poststructuralism, 3, 4, 7, 9, 97, 100, 101, 106, 107

prejudice, 4, 9, 15,29

Prendergast, Catherine, 64

Price, Margaret, 36n5, 54, 6o, 74n7;

Mad at School, 74n 4 
ProTactile, 116, 117

proto-disability, 7,45

psychiatric hospital, 141, 142, 148, 149, 158. See also CESAM State Psychiatric Hospital

psychic life, 148

Quadros, Ronice Muller de: "I am the book," 115

queerness, 70, 72, 73

queer theory, 6

racism, 4, $5^{1}$

Rancière, Jacques, 144

rehabilitation, 45, 126, 127, 128, 129, 130, 131, 138n 4

reparative, $6,14,79$

rape, 3o, 31, 32, 36nio. See also sexual assault

realism, 27-28, 98-99, 102, 105; postpositivist, 7

Resnais, Alain: Hiroshima mon amour, 72

revenge, 10

Rhys, Jean: Wide Sargasso Sea, 63, 73n1, $75^{\text {n11 }}$

Rich, Adrienne, 2

Rodas, Julia Miele, 49, 63

Rooted in Rights, 23-24, 25, 35, 35n2

Rubens, Peter Paul: Portrait of Archduke Albrecht, 14

Samuels, Ellen, 19n5, 47-48; Fantasies of Identification, 2

Sanchez, Rebecca, 16, 114

Scarry, Elaine, 43

Schalk, Sami, 79, 89; Bodyminds Reimagined, 2

Schenker, Heinrich, 130, 138ng

schizophrenia, 131, 134, 138nı1, 138n12, 165

Schoenberg, Arnold, 135, 137n 3

Scott, Joan, 25, 28, 33, 34; "The Evidence of Experience," 26-27

Scott, Paul: "Two Books," 115, 116

Sedgwick, Eve Kosofsky: Touching Feeling, 6
Seeber, Barbara K.: The Slow Professor, $46-48$

self-victimization, 100

sensus communis, 144

sex, 11, 12-13, 15-16; "sex of architecture," 25,29

sexual: abuse, 15, 24, 62; access, 12, 15, 25, 28, 29; activity, 12; agency, 16, 99; assault, 15, 24, 25, 31-32, 33, 34, 35, 36 nı (see also rape); citizenship, 13 , 29, 30; culture, 13, 29; difference, 33; encounter, 59; environments, 29; experience, 29, 34; expression, 29; freedoms, 19n7; harassment, 23; health, 29; history, 32; injury, 15; minorities, 12, 19; needs, 29; opportunity, 12; practices, 12, 29; procreative, 19n7; relationship, 121; rights, 24; subjectivity, 16 ; violence, $15,23,30,31,37,133$

sexuality, 2, 10, 24; disabled, 13, 98; politicizing, 29

sexual reproduction, 12 Shihab, Aziz, 77, 8o, 83, 84, 92

Siebers, Tobin, 15, 19n 5

Among Men, 16, 44, $5^{1}$

The Body Aesthetic, 13

centrality of disability, 14

Cold War Criticism and the Politics of Skepticism, 4, 5, 6, 7, 8, 14

critique of Brown, 10

disability aesthetics, 17, 124-26, 143

Disability Aesthetics, 3, 8, 13-14, 58,

$87,113,114,122,143-44,145$,

$153,154,161$

disability as masquerade, $5^{\circ}$

"disability experience on trial," 15 , 25-26, 28-29, 33

"Disability in Theory," 141, 143, $153-54$

disability studies, 1, 2-3, 11-12, 45, 65,71

Disability Theory, 3, 8-9, 13, 16, 24, $25,35,96-108,113-14$ objections, 101-7

The Ethics of Criticism, 3-4, 7, 8-9 human agency, 10-11, $55^{\mathrm{n}} 4$ 
identity, 13,16

identity politics, 49, 98

intersectional identity, 62

language, 59, 68, 70

misfit, $3^{6 n_{5}}$

misrepresenting gait, 11

pain medication, 41

"realism," 27-28, 102

representation, 62

sex, 12-13

"sex of architecture," 25

"socially constructed fictions," 27

thought, 105,154

trauma art, 63

"verifiable knowledge claims," 28

working-class origins, $5^{1,}, 53$

writing, 44

See also specific topics, e.g., complex embodiment

signed languages, 16, 114, 115, 117

situations of extreme precarity, 61, 62

Skloot, Rebecca: The Immortal Life of Henrietta Lacks, 78

Smith, David, 147, 155-56; One Flew Over the Void (Bala perdida), $15^{6-}$ $5^{8}$

Smith, Dorothy, 97, 101, 102-3, 105

Smith, Tony: Die, $15^{1-5}{ }^{2}$

Snyder, Sharon L., 74n6, 82, 83; The Biopolitics of Disability, 169; narrative prosthesis, 63; Narrative Prosthesis, 2

Spanish Civil War, 149

Spillers, Hortense: "Mama’s Baby, Papa's Maybe," 82

Spivak, Gayatri, 63; “Three Women's Texts," $75^{\mathrm{n} 11}$

splinteredness, 132, 138n 7

Stafford, William, 81

State of Georgia v. William Jeffrey Dumas, $30-31$

Stiker, Henri-Jacques, 126, 128; "birth of rehabilitation," 130, 138n4

Stone-Mediatore, Shari, 27, 35n 4

Straus, Joseph N., 16-17

Stravinsky, Igor, 129, 130, 132, 133, 134, 137n3, 138n7
Superior Court of Fayette County, Georgia, 3o, 32, 36ng

Supplemental Security Income, $36 \mathrm{n} 6$ Supreme Court, 25-26, 29, 36n6. See also Buck v. Bell; Tennessee v. Lane

Sutton-Spence, Rachel: "I am the book," 115

Téllez, Javier, 17, 141-59; cure of folly, 147-5o; inclusion, 150, 159n3; La extraccion de la piedra de la locura ("The Extraction of the Stone of Madness"), 141-49, $15^{8}$; "Madness Is the Language of the Excluded," 141; Passion of Joan of Arc, 15 o; thought, 158 ; You Are Here, $147,15^{0-55}, 15^{8}$

Tennessee v. Lane, 25, 26, 28-29, 30, 98. See also Jones, Beverly; Lane, George

"testimony," 34, 35

Third World, $142,15^{6}$

thought: Enlightenment-descended, 7; European, 157; experiment, 53-54; mental disability, 15 ; organize, 101; postmodern, 8; poststructuralist, 8, 10; postwar critical, 149; radical, 149, 158 ; schools, 5; Siebers, 105, 154; Téllez, ${ }_{5}^{8}$; twentieth century, 159 n2

\#TimesUp movement, 23, 24

Tosquelles, François, 149, 159n2

Toth, László, 14

Toulouse-Lautrec, Henri, 165 transatlantic slave trade, 83,104 trauma, 58-59, 6o, 62, 63-69, 72, 73, $73 \mathrm{n} 3,74 \mathrm{n}_{5}, 74 \mathrm{n} 7,74 \mathrm{n} 8,74 \mathrm{n} 10$, $88,93,124,152 ;$ art, 63

Trump, Donald: Crippled America, $17-18$

20oI: A Space Odyssey, 121

Tyler, Dennis, Jr., 79, 89

"ugly laws," 129, 138n5

"Valley," 9o, 93

Varèse, Edgard, 129, 137n3 
Vazquez, Rolando, 157

virtue, 44, 45

war, 94, 136; conceptual language, 5; multinational, 5 ; oppression, 93. See also American Civil War; Cold War; Dirty War; Great War; Spanish Civil War; World War I; World War II

Webern, Anton, 130, 135, 137n1

Weiss, Sophia: Sensorial Shift, 165

"When One Is So Far From Home, Life Is a Mix of Fact and Fiction," 92 witnessing disabled experiences of sexual assault, $15^{-16}$, 23-35

Wolfensberger, Wolf, 104

words, 16, 59-6o, 61, 69, 7o, 71, 8o, $90,113,114,115,118,119,121,122$, 167

Wordsworth, William, 133

World War I, 124, 128

World War II, 4

wounds, 10, $5^{8}, 59,65,88,126$; combat-related, 128, 130

Wu, Cynthia, 1-2

Zavitsanos, Tina, 118-19 